\title{
Geothermal Innovative Technologies Catalog
}

September 1988

Submitted to:

The U.S. Department of Energy

San Francisco Operations Office

Oakland, CA 94612

Under Contract No. DE-AC03-865SF-16299

(Meridian Contract No. 267)

Prepared for:

The U.S. Department of Energy

Geothermal Technology Division

Washington, DC 20585

Prepared by:

Meridian Corporation

4300 King Street, Suite 400

Alexandria, VA 22302-1508 


\section{DISCLAIMER}

This report was prepared as an account of work sponsored by an agency of the United States Government. Neither the United States Government nor any agency Thereof, nor any of their employees, makes any warranty, express or implied, or assumes any legal liability or responsibility for the accuracy, completeness, or usefulness of any information, apparatus, product, or process disclosed, or represents that its use would not infringe privately owned rights. Reference herein to any specific commercial product, process, or service by trade name, trademark, manufacturer, or otherwise does not necessarily constitute or imply its endorsement, recommendation, or favoring by the United States Government or any agency thereof. The views and opinions of authors expressed herein do not necessarily state or reflect those of the United States Government or any agency thereof. 


\section{DISCLAIMER}

Portions of this document may be illegible in electronic image products. Images are produced from the best available original document. 


\section{Department of Energy}

Washington, DC 20585

Ju1y 1988

To The Reader:

The U.S. Department of Energy is comitted to assisting industry in the development of renewable energy technologies that are economically, socially, and environmentally acceptable. Geothermal energy is one of these technologies and has received federal research and development support since 1971 .

Over the years, DOE-sponsored R\&D has generated many innovations crucial to the exploitation of a large fraction of known geothermal reservoirs and the discovery and confimation of additional geothermal resources. Since technology transfer is an important and integral element of the Department's geothermal R\&D program, vigorous efforts have been made to expedite the transfer of DOE-developed technology to the U.S. geothermal industry.

As an important aspect of these efforts, the Geothermal Technology Division has prepared this Geothermal Innovative Technologies Catalog. It is intended for the U.S. industry and other entities interested in the development and utilization of both domestic and international geothermal resources. With this catalog, GTO has attempted to identify and assemble the significant advances in geothermal technology that have flowed from GTD-sponsored R\&D. The purpose of this document is not to present in-depth descriptions of new technologies but rather to alert industry to their availability and to identify appropriate contacts for additional information, thereby assuring the ultimate comercial use of those technologies by the private sector.

Your further interest and involvement are welcome.

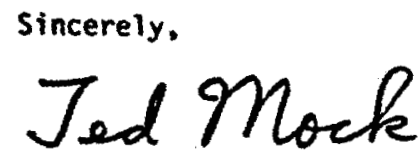

John E. Mock, Director Geothermal Technology Division Conservation and Renewable Energy 


\section{ACKNOWLEDGEMENTS}

This catalog is a collaboration of efforts of a number of individuals and organizations who have collectively contributed to this important technology transfer initiative. Appreciation is extended to John E. Mock and Ralph Burr of the U.S. Department of Energy Geothermal Technology Division (GTD) for their initial interest in the project, their assistance in promoting development of the catalog, and their review of the final product. Special thanks to John Crawford of the U.S. DOE San Francisco Operations Office for his timely review and valuable suggestions for improvement of the draft version of the document. Individual program managers at DOE/GTD and the various national laboratories and research institutions are also recognized for their help in identifying, clarifying, and updating relevant items of DOE-sponsored research for inclusion in the catalog. In addition, acknowledgements go to those at Meridian Corporation who were ultimately responsible for compiling the final document: the project manager and editor, Deepak Kenkeremath; the principal contributors, Clinton Andrews, Robert Blackett, Daniel J. Entingh, Mamo HaileMariam, Helen M. Kutska, and James V. Satrape; and the production staff, Claudia MacDonnell and Kelly Poe. 


\section{TABLE OF CONTENTS}

\subsection{INTRODUCTION}

$\begin{array}{llr}2.0 & \text { EXPLORATION } & 5\end{array}$

2.1 Hardware

2.1.1 Acoustic Source Detonator

2.1.2 Crosswell Acoustic Transceiver-Transmitter 10

$\begin{array}{ll}\text { 2.1.3 Downhole Geophone } & 12\end{array}$

2.1.4 Slimline Detonator Tool and String Shot $\quad 14$

2.2 Sof tware

2.2.1 Self-Potential Data Interpretation -- Theory $\begin{array}{ll}\text { and Computer Program } & 16\end{array}$

2.2.1 Computer Programs for Geophysical Data 18

2.3 Data Bases

2.3.1 DOD Geothermal Projects 20

2.3.2 Exploration Technology Data Base 21

2.3.3 Industry Coupled Drilling Program Data Base 22

2.3.4 LOGDEX Data Base 24

2.3.5 GEOTHERM Data Base 26

2.3.6 OIT Site Data Base Reports $\quad 27$

2.3.7 State Coupled Resource Assessment Program 28

2.3.8 UURI/ESL Geothermal Sample Library 29

2.3.9 User Coupled Confirmation Drilling Program $\quad 30$

2.4 Processes/Procedures $\quad 31$

2.4.1 Automated Seismic Processor ..... 32

B.4.2 Borehole Geophysical Research for Fracture
Detection

2.4.3 Controlled Source Electromagnetic System 36

2.4.4 Cascade Range Exploration Technology 38

2.4.5 Gas Contents of Geothermal Fluids 39

2.4.6 Fluid Movement in Volcanic Terrains 40

2.4.7 Fracture Detection Using Low Frequency Cross-Hole
Electromagnetic Techniques

2.4.8 Geothermal Exploration Strategy $\quad: \quad 44$

2.4.9 Geologic Mapping -- Geothermal Areas $\quad 46$

2.4.10 Geologic Model of Baca Geothermal Reservoirs 48

2.4.11 Interpretation of Drill Cuttings from

2.4.12 Magnetotelluric Data Interpretation 50

2.4.13 Magnetotelluric Survey $\quad 52$

2.4.14 Mapping Flow Paths in Fracture-Dominated
Reservoirs

2.4.15 Trace Element Geochemistry of Hydrothermal Systems 54

2.4.16 Acoustic Borehole Mapping of Seismicity 56

3.0 DRILLING, WELL COMPLETION, AND RESERVOIR PRODUCTION

$\begin{array}{ll}3.1 \text { Hardware } & 59\end{array}$

$\begin{array}{lll}\text { 3.1.1 Acoustic Borehole Televiewer } & 60\end{array}$

$\begin{array}{lll}3.1 .2 & \text { Borehole Fluid Sampler } & 62\end{array}$

$\begin{array}{lll}\text { 3.1.3 Caliper Tool } & 64\end{array}$ 
3.1.4 Cavitating Drill Bit Nozzles 66

$\begin{array}{ll}\text { 3.1.5 Downhole Flow Meter } & 68\end{array}$

3.1.6 Downhole Injector and Gamma Ray Detector 70

$\begin{array}{lll}\text { 3.1.7 Cement Placement Tool } & 72\end{array}$

3.1.8 Downhole Fluid Injector $\quad 73$

3.1.9 Drill Pipe Severing Device 74

3.1.10 Explosive Fracture Initiation Tool $\quad 75$

3.1.11 Explosive Side Tracking Tool 76

3.1.12 Hard Rock Geothermal Drill Bit 77

$\begin{array}{lll}\text { 3.1.13 Fluid Velocity (Spinner) Probe } & 78\end{array}$

3.1.14 High Temperature Casing Packer $\quad 80$

3.1.15 High Temperature Downhole Fluid Sampler $\quad \ldots \quad 82$

$\begin{array}{lll}\text { 3.1.16 High Temperature Drilling Jars } & 83\end{array}$

3.1.17 High Temperature Electronics and Instrumentation $\quad 84$

3.1.18 Passive Thermal Protection System $\quad 85$

3.1.19 High Temperature, High Pressure Cablehead 86

3.1.20 High Temperature Open Hole Packers 88

3.1.21 High Temperature Turbodrill $\quad 90$

3.1.22 PDC Drill Bits $\quad 92$

3.1.23 Spinner/Temperature/Pressure with Collar Locator 94

3.1.24 Temperature Probes 95

3.1.25 Wellbore Inertial Navigation System 96

$\begin{array}{ll}3.2 \text { Software } & 99\end{array}$

3.2.1 CCC Computer Model $\quad 100$

$\begin{array}{lll}\text { 3.2.2 } & 102\end{array}$

3.2.3 DEGEOWEL Two-Phase Flow Computer Model 103

3.2.4 Geophysical Well Log Data Base Management 104

$\begin{array}{lll}3.2 .5 & \text { GEOTEMP2 Computer Model } & 106\end{array}$

$\begin{array}{lll}3.2 .6 & \text { GRITS Computer Model } & 108\end{array}$

$\begin{array}{lll}3.2 .7 & \text { PT Computer Model } & 110\end{array}$

$\begin{array}{lll}3.2 .8 & \text { PTC Computer Model } & 112\end{array}$

$\begin{array}{lll}3.2 .9 & \text { SHAFT79 Computer Model } & 114\end{array}$

3.2.10 TERZAGI Computer Model 116

3.2.11 WELBORE Computer Model $\quad 118$

$\begin{array}{ll}3.2 .12 & 120\end{array}$

$\begin{array}{llr}3.3 & \text { Processes/Procedures } & 121\end{array}$

$\begin{array}{ll}\text { 3.3.1 Hydraulic Fracturing } & 122\end{array}$

$\begin{array}{lll}\text { 3.3.2 Hot Dry Rock Drilling Technology } & 124\end{array}$

$\begin{array}{lll}\text { 3.3.3 Scale Control for Geopressured-Geothermal Wells } & 125\end{array}$

3.3.4 Scale Inhibitor Effectiveness: Injection-

$\begin{array}{ll}\text { 3.3.5 Tracer Investigations for Geothermal Injection } & 127\end{array}$

$\begin{array}{llr}3.4 & \text { Test Facilities } & 129\end{array}$

$\begin{array}{lll}\text { 3.4.1 Lost Circulation Test Facility } & 130\end{array}$

$\begin{array}{ll}\text { 3.4.2 Magma Simulation Facility } & 132\end{array}$

$\begin{array}{lll}3.5 & \text { Handbooks } & 133\end{array}$

3.5.1 Geothermal Well Design Handbook $\quad 134$

3.5.2 Corrosion Handbook for Downhole Components 136

$\begin{array}{lll}\text { 4.0 MATERIALS AND BRINE CHEMISTRY } & 137\end{array}$

$\begin{array}{lll}4.1 & \text { Hardware } & 139\end{array}$

$\begin{array}{ll}\text { 4.1.1 Cements for Geothermal Wells } & 140\end{array}$

4.1.2 High Temperature Elastomers $\quad \cdots \quad 141$

4.1.3 High Temperature Drilling Mud 142 
4.1.4 Improved Well Casing Material 144

4.1.5 Polymer Concrete Pipe 145

$\begin{array}{llr}4.2 & \text { Test Facilities } & 147\end{array}$

$\begin{array}{lll}\text { 4.2.1 Two-Phase Flow Facility } & 148\end{array}$

$\begin{array}{lll}4.3 & \text { Handbooks } & 151\end{array}$

4.3.1 Geothermal Materials Selection Handbook 152

$\begin{array}{llr}\text { 5.0 DIRECT USE } & 153\end{array}$

5.1 Data Bases $\quad 155$

5.1.1 Direct Use Information Services 156

5.1.2 Direct Use Technical Services 157

5.1.3 Downhole Heat Exchanger Performance 158

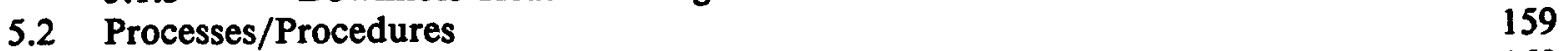

5.2.1 Mineral Heap-Leaching Process 160

$\begin{array}{lll}5.3 & \text { Handbooks } & 161\end{array}$

5.3.1 District Heating System Performance of

Materials and Equipment 162

5.3.2 Geothermal Direct Use Engineering and Design Guidebook 163

$\begin{array}{llr}6.0 & \text { ECONOMICS } & 165\end{array}$

$\begin{array}{lll}6.1 & \text { Software } & 167\end{array}$

$\begin{array}{lll}\text { 6.1.1 } & \text { GCFM Computer Model } & 168\end{array}$

6.1.2 GEOCITY Computer Model $\quad 170$

$\begin{array}{lll}\text { 6.1.3 GEOCOST Computer Model } & 172\end{array}$

6.1.4 GEOCOST-BC Computer Model $\quad 174$

$\begin{array}{lll}6.2 & \text { Handbooks } & 177\end{array}$

6.2.1 Hot Dry Rock Venture Risk Investigation 178

$\begin{array}{lr}\text { INDEX } & 181\end{array}$

$\begin{array}{lr}\text { APPENDIX A } & 185\end{array}$

$\begin{array}{llr}\text { A.1 Directory of Contacts (Individual) } & 187\end{array}$

A.2 Directory of Contacts (Organizational) 193 
CHAPTER 1

INTRODUCTION

$1 / 2$ 



\section{INTRODUCTION}

The "Geothermal Innovative Technologies Catalog" has been compiled on behalf of the U.S. Department of Energy, Geothermal Technology Division (GTD) as part of continuing efforts toward fostering the transfer of DOE-sponsored geothermal technology into the commercial marketplace. The purpose of the catalog is to provide private sector firms with a guide to marketable and nearly marketable products that are the direct result of federally sponsored R\&D.

The catalog is the result of the cooperation of DOE field offices, national labs, universities, and DOE contractors. The contributors initially reviewed a preliminary list of approximately 200 candidate technologies selected from various laboratory annual reports, technical journals, and other reports of DOE-sponsored work. They then selected the most appropriate technology items for inclusion in the catalog and provided technical descriptions for each of the chosen items. In some instances, catalog contributors provided additional suggestions for catalog entries.

The technology items reported were selected on the basis of technological readiness and applicability to current technology transfer thrusts. The items include technologies that are considered to be within 2 to 3 years of being transferred. While the catalog does not profess to be entirely complete, it does represent an intitial attempt at archiving innovative geothermal technologies with ample room for additions as they occur.

The catalog itself is divided into five major functional areas: Exploration; Drilling, Well Completion, and Reservoir Production; Materials and Brine Chemistry; Direct Use; and Economics. Within these major divisions are sub-categories identifying specific types of technological advances: Hardware; Sof tware; Data Base; Process/Procedure; Test Facility; and Handbook.

The "Exploration" chapter covers all technologies related to the search and discovery of geothermal resources. "Drilling, Well Completion, and Reservoir Production" refers to the subsequent exploitation of the resource involving the drilling of a new well, the completion of the well, and the ensuing production from the well. "Materials and Brine Chemistry" addresses new innovations in the areas of materials development for application under geothermal conditions. The "Direct Use" chapter deals with technologies that pertain to the many direct applications of geothermal energy. Finally, the "Economics" chapter focuses on advances in economic analysis methods of geothermal systems.

The sub-category "Hardware" denotes innovative items that describe special materials, drilling components, casing, well testing devices and instruments, and complete power plant systems. "Software" primarily includes computer codes developed to model subsurface parameters or the economics of geothermal systems. For the most part, these items are the result of DOE programs that emphasized the analyses of reservoirs based upon limited knowledge of the geothermal system. Physical computer models involve the flow of thermal energy and fluids in a geothermal reservoir. Economic models provide analyses of the cost of electric and direct heat systems with respect to the quality of the resource. "Data Base" as used here refers to either computerized or manual data sets and includes such things as institutional data on geothermal resource areas, physical and chemical data on the resources themselves, and libraries containing geologic materials (cores and cuttings). Items categorized by the terminology "Process/Procedure" are innovative methodologies related to geothermal development that have been documented, such as geophysical surveys, drilling methods, or innovative geochemical techniques in exploration or well testing. A "Test Facility" is a combination of components used to test specific aspects of geothermal 
research. Such facilities may include large-scale demonstration projects and field tests, or smaller scaled-down laboratory facilities for use in modeling ideal conditions in a geothermal system. "Handbooks" consist of compendiums of established technical procedures in geothermal development. A number of handbooks have been compiled which include methodologies derived from DOE-sponsored work.

The purpose of the above described divisions is to enable the reader to easily locate technology items of particular interest. An index organized according to the technology type (hardware, software, etc.) is located at the conclusion of the text for additional reference. In addition, an individual and organizational directory of contacts is provided at the end of the document to provide readers interested in obtaining additional information quick and easy access to specific R\&D individuals and organizations. The items included in this catalog are generally in the public domain, and therefore, available for commercial use. 


\section{CHAPTER 2}

EXPLORATION 
2.1 HARDWARE

6 


\section{ACOUSTIC SOURCE DETONATOR}

The multiple fire denotator sonde can sequentially fire up to 12 detonators that simulate an acoustic signal from a known location in a wellbore. The signal is detected by the geophone packages deployed in adjacent boreholes and is used to calibrate the geophone array in each sonde. The downhole firing system consists of the firing module, detonator rack, and high-temperature detonators. The detonator rack has three levels, each of which accomodates four exploding-foil detonators designed for high temperature and high fluid pressures. These detonators are inherently safe from accidental detonation during transit and handling.

\section{OPERATING SPECIFICATIONS}

Temperature Rating $250^{\circ} \mathrm{C}$

Fluid Pressure 10,000 psi

Length 152 in.

Diameter $\quad 5.75$ in.

Weight 520 lbs

Detonator Size $\quad 1.33 \mathrm{~g}$

For Additional Information:

Contact: $\quad$ Bert R. Dennis

Mail Stop D448

Los Alamos National Laboratory

Los Alamos, NM 87545

(505) 667-0728

Reference:

Dennis, Bert R., Koczan, Steven P., Stephani, Evon L.: High Temperature Borehole Instrumentation: Los Alamos National Laboratory, LA-10558-HDR, 1985. 



\section{ACOUSTIC SOURCE DETONATOR}

1. DETONATORS (12)

2. DETONATOR RACK

3. DEWAR, (STAINLESS STEEL)

4. INSULATION (MIN-K)

5. HEAT SINK (CERROBEND)

6. ELECTRONICS PACKAGE

7. SUB TO CABLE HEAD

8. PRESSURE VESSEL

OPERATING ENVIRONMENT $275^{\circ} \mathrm{C} 10,000$ psi

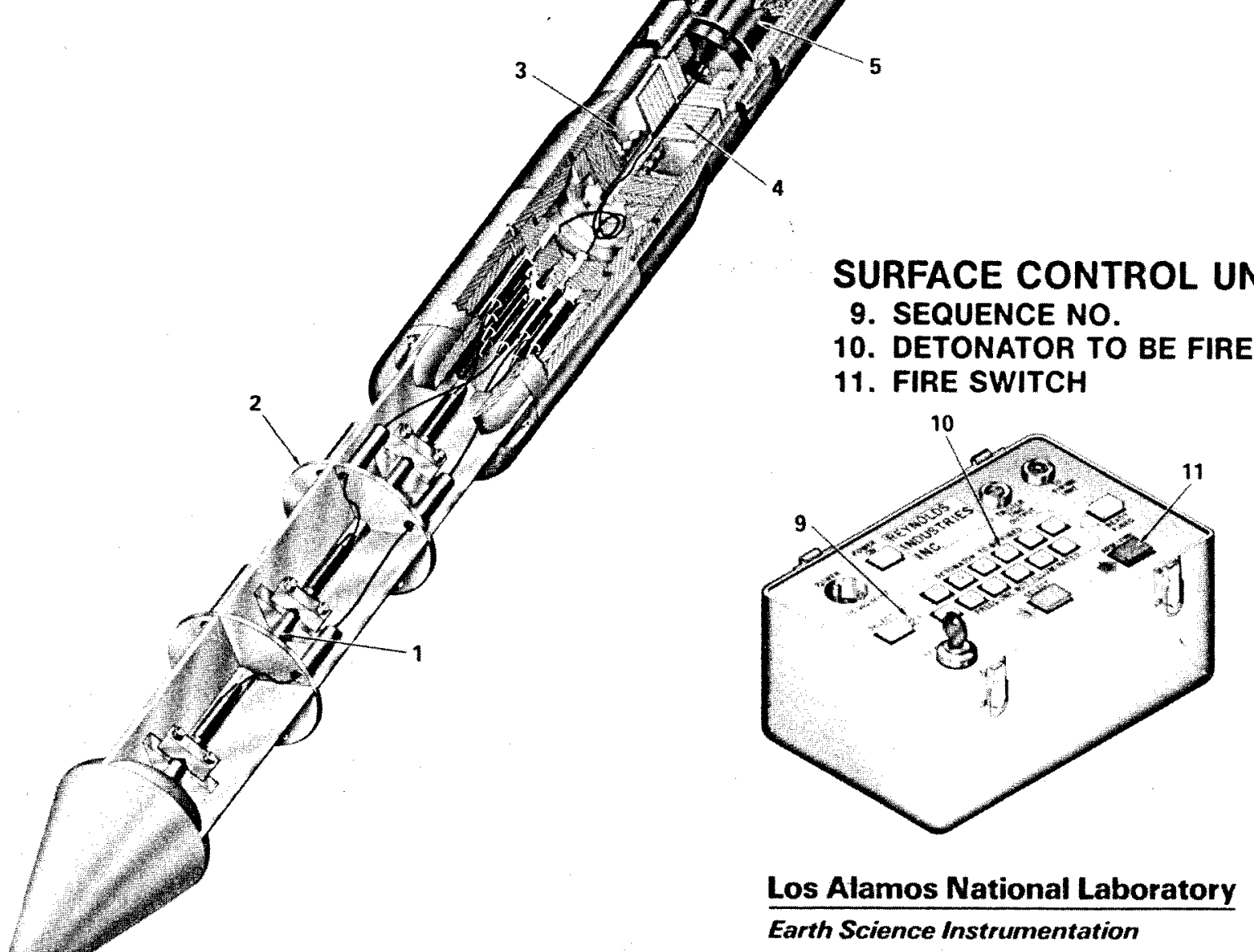




\section{CROSSWELL ACOUSTIC TRANSCEIVER-TRANSMITTER}

The transmitter generates an acoustic pulse by discharging a large high temperature capacitor through an SCR firing circuit to two magnetorestrictive transducers. A digital timing circuit controls the source repetition rate. The scrolls are housed in an oil-filled cavity and source coupling takes place through a teflon window. Pressure inside the window is balanced using a movable piston assembly. The transmitter is capable of generating acoustic signals at a power level of 3 joules.

\section{OPERATING SPECIFICATIONS}

Temperature Rating $527^{\circ} \mathrm{F}\left(275^{\circ} \mathrm{C}\right)$

Fluid Pressure

Length 10,000 psi

Diameter 204 in.

Weight 5.25 in.

Repetition Rate $480 \mathrm{lbs}$ 200 pps

For Additional Information:

Contact: Bert R. Dennis
Los Alamos National Laboratory
Mail Stop D448
Los Alamos, NM 87545
$(505) 667-0728$

Reference:

Dennis, Bert R., Koczan, Steven P., Stephani, Evon L.: High Temperature Borehole Instrumentation: Los Alamos National Laboratory, LA-10558-HDR, 1985. 


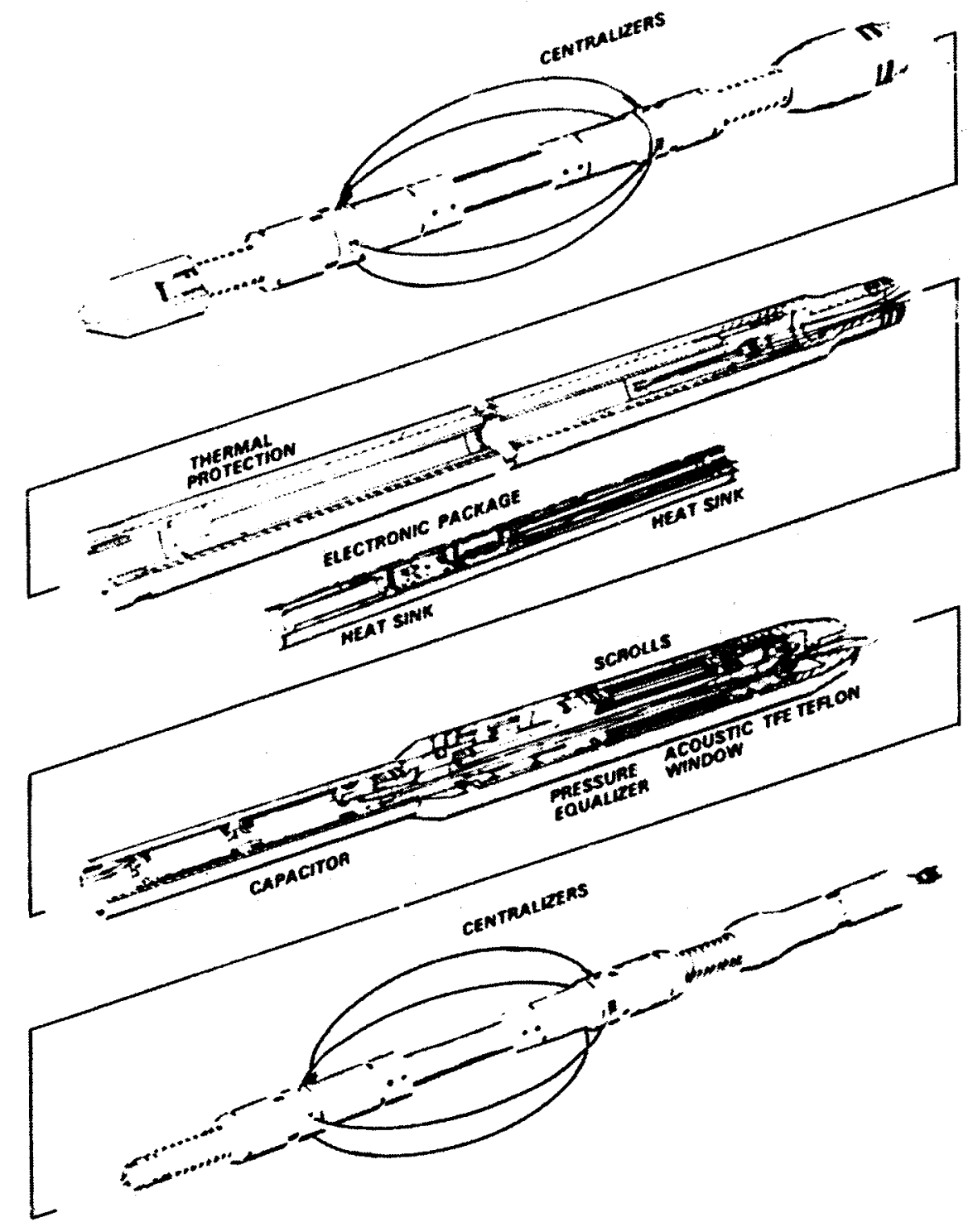

ACOUSTIC TRANSCEIVER - TRANSMITTER 


\section{DOWNHOLE GEOPHONE}

The Triaxial Geophone Detector incorporates a downhole multiplex system to enhance signal-to-noise and increase data frequency transmission. The multiplexer, housed in a thermal protection system, also allows monitoring of additional pertinent data such as the internal dewar flask temperature, sonde orientation, and power supply voltages. Borehole slant angle is measured and referenced to previous wellbore surveys to provide geophone orientation.

\section{OPERATING SPECIFICATIONS}

\section{Standard}

Temperature Rating

Fluid Pressure

Length

Diameter

Weight

Natural Frequency $527^{\circ} \mathrm{F}\left(275^{\circ} \mathrm{C}\right)$

15,000 psi

68 in.

$5.5 \mathrm{in}$.

160 lbs.

$30 \mathrm{~Hz}$
Slimline

$527^{\circ} \mathrm{F}\left(275^{\circ} \mathrm{C}\right)$

15,000 psi

152 in.

$3.25 \mathrm{in}$.

52 lbs.

$30 \mathrm{~Hz}$

For Additional Information:

Contact: $\quad$ Bert R. Dennis

Los Alamos National Laboratory

Mail Stop D448

Los Alamos, NM 87545

(505) 667-0728

Reference:

Dennis, Bert R., Koczan, Steven P., Stephani, Evon L.: High Temperature Borehole Instrumentation: Los Alamos National Laboratory, LA-10558-HDR, 1985. 
1. BULKHEAD (FEED THROUGH)

2. HIGH TEMPERATUAE CONNECTOR

3. INSULATION

4. HEAT SINK (CERROBENO MELTING TEMP. 70 ${ }^{\circ} \mathrm{C}$ )

5. INCLINOMETER (2 AXIS)

6. P.C. BOARD (AMPLIFIER \& SWITCHING)

7. BATTEAY PACK (14 VOLT)

8. DEWAR (STAINLESS STEEL)

9. GEOPHONES (B HORIZONTAL, 4 VERTICAL)

10. D.C. MOTOA \& LEAD SCREW ASSEMBLY

11. LOCKING ARM MECHANISM

12. SHEAR PIN ASSEMBLY

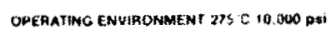

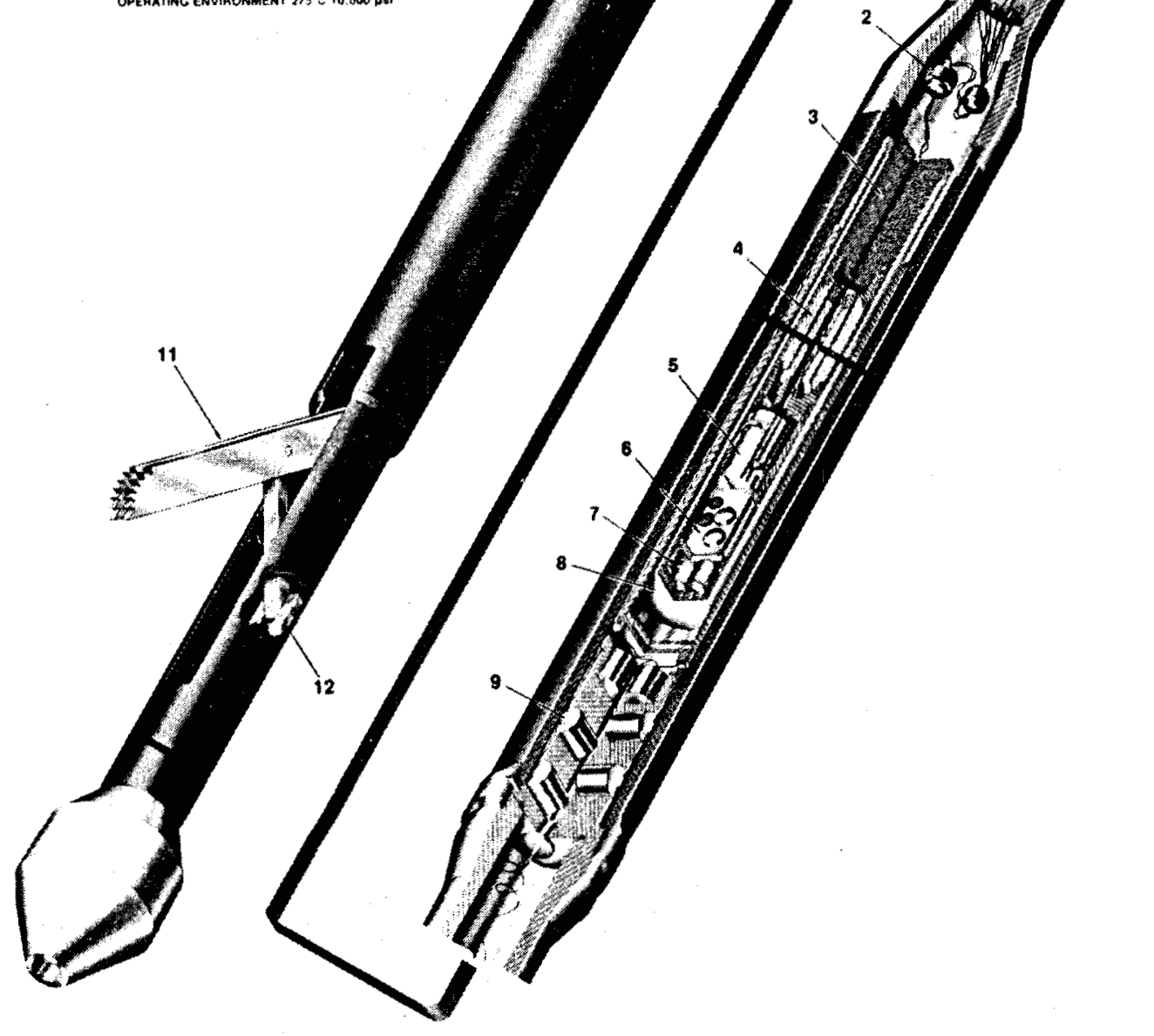

DOWNHOLE GEOPHONE DETECTOR. 


\section{SLIMLINE DETONATOR TOOL AND STRING SHOT}

The slimline detonator tool was designed to run in drill pipe or frac-string. It can fire two detonators and except for size is based upon the multi-shot detonator acoustic source. This tool has been modified by adding a front end carrier of a larger explosive charge that now can be used for a high temperature string shot or backoff tool.

Operating Specifications

Temperature Rating $320^{\circ} \mathrm{C}$

Fluid Pressure

Length $15,000 \mathrm{psi}$

Diameter

Weight

Size Detonator

139 in.

3.5 in.

Size String Shot

$145 \mathrm{lbs}$

$2.66 \mathrm{~g}$

$200 \mathrm{~g}$

For Additional Information:

Contact: $\quad$ Bert R. Dennis

Los Alamos National Laboratory

Mail Stop D448

Los Alamos, NM 87545

(505) 667-0728

Reference:

Dennis, Bert R., Koczan, Steven P., Stephani, Evon L.: High Temperature Borehole Instrumentation: Los Alamos National Laboratory, LA-10558-HDR, 1985.

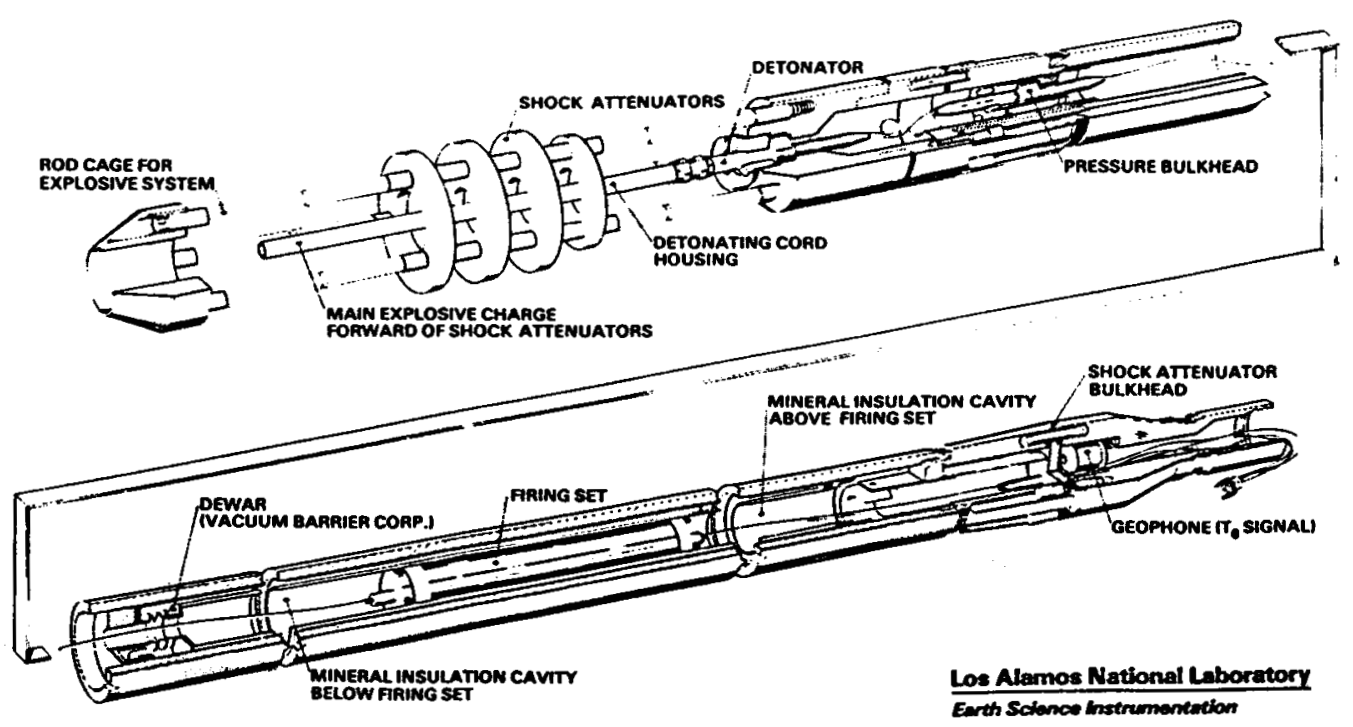

SLIMLINE DETONATOR TOOL and STRING SHOT 


\section{SELF-POTENTIAL DATA INTERPRETATION - THEORY AND COMPUTER PROGRAMS}

The spontaneous-potential or self-potential (SP) method has been used extensively in geothermal exploration and SP anomalies have been found over several convective hydrothermal systems. These anomalies are generally negative but may be dipolar or quadripolar when mapped in detail at the surface. The close association of SP anomalies with geothermal systems suggests the opportunity for a better understanding of the convective system if the SP phenomena could be understood in detail. Most of the SP surveys reported in the literature have contributed little to exploration because interpretation techniques have not been adequate to interpret the SP data in geologic terms.

DOE/GTD has sponsored research at the University of Utah, Department of Geology and Geophysics, leading to significant breakthroughs in the understanding of selfpotential effects associated with convective geothermal systems. Sill (1983) showed that electrical currents are due to divergences of the fluid convection current which is driven, in turn, by a primary flow of either heat or fluid. The fluid flow in the ground gives rise to drag (convection) currents, and the interaction with the electrical structure of the earth gives rise to the electrical spontaneous potential (SP). Sill (1983) further showed that this convective current approach could be adapted to numerical modeling techniques and he implemented a 2-D transmission-surface algorithm for the computation of potentials from basic physical properties of electrical and thermal resistivity, permeability, and temperature. This approach has substantial potential for contributing to a better understanding of SP data in geothermal areas.

Program SPXCPL, which calculates self-potential effects from cross-coupled fluid and heat flow for two-dimensional bodies, has been submitted to the National Energy Software Center (Argonne National Laboratory) for distribution to the public. Theoretical and numerical modeling results have been published in Geophysics.

For Additional Information:

Laboratory Contact: $\quad$ Phillip M. Wright

University of Utah Research Institute

Earth Science Laboratory

391 Chipeta Way, Suite C

Salt Lake City, UT 84108

(801) 524-3422

Sof tware Contact: National Energy Sof tware Center

Argonne National Laboratory

9200 South Cass Avenue

Argonne, IL 60439

(312) $972-2000$

References:

Sill, W.R., and Johng, D.S.: Self-Potential Survey. Roosevelt Hot Springs, Utah. DOE/DGE topical report, contract DE-AC07-78E\#392, University of Utah, 1979.

Sill, W.R.: A Model for the Crosscoupling Parameters of Rocks. University of

Utah, DOE report no. DOE/ID/12079-96, 1982. 

Sill, W.R.: "Self-Potential Modeling from Primary Flows." Geophysics 48 (1983): 76-86.

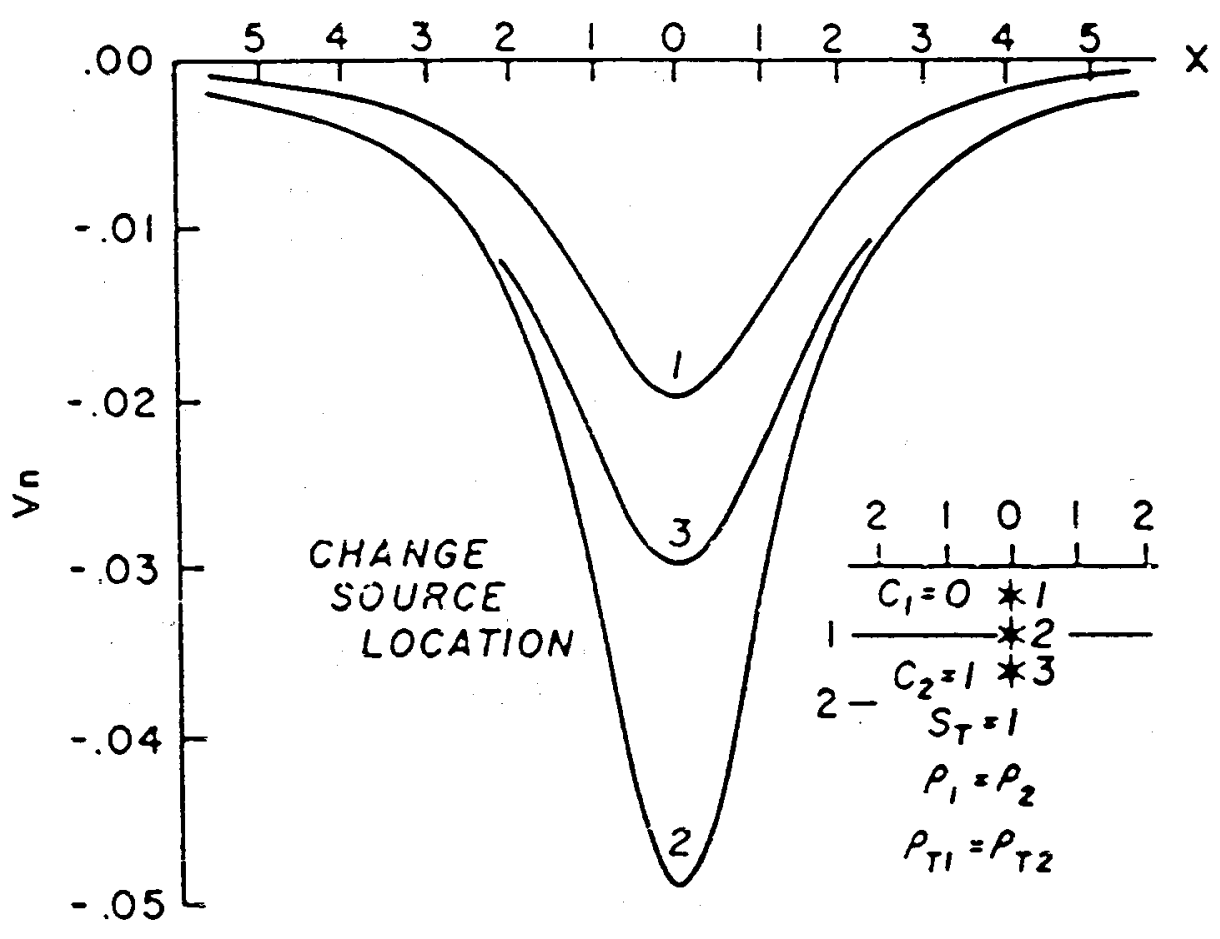

Surface voltage $(y=0, z=0)$ for a point temperature source and an overburden model, showing the effects of variations in the source location. 


\section{COMPUTER PROGRAMS FOR GEOPHYSICAL DATA INTERPRETATION}

Numerous studies have shown that geophysical methods can play a major role in costeffective exploration for, and delineation of, geothermal reservoirs. To be most effective, the geophysical data should be interpreted in a quantitative manner, i.e. through numerical modeling. Numerical modeling of a geophysical data set should result in the definition of subsurface geometries and physical properties which are a reasonable approximation to actual geologic bodies. This is normally accomplished through an iterative process of matching computed geophysical data values to the observed data, and then modifying the model to achieve a better match. An appropriate geometric/physical property model of the subsurface, integrated with existing geologic data, provides the best basis for siting costly drill holes, and thereby testing the prospect.

In support of various DOE/GTD programs, the Earth Science Laboratory/UURI generated a number of computer programs for modeling and interpretation of conventional geophysical data. These programs perform forward modeling for gravity and magnetic data in two, two and a half, and three dimensional geometries, and terrain correction for gravity data. Other programs effect a forward modeling or inversion of Schlumberger electrical resistivity data, and the forward modeling of dipole-dipole array electrical resistivity data (two dimensional bodies). The computer programs have been throughly documented and submitted to the National Energy Sof tware Center (NESC-Argonne National Laboratory) for release to the public. Programs and documentation were made directly available to geothermal users prior to NESC availability. Numerous technical reports have been distributed and published which illustrate the techniques and utility of numerical modeling in geothermal exploration and development.

Technical reports, computer program documentation and program listings or tapes are made available at reproduction and handling costs, which are a small fraction of the development costs. The interpretation concepts and sof tware itself have been effectively transferred to industry and other user via diffusion.

For Additional Information:

Laboratory Contact:

Philip E. Wannamaker

University of Utah Research Institute

Earth Science Laboratory

391 Chipeta Way, Suite C

Salt Lake City, UT 84108

(801) 524-3422

References:
Sof tware Contact:

National Energy Software Center

Argonne National Laboratory

9700 South Cass Avenue

Argonne, IL 60439

(312) 972-2000

Killpack, T.J., and Hohmann, G.W.: Interactive Dipole-Dipole Resistivity and IP Modeling of Arbitrary Two-Dimensional Structures. (IP2D Users Guide and Documentation) UURI/Earth Science Laboratory Rep. 15, 1979.

Maurer, J., and Atwood, J.W.: GM3D; Interactive Three-Dimensional Gravity and Magnetic Modeling Program. (GM3D. Rev 1 User's Guide) UURI/Earth Science Laboratory Rep. 44, 1979.

Ross, H.P., and Moors, J.N.: "Geophysical Investigations of the Cove FortSulphurdale Geothermal System, Utah." Geophysics, 50 (in press) 1985. 
2.3 DATA BASES 


\section{DOD GEOTHERMAL PROJECTS}

The following are Department of Defense Geothermal projects for which project descriptions are available:

\section{China Lake Naval Station, California}

Geologic and geophysical studies were conducted by UURI/ESL in 1977-78 in support of DOE/DGE drilling of CGEH-\#1, and contributed to the resource assessment of the Coso KGRA. Geoscience data was released as publications and presentations.

Hill Air Force Base, Utah

UURI/ESL completed geologic and geophysical surveys at Hill Air Force Base, $\mathrm{UT}$, in an attempt to identify a geothermal resource for base space heating, 1979-80. Geoscience data has been released to open file and published.

\section{Williams Air Force Base, Arizona}

UURI/ESL reviewed well log and production data and advised DOE/DGE regarding geothermal reservoir potential at William Air Force Base, Arizona during 1979-1980. Additional DOE work followed without UURI/ESL involvement.

Ascension Auxilary Airfield, Ascension Island, South Atlantic Geologic and geophysical exploration has been conducted by UURI/ESL in an attempt to identify and delineate a geothermal resource on Ascension. This project has been active since 1982, and awaits further funding. Report distribution has been limited to DOE and DOD.

Adak Naval Air Station, Alaska UURI/ESL completed land surveys and supervised a microearthquake survey at the Adak Naval Air Station in 1982 in support of the China Lake geothermal resource exploration. Data and reports were submitted to China Lake.

\section{Lackland Air Force Base, Texas}

UURI/ESL provided geologic support and drilling supervision for a DOD/DOE drilling project at Lackland Air Force Base during 1982-83. Reports have been distributed to DOE and DOD.

For Additional Information:

Contact:

Phillip M.'Wright

University of Utah Research Institute

Earth Science Laboratory

Salt Lake City, UT 84108

(801) 524-3422 


\section{EXPLORATION TECHNOLOGY - DATA BASE}

The Department of Energy/Geothermal Technology Division (DOE/GTD) supported a variety of basic research and technology evaluation efforts under the Geothermal Exploration and Assessment Technology Program. The research and technology development required by the U.S. geothermal industry to meet DOE production goals were identified by a canvas of industry program managers and scientists, and then discussed and prioritized at conferences at the University of Utah, Salt Lake City, Utah, and in Marina Del Ray, California.

This program sought to reduce drilling costs in the geothermal industry through better target definition from geologic, geochemical, and geophysical data. Method research and field surveys were conducted at several project areas of the Industry Coupled Program. The results were evaluated and made available to the public.

A borehole seismic survey was completed at Roosevelt Hot Springs, Utah, and reflection seismic surveys were completed at Dixie Valley, Stillwater, Beowawe and Leach Hot Springs (all Nevada) and the data was released to the public. Additional research included theoretical modeling and field surveys in electrical geophysical methods, thermal gradient studies and trace element geochemistry. This data made specific contributions to the known geology of each site surveyed, and provided an educational function for scientists and exploration managers.

Technology transfer was effected through open-file data releases, presentations, and technical reports. The products included field tests, new exploration concepts, and diffusion of existing technology.

For Additional Information:

Contact: Dennis L. Nielson

University of Utah Research Institute

Earth Science Laboratory

391 Chipeta Way, Suite C

Salt Lake City, UT 84108

(801) 524-3422

\section{References:}

Nielson, D.L., ed.: Program Review, Geothermal Exploration and Assessment Technology Program. University Utah Research Institute, Earth Science Laboratory Rep. 29, 1979.

Holombe, H.T. and Jiracek, G.R.: "Three-Dimensional Terrain Corrections in Resistivity Surveys." Geophysics, 49 (1984): 439-452.

Ross, H.P., Glenn, W.E., and Swift, C.M.: "Reflection Seismic Surveys for Basin and Range Geothermal Areas - An Assessment." Presented at the 66th Ann. AAPG Meeting, San Francisco, 1981. 


\section{INDUSTRY.COUPLED DRILLING PROGRAM DATABASE}

The U.S. DOE Division of Geothermal Energy (DGE) initiated the Industry Coupled Program in 1977 to accelerate development of high-temperature geothermal resources. Two key aspects of the program were (1) cost sharing with industry for exploration, reservoir assessment, and reservoir confirmation; and (2) the release of geologic, geophysical, geochemical, and drilling data to improve knowledge and understanding of geothermal reservoirs. A third aspect of the program was to evaluate techniques and current methods on a cost-effective basis. The geothermal resource areas included in the program were located in south-central Utah and the northern Basin and Range Province in Nevada.

The database resulting from the Industry Coupled Program represents more than $\$ 25,000,000$ in expenditures in 14 promising resource areas. The data made available by the participating companies include a wide variety of geophysical surveys, geochemical and geologic data, drill cuttings, drill technology, and suites of well logs. Additional geologic, geophysical, and geochemical work by the Earth Science Laboratory/University of Utah Research Institute has resulted in numerous technical publications and several case history publications. This program contributed directly to new electric power on line at Beowawe, Nevada, and Cove Fort-Sulphurdale, Utah, and supported electric power development at Roosevelt Hot Springs, Utah, Dixie Valley, Nevada, and other areas.

The recent discovery of a high quality steam resource at Cove Fort Sulphurdale followed a reinterpretation of Industry Coupled data and acquisition of limited new data. Additional electric generation or direct heat utilization projects in other areas will be supported by these site specific data. Geologic knowledge of high-temperature resources has been advanced by these data. The cost-effectiveness of many geologic, geochemical, and geophysical techniques has been evaluated from the database and reported to the geothermal community.

The technology resulting from this program includes a variety of concepts, field tests, and engineering developments. Technology transfer has been accomplished through open file data release, technical publications, and presentations.

For Additional Information:

Open-file data and reports:

Dennis L. Nielson

University of Utah Research Institute

Earth Science Laboratory

391 Chipeta Way, Suite C

Salt Lake City, UT 84108

(801) 524-3422

Geophysical well logs:

Rocky Mountain Well Log Service

P.O. Box 3150

Denver, CO 80201

(303) 825-2181 


\section{References:}

Fiore, J. N.: "Overview and Status of the U.S. Department of Energy's Industry Coupled Geothermal Reservoir Assessment Program." Geothermal Resources Council Transactions. Volume 3, 1979, pp. 99-102.

Ross, H. P., Nielson. D. L., and Moore, J. N.: "An Exploration Case Study of the Roosevelt Hot Springs Geothermal System, Utah" Bulletin, AAPG, 66, 1982, pp. 879-902.

Ross, H. P., and Moore, J. N.: "Geophysical Investigations of the Cove FortSulphurdale Geothermal System, Utah," Geophysics. 50, in press, 1985.

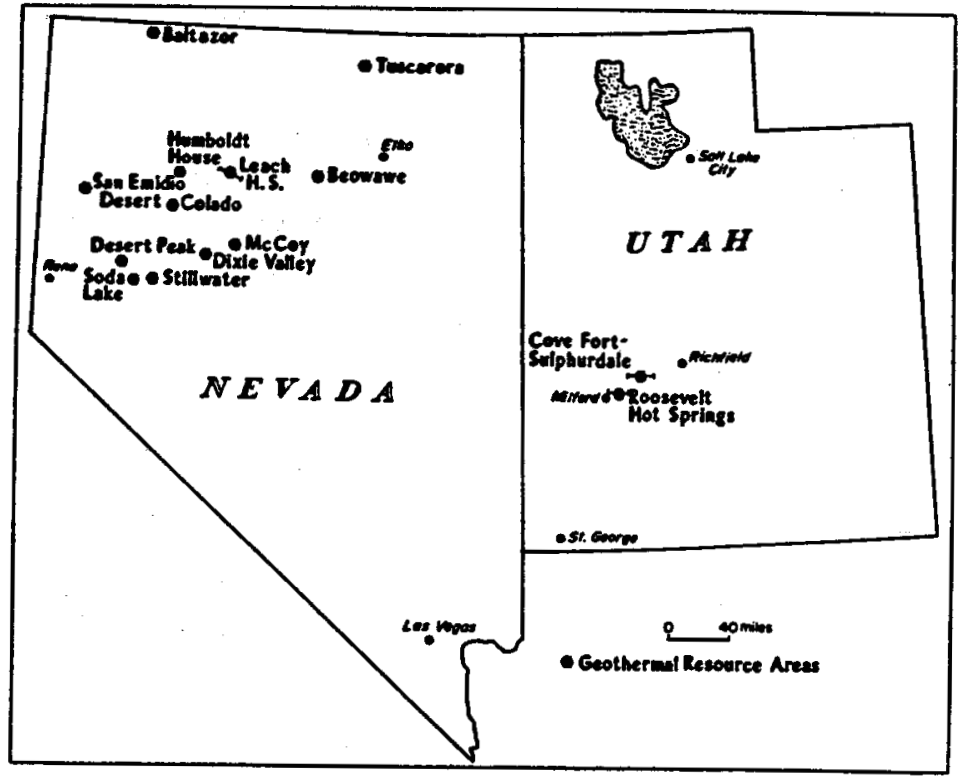

Index map of Industry Coupled Program bydrothermal systems.
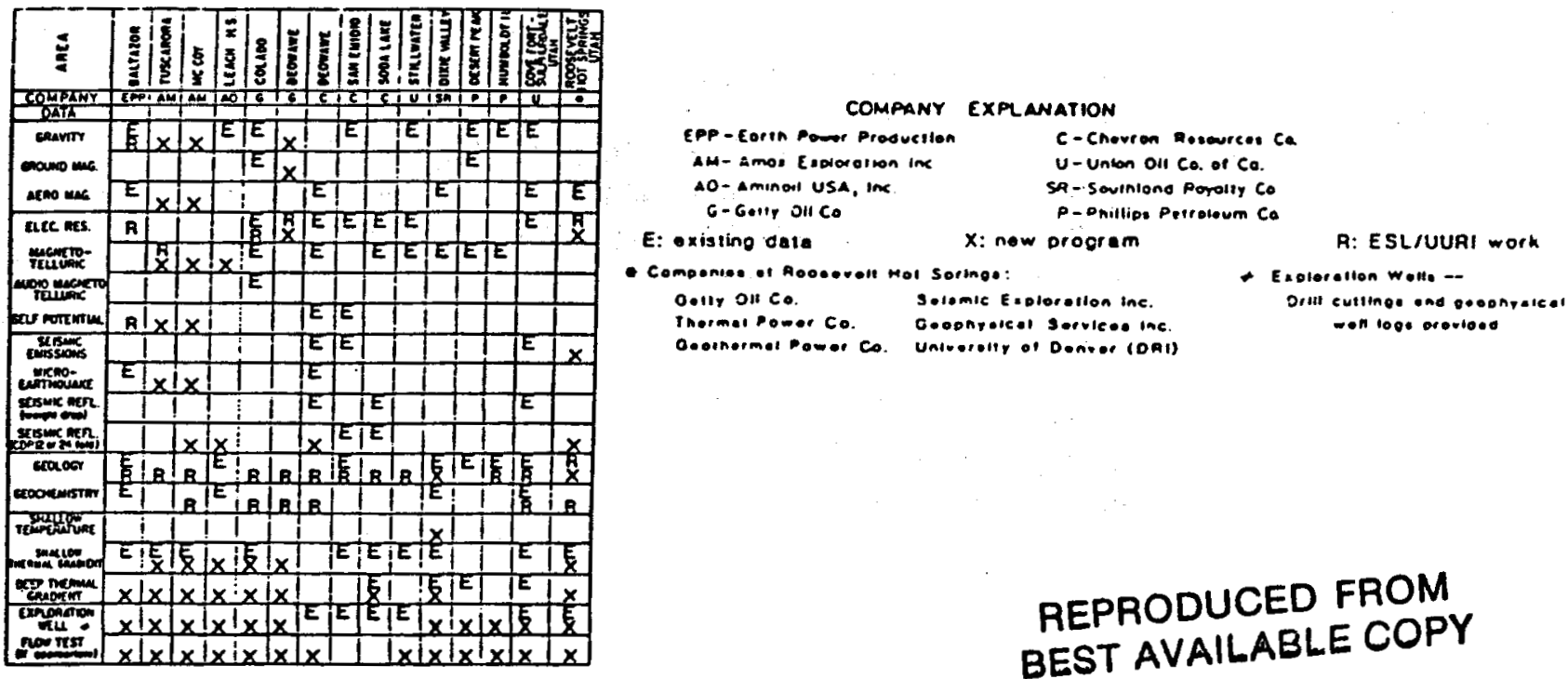


\section{LOGDEX DATA BASE}

The LOGDEX data base has been developed by the University of Texas at Austin, Center for Energy Studies (CES), in support of programs sponsored by the U.S. Department of Energy that deal with the assessment of geopressured geothermal energy resources. The data base consists of digitized well log information for several hundred oil and gas test wells located along the northern Gulf Coast of Texas and Louisiana. A subsidiary data base compiled by the CES, the Geopressured Geothermal Information System Bibliography (GEOBIB) includes a bibliography and citation extracts of references dealing with geopressured resource and utilization. Compilation of the data base began in 1977. Completion was expected in late 1985; when digitized well log data would be available on magnetic tape.

The LOGDEX data base was developed to serve as a resource base for the many DOE sponsored geopressured geothermal programs along the Texas-Louisiana Gulf Coast. The data base was assembled to complement geoscience research and well log analysis.

LOGDEX is comprised of data from over 350 wells situated in potential geopressured geothermal areas along the northern Gulf Coast. The well logs were obtained from various oil companies and then digitized to numeric information on magnetic tape. The overall data base includes a summary and index to well information based upon a classification criteria and the digitized well logs.

The data components provided in the summary listing include: 1) LOGDEX unique identification number; 2) name of the operator; 3) well name; 4) well location; 5) abstract, track, or block name; 6) API number (if applicable); and 7) $\log$ types available.

The reports containing the summary listing, index, and bibliographic information as listed above are available through NTIS. The digitized log data base is available only to persons with access to the computer center at the University of Texas at Austin.

Application programs have been developed at the CES which makes use of the digitized data. These application programs range from simply plotting the curves available for a given log to analyzing digitized well logs for generating synthetic seismograms. Future plans include the continued updating of the data base through early 1985. The CES is currently in the process of making the digitized base available for purchase to private individuals by late 1985 .

For Additional Information:

Contact: $\quad$ R. Schneider

University of Texas at Austin

Center for Energy Studies.

Austin, TX 78712

(415) 853-8300 
References:

Hill, T. and Sepehrnoori, K.: Summary of LOGDEX Data Base. U.S. Department of Energy Report DOE/ET/27018-1 Summary, 1981.

Hill, T., and Sepehrnoori, K.: Geopressured Geothermal Bibliography, Volume I: Citation Extracts, and Volume II: Geopressure Thesaurus. U.S. Department of Energy Report DOE/ET/27018-1, 1981. 


\section{GEOTHERM DATA BASE}

The GEOTHERM data base was compiled by the U.S. Geological Survey and represents the most complete data set of an overall geothermal resource assessment of the United States. Data from GEOTHERM, which include fluid geochemistry, stable isotopes, gas condensate, temperature, and production rate measurements of over 10,000 thermal wells and springs in the U.S., can be used to augment regional, area, and prospect-sized geothermal evaluations. Data for GEOTHERM were input until 1981. The file was released for distribution in 1982. The input period covered the major portion of government sponsored resource assessment and commercialization planning programs and therefore contain the principal set of nonproprietary data elements gathered from government/state cooperative and government/industry cooperative programs.

The purpose of GEOTHERM is to gather, organize and provide an information data base pertaining to geothermal wells, springs, fumaroles, etc. as they may relate to resource characterization.

The GEOTHERM data base contains some 10405 records on magnetic tape. The records give information on resource location, temperature, and fluid geochemistry. Records may contain up to 118 items. Analyses and concentration of condensate, gas and stable isotopes may be present. All numeric fields use the following format: Cy999 where $\mathbf{C}=$ qualification code which is always present. $y$ is blank, and 999 is the numeric field for concentration values. Entries include: $L=$ less than, $\mathbf{G}=$ greater than, $T=$ trace (not followed by a number), $Q=$ qualified (other data in qualification field), $E$ = estimated, $R=$ midpoint of range (actual range in qualification field). Analytical values for some 55 elements and compounds may be contained within the record, plus analyses of stable isotypes of oxygen, sulfur, and carbon. Production flow rates are also included.

The GEOTHERM file is available on magnetic tape through NTIS at a cost of $\$ 140.00$, NTIS Order No. is PB 84-107705. A hard copy as either paper or microfiche is available through the USGS. GEOTHERM was also published as a series of U.S. Geological Survey Open-File Reports (Nos. 83-426 through 83-440).

For Additional Information:

R\&D Contact:

J. D. Bliss

U.S. Geological Survey

Menlo Park, CA 92008

(415) 853-8300

Software Contact: National Technical Information Service

U.S. Department of Commerce

5285 Port Royal Road

Springfield, VA 22161

(703) 487-4650

\section{References:}

Bliss, J. D., and Rapport, A.: GEOTHERMAL - The U.S. Geological Survey Geothermal Information System Computers and Geosciences. V.9, no. 1 (1982): 3539. 


\section{OIT SITE DATA BASE REPORTS}

The Oregon Institute of Technology (OIT) developed status reports for geothermal development in the states of Alaska, Idaho, Montana, Oregon, Washington, and Wyoming. The reports not only include resource characteristics, but also environmental data that could be used by geothermal developers as an aid to planning and commercialization. State by state institutional analyses are included that address major obstacles to geothermal development.

The site status reports by OIT represent a basic compilation of physical and institutional factors surrounding all geothermal areas in the particular states. The data are several years old and, therefore, the institutional portions should be used with a degree of caution as legislative and economic factors change over time.

The project was initiated in 1978 in support of DOE's National and Regional Planning and Operations Research. Reporting was completed in 1982.

The collective goal of these studies has been to summarize, on a site specific basis, the various factors affecting development. Information includes: resource data, site geologic descriptions, reservoir characteristics, environmental characteristics, leasing and development status, institutional factors, population and market potential.

For Additional Information:

Contact: $\quad$ Paul J. Lienau

Oregon Institute of Technology

Geo-Heat Center

Klamath Falls, OR 97601

(503) 882-3583

References:

Bloomquist, R.G. Geothermal Energy in Washington--Site Data Base and Development Status, report to USDOE. 1979; available from Geo-Heat Center and NTIS.

Brown, Keith E. Geothermal Energy in Montana--Site Data Base and Development Status, report to USDOE. 1979; available from Geo-Heat Center and NTIS.

James, R. Geothermal Energy in Wyoming - Site Data Base and Development Status, report to USDOE. 1979; available from Geo-Heat Center and NTIS.

Justus, D. Geothermal Resources in Oregon--Site Data Base and Development Status, report to USDOE. 1979; available from Geo-Heat Center and NTIS.

Markle, D. Geothermal Energy in Alaska--Site Data Base and Development Status, report to USDOE. 1979; available from Geo-Heat Center and NTIS.

McClain, D. Geothermal Energy in Idaho--Site Data Base and Development Status, report to USDOE. 1979; available from Geo-Heat Center and NTIS. 


\section{STATE COUUPLE RESOURCE ASSESSMENT PROGRAM}

Low $-\left(20^{\circ}-90^{\circ} \mathrm{C}\right)$ and moderate- $\left(90^{\circ}-150^{\circ} \mathrm{C}\right)$ temperature geothermal resources are relatively plentiful in the western United States and have significant potential for contributing to the nation's energy requirements in future years. These resources are already being used for space heating, industrial process heating, aquaculture, etc. The State Coupled Resource Assessment Program, begun in 1977, has supported the inventory, investigation, characterization, and information dissemination of these resources.

Utilization of low- to moderate-temperature resources generally requires colocation of the resource and the user at an identified resource site. Dissemination of information about the location and quality of the resource to the industry and the general public has been a principal aim of the State Coupled Program.

A state agency has been identified in each of 20 states to take a lead role in data compilation, exploration, and interpretation within that state in accordance with DOE/GTD guidelines and program goals. A limited amount of site-specific geoscience surveys and drill testing has been included in the program. Basic data from the program have been included in GEOTHERM (the U.S. Geological Survey computer file) and in U.S. Geological Survey assessment of geothermal resources (Circulars 729, 790, and 892). Each participating state has published a simplified resource occurrence (public) map, and some states have published a more involved (technical) data map describing these resources. Technology has been effectively transferred to potential users via these maps, reports, and technical presentations, and utilization of several resources is presently being considered.

For Additional Information:

Contact: Howard P. Ross

University of Utah Research Institute

Earth Science Laboratory

391 Chipeta Way, Suite C

Salt Lake City, UT 84108

(801) 524-3422

\section{References:}

State Geothermal Resource Maps, 20 participating states.

Foley, D., Brophy, G.P., Mink, L.L., and Blackett, R.E.: "The State Coupled Program - A New Emphasis Geothermal Res. Council Transactions. Volume 4. (1980): 779-781.

Reed, M.J., Ed.: Assessment of Low-Temperature Geothermal Resources of the United States - 1982. U.S. Geological Survey Circular 892, 1983. 


\section{UURI/ESL GEOTHERMAL SAMPLE LIBRARY}

The Geothermal Sample Library is located is Salt Lake City, Utah, and provides openfile access and archival storage for field and drill samples as well as reference to analysis done on the samples. Proprietary storage is provided for confidential samples as well as storage of samples that are accessible to the public. At present, the library contains over 80,000 meters of drill chip samples and 2,100 meters of core from 171 shallow thermal gradient holes and deep holes, mainly from geothermal areas of the western United States. Included are samples from the 14 U.S. Department of Energy Industry Coupled Program areas in Utah and Nevada; Cosco KGRA, CA; Raft River, Idaho; and samples from DOE and private geothermal projects in Wyoming, Colorado, Idaho, Washington, and New Mexico.

The sample library has been used to archive samples from DOE projects and to distribute samples for authorized research and study. It has been used advantageously by geologists and researchers in preparation for drilling within the areas represented and for comparison with drill samples from other project areas. Chipboards have been prepared for most DOE-supported geothermal holes in order to facilitate study.

Sample preparation facilities are available and are used prior to sample storage, and also for routine or special chemical and physical analyses. Density and magnetic susceptibility measurements can also be done at this facility.

\section{For Additional Information:}

Contact: Dennis L. Nielson

University of Utah Research Institute

Earth Science Laboratory

Salt Lake City, UT 84108

(801) 524-3422

\section{Reference:}

Hulen, J.B., and Sibbett, B.S.: Interpretation of Drill Cuttings from Geothermal Wells. Univ. of Utah Res. Inst., Earth Science Lab Report No. DOE/10/12079-37, ESL-57, 1981. 


\section{USER COUPLED CONFIRMATION DRILLING PROGRAM}

Increased utilization of low- to moderate- $\left(20^{\circ}-150^{\circ} \mathrm{C}\right)$ temperature resources could reduce U.S. energy dependence on foreign oil imports. Direct heat utilization has been limited because of high front-end risk and cost of geothermal development, and limited consideration by industry and potential developers of geothermal energy resources. The User Coupled Confirmation Drilling Program (UCCDP) was implemented between 1980 and 1984 to cost share exploration, drilling, flow testing and reservoir engineering efforts with developers. Technical data resulting from the program has been made public to further assist in expanding the development and understanding of these resources.

Under this program, two areas were drill tested: The Wendel-Amedee KGRA near Honey Lake, California, and a site near Alamosa, Colorado. The industrial partner for the Honey Lake project was Geoproducts, Inc., who completed two successful wells. The Alamosa project, supervised for the City of Alamosa, Colorado by Energy Services, Inc., failed to produce geothermal fluids at commercial temperature and volume.

The data has been made available to the public through open file data release and project reports.

For Additional Information:

Contact: Phillip M. Wright

University of Utah Research Institute

Earth Science Laboratory

Salt Lake City, UT 84108

(801) 524-3422

References:

Gray, R.A., Prestwich, S.M., Wright, P.M., and Dolenc, M.R.: Geothermal Resources Council Transactions. Volume 4. User-Coupled Confirmation Drilling Program, pp. 783-785, 1980.

Zeisloft, J.; Sibbett, B.S.; and Adams, M.C.: Case Study of the Wendel-Amedee Exploration Drilling Proiect. Lassen County. California. User Coupled Confirmation Univ. of Utah Research Inst., Earth Science Lab Rep. No. DOE/ID/12079-108, ESL-129, 1984.

Zeisloft, J., and Sibbett, B.S.: City of Alamosa. Colorado Alamosa \#1 Geothermal Well UCCDP Proiect Case Study. University of Utah Research Institute, Earth Science Laboratory Report No. DOE/ID/12079-126, ESL-161, 1985.

Sibbett, B.C.: Geoproducts WEN-2 Well. Wendel-Amedee. California. University of Utah Research Institute, Earth Science Laboratory Report No. DOE/ID/12079, ESL-152, 1985. 


\subsection{PROCESSES/PROCEDURES}




\section{AUTOMATED SEISMIC PROCESSOR (ASP)}

ASP is a real-time, distributed processing system that continuously monitors a seismic array, automatically detects events, and provides complete calculation of seismological source parameters within one minute of each event.

ASP is a cost-effective, modular, building-block system that eliminates routine, labor intensive analysis, freeing scientific personnel to concentrate on interpretation of results. The output modes an operator may select include:

Mode A - Worker raw data set (debug mode)

Mode B - Event count and time with print option selected:

Average $\mathbf{P} \& \mathrm{~S}$ amplitudes

Average S-P time

S-P time histogram

Nearest station

Mode C - Running b values, cumulative and interval

Mode D - Hypocentral location

Mode E - P-Wave FFT raw data

S-Wave FFT raw data

Mode G - FFT-derived source parameters for each station

Mode H - $\quad$ Average of FFT-derived P-Wave source parameters

Average of FFT-derived S-Wave source parameters

Mode I - Principal stress direction (fault-plane solution) with moment components

Mode J - Wadati Vp/Vs value.

The system may be configured for laboratory or field deployment in easily expandable networks from 8 to 127 channels. Critical results are provided immediately, not weeks later. Archival costs may be dramatically reduced since raw station data and complete data analysis results are stored on high speed tape cartridges.

In geothermal field monitoring, where the usefulness of event location and analysis diminishes greatly with time delay, ASP's superiority is unquestioned. Literally hundreds of events can occur within a few days. Conventional data reduction and analysis of analog and digital records require months of labor and costly data processing. Due to voluminous data, only selected events are normally analyzed; ASP provides complete data analysis for each event in realtime. There is no trade-off in event selection, and all analysis is done in a consistent, unbiased manner. ASP sof tware capability and accuracy have been 
demonstrated on thousands of events to equal or exceed analysis based on conventional manual $P$ and $S$ wave picking. The analysis effort in ASP operation, unlike that for conventional microearthquake network practice, does not increase with the number of stations, and better data quality through increased network density is easily achieved.

In conventional microearthquake surveys, ASP offers the above advantages as well as the capability to adjust array geometry and detection parameters rapidly to suit particular study objectives and seismicity character. Timely completion of critical facility siting studies by the ASP user of fers obvious cost and competitive advantages. Operational monitoring of seismic activity near such facilities with ASP can eliminate the necessity for high-level technicians, both in the field and in the processing laboratory.

\section{Real-Time Monitoring}

ASP is comprised of a system of CMOS microcomputers arranged with one as a central control unit (BOSS) and a microprocessor for each channel in the array (WORKER). Each WORKER, upon detecting an event, determines times, amplitudes, quality of $\mathbf{P}$ and $\mathbf{S}$ arrivals, and $P$-Wave polarity. Fast Fourier transforms of windowed $P$ and $S$ phases are computed and fitted for low frequency level, corner frequency, and high frequency slope. Raw data are transmitted to BOSS. The BOSS processor monitors the WORKERS and performs event discrimination. When an event is declared, BOSS energizes an 11/23 processor, transmits the WORKER raw-data to the LSI, where an event message is printed and then hypocentral locations and other event parameters appropriate to the user-selected modes are computed and listed on the thermal printer and/or the tape cartridge.

ASP utilizes a Digital Equipment Corporation LSI-11/23 computer, a unit which has become established as a standard in special-purpose computer systems, as the final processor for event source parameters. The standard hypocenter location sof tware utilizes a velocity gradient model with optional station corrections. P- and S-wave spectral parameters and Pwave polarities yield fault-plane solutions through advanced linear inversion techniques. The low power and reliability characteristics of the CMOS technology are not compromised with the use of the LSI-11/23.

For Additional Information:

Laboratory Contact: $\quad$ E. Majer

Lawrence Berkeley Laboratory

Berkeley, CA 94720

(415) 486-6709

Producer Contact: $\quad$ D. Ayden

Sprengnether, Inc.

4150 LaClede

St. Louis, MO 63108

(314) 535-1682

User Contact:

B. Daniel

Unocal Geothermal

Santa Rosa, Ca 95401

(707) 545-7600 


\section{BOREHOLE GEOPHYSICAL RESEARCH FOR FRACTURE DETECTION}

Electrical geophysical methods have been widely used in the exploration for, and delineation of, geothermal occurrences. Surface methods typically suffer from limited depth penetration and resolution when the target is deeply buried, but the initial drill hole within or near the exploration target presents an opportunity for increased depth penetration and vertical and lateral resolution. Borehole geophysical methods include a variety of electrode configurations in which current sources or receiving electrodes are placed in the borehole and on the surface: borehole-to-surface and crossborehole arrays can be used.

The economic development of many geothermal systems is critically dependent upon cost-effective drilling and the successful delineation of fracture zones. Research at UURI has evaluated the state-of-the-art of electrical borehole geophysical methods and has identified the more promising electrical arrays for theoretical study and numerical modeling simulation.

The dip of the body (fracture zone) and location of the energizing electrodes were varied in numerical mis-a-la-masse studies. Locating the buried electrode just outside the body does not significantly alter model results from those when the electrode is placed within the body. The cross-borehole mis-a-la-masse method produces larger anomalies than other cross-borehole methods. Theoretical model results have also been obtained for surface-to-borehole resistivity measurements for a thin oblate spheroid representing a fracture.

Technology transfer has been effected through publication of theoretical and numerical results while the research continues.

For Additional Information:

Contact: $\quad$ Stanley H. Ward

University of Utah Research Institute

Earth Science Laboratory

391 Chipeta Way, Suite C

Salt Lake City, UT 84108

(801) 524-3422

References:

Yang, F.W., and Ward, S.H.: "On the Sensitivity of Surface-to-Borehole Resistivity Measurements to the Attitude and the Depth to Center of a Three-dimensional Spheroid." Geophysics, 50 (1985):1173-1178.

West, R.C. and Ward, S.H.: "The Borehole Transient EM Response of 3-D Fracture Zone in a Conductive Half-Space." To be submitted to Geophysics, 1985.

Yang, F.W. and Ward, S.H.: "Single- and Cross-Borehole Resistivity Anomalies of Thin Ellipsoids and Spheroids." Geophysics, 50 (1985):637-655.

Beasley, C.W., and Ward, S.H.: "Theoretical Borehole-to-Borehole and Boreholeto-Surface Resistivity Anomalies of Geothermal Fracture Zones." Geophysics, 51 (1986, in press). 
Newkirk, D.B.: "Downhole Electrode Resistivity Interpretation with ThreeDimensional Models." M.S. Thesis, University of Utah. 1982.

Ross, H.P., and Ward, S.H.: Borehole Electrical GeoPhysical Methods (A Review of the State-of-the-Art). University of Utah Research Institute/Earth Science Laboratory report $141,1984$.

CROSS - BOREHOLE

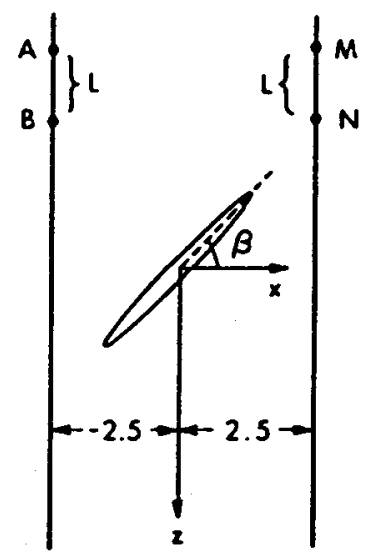

$P_{0} / P_{1}$

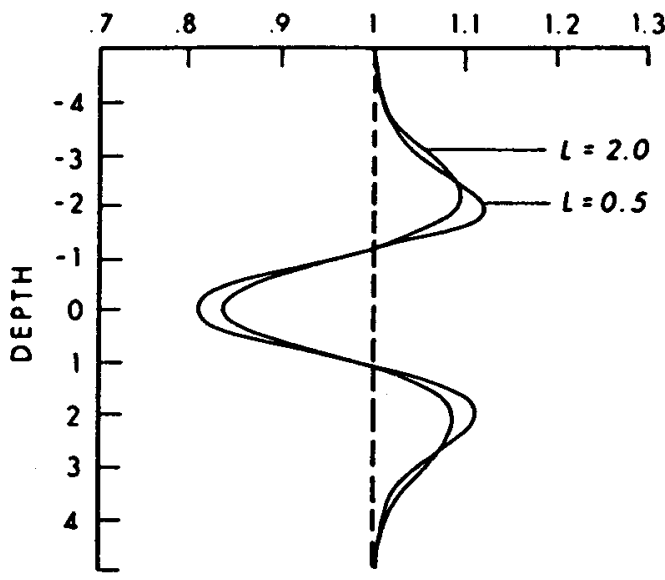

\begin{tabular}{|c|c|c|c|}
\hline Electrode Configuration & Body Size & Angles & Resistivity Contrast \\
\hline Moving Bipole Source & $a=2$ & $a=0^{\circ}$ & $P_{2}=0.10$ \\
Moving Bipole Receiver & $b=2$ & $\beta=45^{\circ}$ & $P_{1}$ \\
SAY $=$ SBY $=0$ & $c=0.2$ & $\gamma=0^{\circ}$ & \\
EMY $=$ ENY $=0$ &
\end{tabular}

Cross-borehole apparent resistivity profiles, for a spheroid dipping at $\beta=45$ degrees, versus the $L$-spacing used in a configuration consisting of a moving-bipole source, and a moving-bipole receiver. The midpoint of $M N$ is the measuring point. All parameters are shown in the figure. 


\section{CONTROLLED-SOURCE ELECTROMAGNETIC SYSTEM}

LBL has developed an ultra-large moment controlled-source electromagnetic system (called the EM-60), and has used the system at a number of geothermal areas to map subsurface conductors associated with geothermal brines. The EM-60 uses a $60 \mathrm{~kW}$ motordriven generator to create square-wave current pulses of up to several hundred amperes that are applied to a large horizontal loop antenna laid out on the ground. The loop, usually square in shape, can be variable in size, but in most applications measures $50 \mathrm{~m}$ to $1 \mathrm{~km}$ on a side. The period of the current pulse is remotely controlled. A typical bandwidth covered ranges from 0.02 to $200 \mathrm{~Hz}$. Because this is a frequency-domain EM system, detection of the primary plus secondary magnetic fields is done while the transmitter is on. Three-component SQUID or coil magnetometers can be used at varying distance and azimuth from the antenna. Depth of investigation depends both on frequency of the current and the transmitter-receiver separation. For large loops, this separation has been up to $10 \mathrm{~km}$.

In-field data processing provides averaged spectra of the amplitude and phase of horizontal (radial and tangential) and vertical magnetic fields plus the complementary ellipticity and wavetilt spectra from 0.02 to $200 \mathrm{~Hz}$. The low-frequency limit is controlled by natural geomagnetic noise whose amplitude at low frequencies increases roughly as $1 / \mathrm{f}^{2}$. The high-frequency limit is controlled by a combination of magnetometer response, radiotelemetry bandwidth, and primary signal strength. To extend the low-frequency end of the bandwidth, a distant-reference magnetometer monitors the horizontal components of the natural geomagnetic field (i.e., noise), assumed to be constant over the area. The telemetered and appropriately scaled reference signal is then electronically subtracted from the local signal prior to processing.

Automatic 1-D inversions of the spectra are done by an iterative program that uses the Marquardt least-squares algorithm to fit amplitude-phase and/or ellipse-polarization parameters jointly or separately to layered models. Observed data are weighted by the calculated error of field measurements. Experience indicates that 1-D interpretations give results that compare well with 2-D interpretations of dc-resistivity data (Wilt et al., 1983). Because of the rapid fall-off in field strength with distance, dipole fields seem to be much less affected by nearby lateral discontinuities and current channeling, which, for example, impair 1-D MT interpretations. Interpretations are currently limited to 1-D models, but 2-D forward modeling of dipole EM data may be done by a finite-element method (Lee, 1978) and a hybrid (finite-element/integral-equation) method (Lee et al., 1981). However, costs of 2-D modeling are high, and the model must be fairly simple to yield an accurate solution.

Rugged terrain presents a. problem in interpretation because of topographic variations between transmitter and receiver and a transmitter that is usually not horizontal. To overcome a major part of this problem, one can treat the transmitted (primary) signal as arising from three mutually orthogonal dipoles located above or below the receiver. To interpret field data properly for this case, Haught et al. (1981) developed a computer program that combines layered-model solutions for vertical and horizontal dipoles.

The EM-60 has been used at a number of geothermal prospect areas in the Basin and Range and in the Cascades.

For Additional Information:

Laboratory Contact: Norman E. Goldstein

Lawrence Berkeley Laboratory

Berkeley, CA 94720

(415) 486-5961 


\section{References:}

Goldstein, N.E., Mozley, E., and Wilt, M.J.: Interpretation of shallow electrical features from electromagnetic and magnetotelluric measurements at Mount Hood, Oregon: J. Geophys. Res., (1982), 87, 2815-2828.

Haught, J.R., Wilt, M.J. and Goldstein, N.E.: Deep induction sounding for geothermal exploitation from an arbitrarily oriented magnetic dipole (abstr.): Geophysics, (1981), $46,458$.

Lee, K.H.: Electromagnetic scattering by a two-dimensional inhomogeneity due to an oscillating magnetic dipole: Ph.D. Thesis, U.S. Berkeley, Engineering Sciences. Lawrence Berkeley Laboratory LBL-8275, 1978.

Lee, K.H., Pridmore, D.F., and Morrison, H.F.: A hybrid three-dimensional electromagentic modeling scheme: Geophysics, (1981), 46 796-805.

Morrison, H.F., Goldstein, N.E., Hoversten, G.M., Oppliger, G. and Riveras, C.: Description, field test and data analysis of controlled-source EM system (EM-60): Lawrence Berkeley Laboratory, LBL-7088, 1978.

Wilt, M., Goldstein, N.E., Stark, M., Haught, J.R., and Morrison, H.F.: Experience with the EM-60 electromagnetic system for geothermal exploration in Nevada: Geophysics, (1983), 48, 1090-1101.
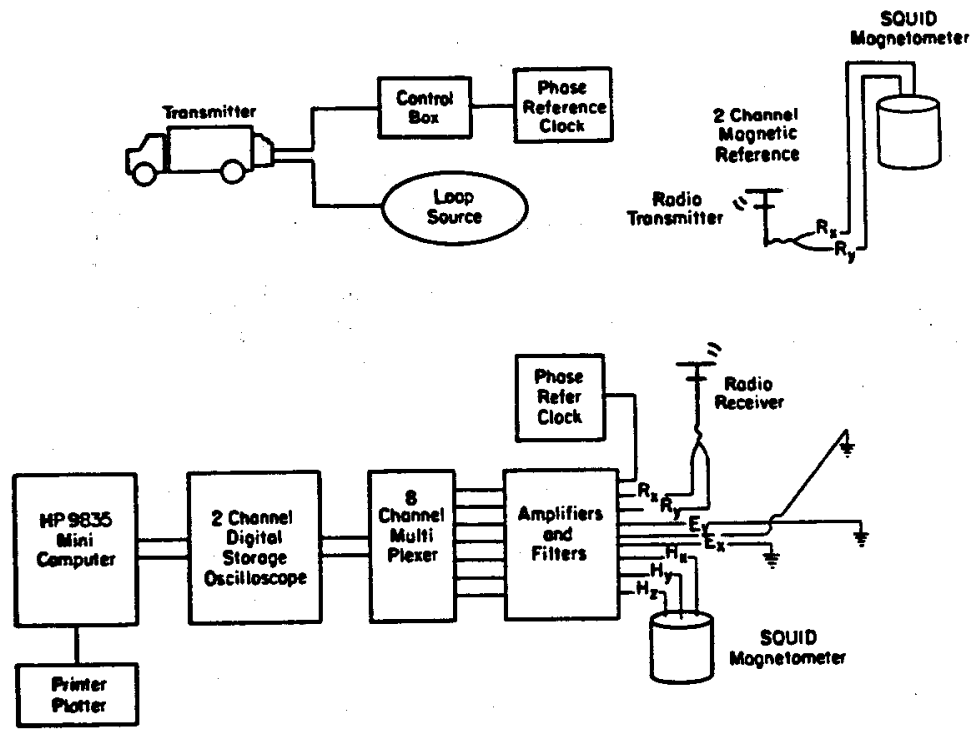

Block diagram of frequency-domain electromagnetic transmitter and in-field processing system developed at Lawrence Berkeley Laboratory and UC Berkeley (from Wilt et al., 1983) 


\section{CASCADE RANGE EXPLORATION TECHNOLOGY, RAIN CURTAIN}

Geothermal exploration and development in the Cascades Range have been impeded by the high annual rainfall and the deep circulation of cool meteoric waters. Surface manifestations of geothermal systems are not generally present and high-temperature, lowresistivity fluids common to most geothermal areas are too deep for detection by shallow-to intermediate depth thermal-gradient holes and conventional resistivity surveys.

DOE/GTD has initiated a program of cost-shared drilling with industry partners in three areas for the purpose of penetrating the cold water overflow and assessing geothermal potential.

Drilling will be conducted at Newberry Crater, Blue Lake, and at a location east of Breitenbush Hot Spring during 1985 and 1986. Supporting research will include the following studies: interpretation of surface geology and geophysical data and interpretation of well logs; acquisition of physical property data on rocks; regional geologic studies and development of permeability models; geochemistry of drill cuttings, surface water and groundwater; and development of conceptual resource models and exploration strategies.

Technology transfer will be effected through open file data releases, technical presentations, and reports (i.e. diffusion).

For Additional Information:

Contact: Phillip M. Wright

University of Utah Research Institute

Earth Science Laboratory

Salt Lake City, UT 84108

(801) 524-3422

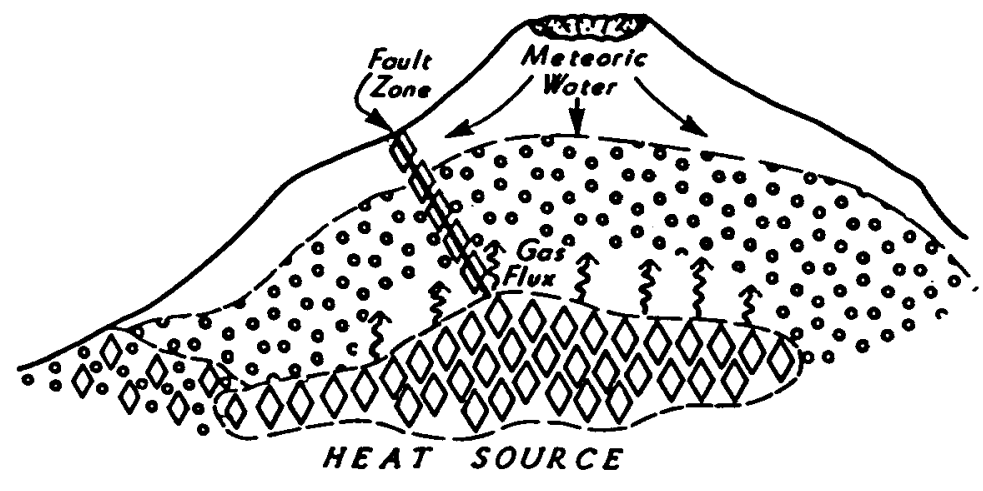

Typical fluid reservoir geometry in volcanic systems. Fluid mixing occurs at the boundaries between the reservoirs (shown by different patterns). 


\section{GAS CONTENTS OF GEOTHERMAL FLUIDS}

Geothermal fluids sampled at the surface may differ in several important respects from their subsurface counterparts as a result of boiling, gas loss and mineral deposition. Fluid inclusions are small samples of the geothermal fluids that have been trapped in secondary mineral phases during their growth. Analysis of these samples can thus provide information on the chemistry of the fluids in the thermal system that is unattainable through routine analysis of surface fluids and gases.

The DOE/GTD is currently supporting research on the composition of fluid inclusion gases using analytical techniques developed at NASA for the investigation of lunar samples. Data are being obtained on the temperature of formation, the fluid salinity and the hydrocarbon, carbon dioxide, and sulfur gas contents of the inclusions. Results of this research will be transferred through technical publications and presentations.

For Additional Information:

Contact:

Joseph N. Moore

University of Utah Research Institute

Earth Science Laboratory

391 Chipeta Way, Suite A

Salt Lake City, UT 84108

(801) 524-3422 


\section{FLUID MOVEMENT IN VOLCANIC TERRAINS}

Active volcanic systems of the Cascades and its northern extension, the Garibaldi Volcanic Belt, are generally believed to contain significant geothermal resources. As yet these resources remain untapped. Detailed geologic, geochemical and mineralogic investigations were conducted at Meager Mountain, British Columbia, in order to elucidate the characteristics of this potentially important resource type.

These studies have resulted in several basic conclusions on the nature of the Meager Mountain geothermal field. These are: (1) fluid flow is confined to discrete fractures, (2) the deep and shallow thermal fluids are isotopically distinct, and no mixture of the two occurs, and (3) the water to rock ratio is extremely low.

This research was supported by DOE/GTD. Technology transfer has been accomplished through publication of the results.

For Additional Information:

Contact:

Joseph N. Moore

University of Utah Research Institute

Earth Science Laboratory

391 Chipeta Way, Suite A

Salt Lake City, UT 84108

(801) 524-3422

References:

Moore, J.N., Adams, M.C., and Stauder, J.: "Geochemistry of the Meager Creek

Geothermal Field, British Columbia, Canada." Geothermal Resource Council Transactions, Volume 7, (1983): 315-320.

Moore, J.N., Adams, M.C., and Stauder, J.J.: "Geologic and Geochemical Investigations of the Meager Creek Geothermal System, British Columbia, Canada." 10th Workshop on Geothermal Reservoir Engineering. Stanford University, (1985): $253=258$.

Adams, M.C., Moore, J.N., and Forster, C.: "Fluid Flow in Volcanic Terrains-Hydrogeochemistry of the Meager Mountain Thermal System." Geothermal Resources Transactions, Volume 9. in press 1985. 


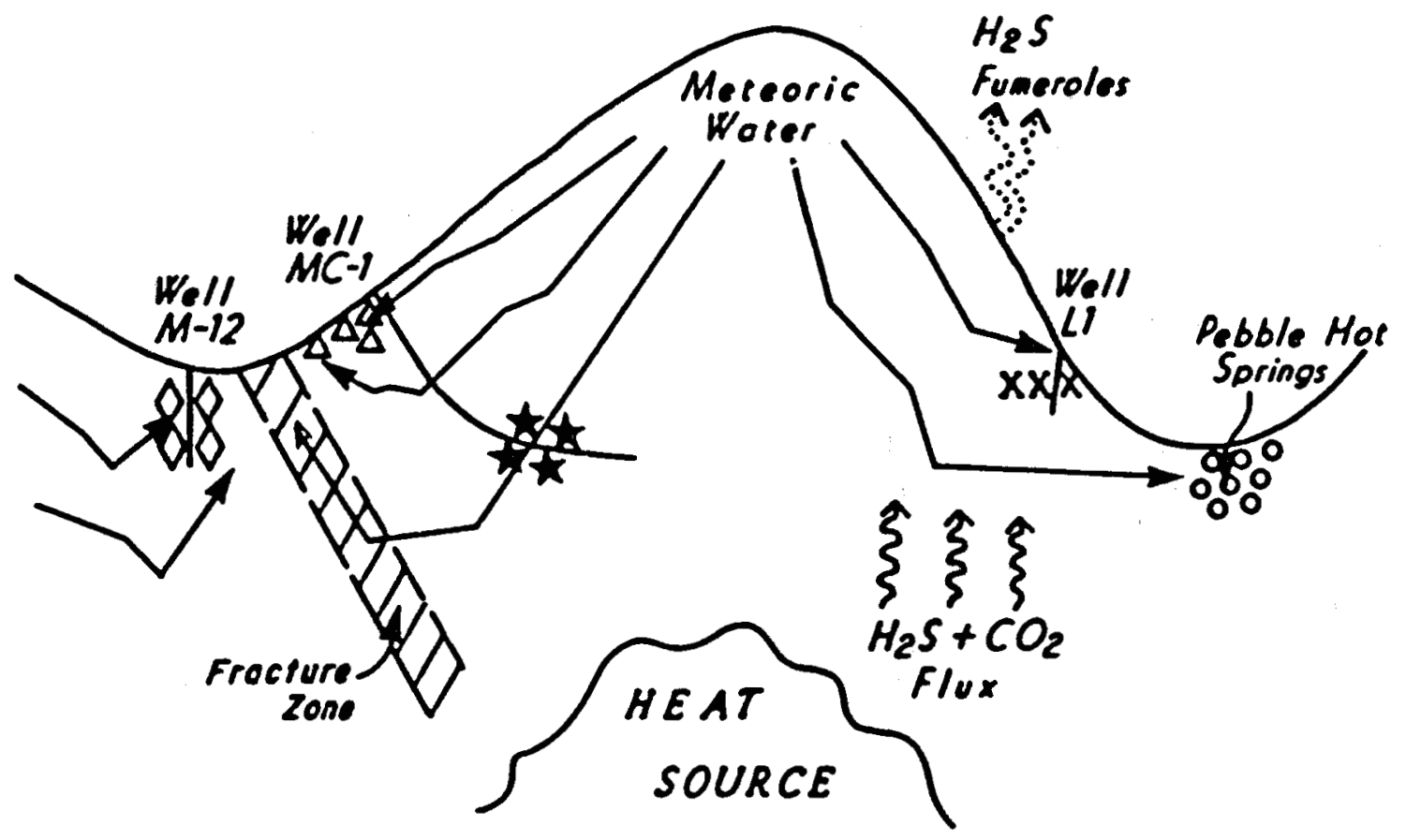

Schematic Diagram of Fluid Flow Plants Paths at Meager Mountain, B.C. Significant Mixing Does Not Occur Between Individual Flow Paths. 


\section{FRACTURE DETECTION USING LOW FREQUENCY CROSS-HOLE ELECTROMAGNETIC TECHNIQUES}

A practical but difficult problem in geothermal exploration and reservoir evaluation is to detect a major fracture zone close to but missed by drill holes. These holes provide the opportunity to use surface-to-borehole and cross-hole electromagnetic techniques for detecting any nearby major fracture. A number of geophysical techniques have been used to address the fracture detection problem, but most of the work has centered on the use of conventional geophysical borehole logs to detect and characterize fractures intersected by the drill (Nelson et al., 1980; Jones et al., 1985). Because most holes are drilled close to vertical, conventional logging techniques are mainly sensitive to flat-dipping discontinuities. To detect the possible presence of a major, steeply-dipping shear or fracture zone that is not intersected by a borehole, workers have recently looked at advanced geophysical techniques. Among these is cross-hole seismic/acoustic tomography to map velocity and attenuation anomalies (Peterson, 1986). Electromagnetic techniques have also been studied in this regard because a clay-rich shear zone or water-filled fracture zone in crystalline rock may have a much lower resistivity than the host medium (Green and Mair, 1983). Deadrick et al., (1982) and Ramirez et al., (1983) used cross-hole radar-frequency geotomography to map fractures. Lytle et al., (1979) studied cross-borehole electromagnetic probing to locate high-contrast anomalies, and Chang et al, (1984) developed a down-hole VHF radar apparatus with directional source and receiver antennas. Because of the high attenuation at radar frequencies, lower frequencies may be more suitable for fracture detection between widely spaced holes or where the host rock is more conductive than a low permeability granite.

We have investigated the applicability of both a down-hole vertical magnetic dipole source (V.M.D.) and a grounded vertical electric dipole source (G.V.E.D.) Zhou et al., 1987). The implied assumptions are always that the fracture is a good scatterer of electromagnetic waves, that it is embedded in a less conductive but otherwise homogeneous region and that it lies somewhere between two holes; a transmitter hole and a receiver hole. The G.V.E.D. source has its unique advantages in these conditions. It has deep penetration and a large response because it can be operated at relatively low frequencies, say below $30 \mathrm{kHz}$. If the host rock is very resistive, the G.V.E.D. source may fail because little current can be injected into the host rock, and a V.M.D. source is needed.

The applicability of cross-hole EM to image a fracture zone has been studied numerically using an approach based on dipole induction by a thin sheet conductor (Weidelt, 1981), and extended to the case of multiple, non-intersecting sheets of finite dimension and arbitrary orientation.

At this time neither the V.M.D. nor the G.E.V.D. concept has been field tested in a controlled experiment. However, LBL has engineering plans, transmitter-receiver hardware, and numerical modeling codes and test results for different transmitter-receiver configurations.

The LBL technology has not yet advanced to the point of commercialization, and LBL is seeking the support from private companies who would like to work cooperatively with LBL to build and field test a cross-hole system. 


\section{For Additional Information:}

Contact: $\quad$ Norman E. Goldstein

Lawrence Berkeley Laboratory

Berkeley, CA 94720

(415) 486-5961

\section{References:}

Chang, H.T., Suhler, S.A. and Owen T.E.: Evaluation of borehole electromagnetic and seismic detection of fractures: Sandia National Laboratories, SAND 84-7109, 75, 1984.

Deadrick, F.J., Ramirez, A.L., and Lytle R.J.: In-situ fracture mapping using geotomography and brine tracers: IEEE Transactions on Nuclear Science, NS-29, No. 1, 1982.

Green, A.G., and Mair, J.A.: Sub-horizontal fracture in a granitic pluton: Their detection and implications for radioactive waste disposal: Geophysics, (1983), 48, 1428-1449.

Jones, J.W., Simpson, E.S., Neuman, S.P. and Keys, W.S.: Field and theoretical investigations of fractured crystalline rock near Oracle, Arizona: Department of Hydrology and Water Resources, University Arizona, NUREG/CR-3736, (1985), 104.

Lytle, R.J., Laine, E.F., Lager, D.L, and Davis D.T.: Cross-borehole electromagnetic probing to locate high-contrast anomalies: Geophysics, (1979), 44, 1667-1676.

Nelson, P.H., Magnusson, K.A., and Rachiele, R.: Applications of borehole geophysics at an experimental waste storage site: Lawrence Berkeley Laboratory, LBL-11982/SAC-3a, (1980), 50.

Peterson, J.E., Jr.: The application of algebraic reconstruction techniques to geophysical problems: Lawrence Berkeley Laboratory, LBL-21498, 188. (Ph.D. thesis, University of California, Berkeley, 1986).

Ramirez, A.L., and Lytle, R.J.: Alterant geophysical tomography: IGRASS, (1983), 2, Paper FA2-9.

Weidelt, P.: Report on dipole induction by a thin plate in a conductive half-space with an overburden: Federal Institute for Earth Science and Raw Materials, Hanover, Germany.

Zhou, Q., Becker, A., Morrison, H.F., Goldstein, N.E., and Lee, K.H.: Fracture detection using subsurface electromagnetic techniques: Farmer, I.W., et al., eds., Rock Mechanics, Proc. 28th U.S. Symposium (1987), A.A. Balkema, Rotterdam, 5-17. 


\section{GEOTHERMAL EXPLORATION STRATEGY}

Although the amount of geothermal energy lost from the earth's surface as heat is very large (estimated at $32 \times 10^{12}$ watts), only a small portion of this heat, namely that concentrated in geothermal resources, can be captured for man's benefit. Geothermal hot spots are manifested as a continuum of several accepted resource types: magma, hot dry rock, convective hydrothermal, geothermal gradient, deep sedimentary basin, geopressured and radiogenic. At present, only the convective hydrothermal and deep sedimentary basin resources are being explored for economic development by industry.

The exploration for new geothermal resources typically begins with the consideration of a large region, perhaps 3,000 to $20,000 \mathrm{~km}^{2}$ within a single geologic province. The costeffective discovery of an economic resource which may be only $2-10 \mathrm{~km}^{2}$ in size requires a carefully structured yet flexible strategy accounting for the local geology and characteristics of the resource type. The University of Utah Research Institute (UURI) has developed generalized exploration strategies by studying the exploration programs and detailed data of several major geothermal companies, and by applying these principles in a number of their own projects for DOE, DOD, and private clients. An important aspect of these strategies is the critique and evaluation of various geologic, hydrologic, geophysical, and geochemical surveys and studies. The sequence of work elements is another key consideration.

The technology associated with the exploration strategy includes concept, process, and field test components. Technology transfer has been effected through presentation at the American Association of Petroleum Geologists Energy Minerals Division, reporting and publication. The strategy has been modified for different geologic environments and recommended to private clients.

For Additional Information:

Laboratory Contact: Howard P. Ross

University of Utah Research Institute

Earth Science Laboratory

391 Chipeta Way, Suite C

Salt Lake City, UT 84108

(801) 524-3422

User Contact: $\quad$ D. Fernando Huertas

Law Engineering, Ibericá, S.A.

Corazon de Maria, 2

28002-Madrid

References:

Ward, S.H., Ross, H.P., and Nielson, D.L.: "Exploration Strategy for HighTemperature Hydrothermal Systems in Basin and Range Province" Bulletin. AAPG, 65 (1981): 86-102, (Reprinted in Energy Minerals, AAPG Reprint Series No. 25, 232-248).

Ward, S.H.: "Exploration Strategies for Regional Assessment of Hydrothermal Resources." Geothermal Energy Technology. Edited by J. C. Bresee and P. A. Witherspoon (1985, in press).

Wright, P.M. et al.: "State-of-the-Art Geophysical Exploration for Geothermal Resources." Geophysics. 50 (December 1985, in press). 


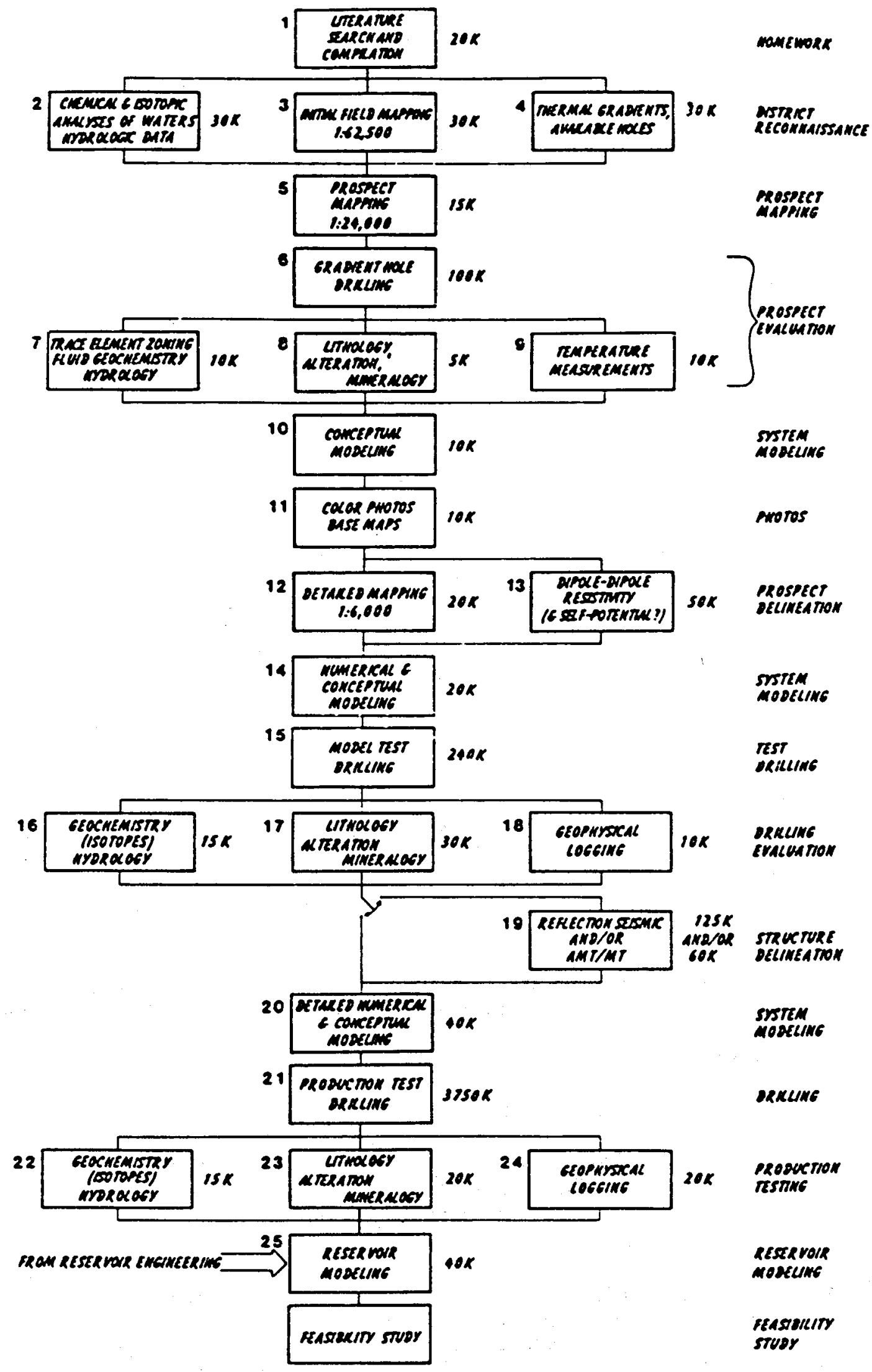

Sugsested higb-iemperature hydrothermal exploration strategy. Numbers at keft of blocks ladicate operatiag sequeace. $K$ ourabers at dight of blocks indicate estlmated dollar cont in thousands. 


\section{GEOLOGIC MAPPING - GEOTHERMAL AREAS}

Perhaps the most important single data base in the exploration and evaluation of a geothermal prospect or resource is a geologic map of sufficient detail and areal coverage. Nevertheless, costly geophysical surveys were being performed and exploration wells drilled without adequate geologic mapping as late as 1978 . Much of the geothermal exploration underway in the Basin and Range Province followed a petroleum exploration mode even though the resources were localized in fractured igneous and volcanic environments.

Detailed geologic maps aid in the selection of appropriate geophysical surveys, indicate the possible utility of surface geochemical studies, and may reveal subtle alteration indications or hydrologic controls. The geologic map also contributes to the interpretation of these data and to the selection of sites for thermal gradient holes or production wells.

A substantial effort was devoted to detailed geologic mapping in support of the Industry Coupled Program, the Coso reservoir evaluation, and several low-temperature resource assessments. Among the Industry Coupled areas mapped were: Roosevelt Hot Springs and Cove Fort-Sulphurdale, Utah; San Emidio, Soda Lake, Beowawe, Colorado, Tuscarora, McCoy, and Baltazor, Nevada. Other areas studied were Coso, California; Auburn, Wyoming; Wells, Nevada; Magic Reservoir, Idaho; and Redondo Dome, New Mexico. Maps have been compiled at a typical scale of 1:24,000 which indicated lithology, alteration, fracturing and faulting, and stratigraphy in the methodology used in mineral exploration efforts.

The technology transfer has been most direct for those involved with exploration at these specific sites. The mapping methodology, which emphasizes alteration, fracture mapping, and structure mapping, has been a more general item of technology transfer of particular value to former petroleum geologists. Detailed geologic mapping played a major role in well siting for the recent Cove Fort-Sulphurdale discovery and contributed to the Colorado, Tuscarora, Beowawe, McCoy and Baltazor exploration efforts. Technology transfer has been effected through the publication and distribution of geologic maps, workshops, and field trips for geoscientists with specific interests, and Geothermal Resources Council field trips.

The cost of geologic mapping varies widely depending on the complexity and size of the area but of ten ranges between $\$ 2,000$ and $\$ 20,000$ for an area of 2 to $40 \mathrm{~km}^{2}$ in size.

For Additional Information:

Laboratory Contact:

Dennis L. Nielson

University of Utah Research Institute

Earth Science Laboratory

391 Chipeta Way, Suite C

Salt Lake City, UT 84108

(801) 524-3422

User Contact:

Wayne Portanova

Mother Earth Industries

Scottsdale, Arizona 


\section{References:}

Moore, J.N., and Samberg, S.M.: Geology of the Cove Fort-Sulphurdale KGRA. University of Utah Research Institute, Earth Science Laboratory Rep. ID0/781701.b.1.1.5, 1979.

Nielson, D. et al.: Geology of the Roosevelt Hot Springs KGRA. Beaver County, Utah University of Utah Research Institute, Earth Science Laboratory Rep. 12, 1978.

Sibbett, B.S.: "Geology of the Tuscarora Geothermal Prospect, Elko County, Nevada." Bulletin, Geological Society of America, 93 (1982): 1264-1271.

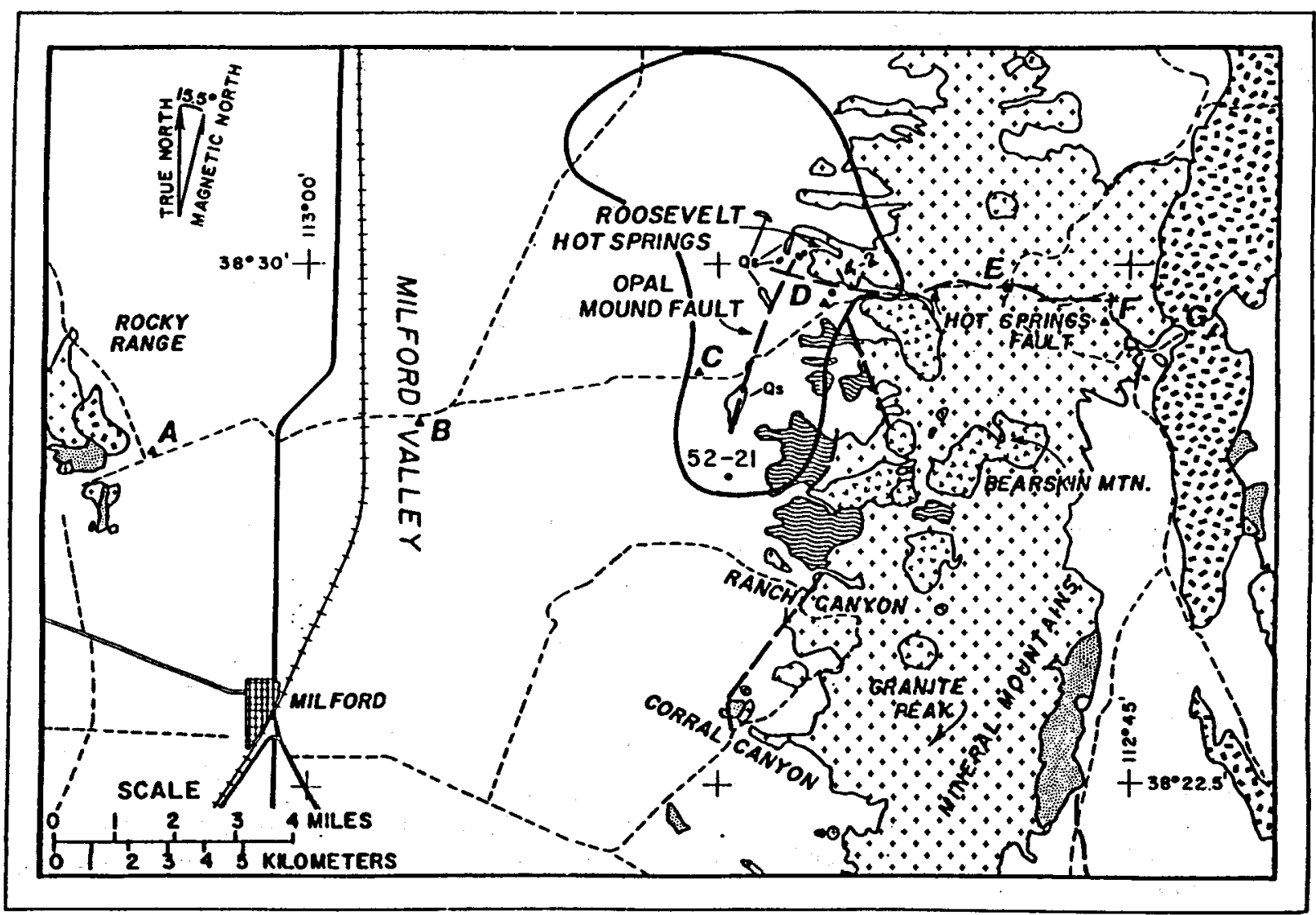

GEOLOGIC MAP OF RODSEVELT HOT SPRINGS KGRA (MILFORD VALLEY AND THE MINERAL MOUNTAINS, UTAH) 


\section{GEOLOGIC MODEL OF THE BACA GEOTHERMAL RESERVOIR, VALLES CALDERA, NEW MEXICO}

The caldera environment represents a complex interaction of volcanic, structural, and hydrothermal processes which is of ten a target for geothermal exploration and development. The reservoir engineer views such systems as a complex interplay of stratigraphic and structural permeability, and changes in permeability which results from the process of hydrothermal alteration and new fracture generation. Cost-effective exploration and development of caldera-type geothermal systems require a detailed understanding of these physical and geologic parameters which is brought together in a geologic model.

The Baca geothermal reservoir is situated in a small portion of the Valles Caldera in New Mexico. Subsurface samples (drill cuttings) from Union Oil Company's Baca project have been made available to UURI by Union and funding for research on these samples has been granted by DOE. The cuttings have been examined in detail using thin section and Xray diffraction techniques to characterize mineralogic and lithologic characteristics. These data have permitted the development of a stratigraphic and structural model and an understanding of the distribution of alteration within the reservoir areas. The geologic model indicates that all commercial geothermal production zones are structurally controlled while subcommercial zones are controlled by both structures and stratigraphic intervals. Numerous former fluid channels have been sealed by alteration. A general conclusion is that resurgent domes are inherently impermeable due to their mode of structural development.

The geologic model has been transferred to geothermal developers at Baca, and to industry for application to other areas, through publication and presentation. The methodology for development of the model has been reported in detail. The model is being used as a guide in understanding foreign caldera resource areas.

For Additional Information:

Contact: Dennis L. Nielson

University of Utah Research Institute

Earth Science Laboratory

391 Chipeta Way, Suite C

Salt Lake City, UT 84108

(801) 524-3422

\section{References:}

Hulen, J.B., and Nielson, D.L.: "Stratigraphy of the Bandelier Tuff and

Characterization of High-Level Clay Alteration in Borehole B-20, Redondo Creek Area, Valles Caldera, New Mexico." Geothermal Resources Council Transactions, Volume 7. (1983): 163-168.

Nielson, D.L., and Hulen, J.B.: "Geologic Model of the Baca Geothermal Reservoir, Valles Caldera, New Mexico." Proceedings Ninth Workshop on Geothermal Reservoir Engineering. Stanford University, (1983): 145-150.

Nielson, D.L., and Hulen, J.B.: "Internal Geology and Evolution of the Redondo Dome, Valles Caldera, New Mexico." Journal Geophysical Research. 89 (1984): 86958712. 


\section{INTERPRETATION OF DRILL CUTTINGS FROM GEOTHERMAL WELLS}

The drilling of a geothermal well is a major milestone in the exploration or development of a geothermal resource and may cost from $\$ 500,000$ to more than $\$ 2,000,000$. Drill cuttings, compared to core, are relatively inexpensive and easy to obtain. These are the samples typically collected from geothermal wells. They are the principal source of the direct downhole geologic information essential for successful subsurface investigation.

Cuttings, however, can be far more difficult to interpret than core. They are commonly contaminated samples of formerly coherent rock that are finely ground, mixed, and of ten from an unknown depth. Therefore, data derived from cuttings can present special interpretation problems. The procedures and problems of geothermal cuttings interpretation may be significantly different than those from petroleum wells. In particular, the identification of faults, fractures and igneous and metamorphic rock types is of ten difficult from drill cuttings and is critically important for geothermal wells.

New procedures for interpretation of drill cuttings data were developed at UURI through the integrated study of drill cuttings, geophysical well logs, thin section study, and geochemical analyses from a large number of geothermal drill holes. These concepts and interpretation procedures have been transferred to the geothermal industry through reports, publications, and as part of a Geothermal Resources Council Technical Training Course (No. 7).

\section{For Additional Information:}

Contact: $\quad$ Jeffrey B. Hulen University of Utah Research Institute

Earth Science Laboratory

391 Chipeta Way, Suite C

Salt Lake City, UT 84108

(801) 524-3422

References:

Hulen, J,B., and Sibbett, B.S.: "Sampling and Interpretation of Drill Cuttings from Geothermal Wells." Geothermal Log Interpretation Handbook. Vol. 4, no. 3 Society of Professional Well Log Analysts, 1982.

Hulen, J.B., and Sibbett, B.S.: Interpretation of Drill Cuttings from Geothermal Wells. University of Utah Research Institute/Earth Science Lab. Rep. 57, (no date). 


\section{MAGNETOTELLURIC DATA INTERPRETATION - THEORY, METHODOLOGY, AND COMPUTER ALGORITHMS}

Magnetotelluric (MT) surveys have been completed at most high-temperature geothermal prospects in the U.S. due to the potential of the method to detect low resistivity zones indicating the presence of thermal fluids, wall rock alteration and, possibly, magma. Because of the expense of data acquisition and the complexity of interpretation, it is not clear how cost-effective the method has been or whether it has played a major role in the discovery or development of geothermal resources.

At UURI, substantial gains in acquisition and interpretation of MT have occurred with the support of DOE/GTD. Advances in 2-D modeling using finite elements include implementation of a direct secondary field formulation to stabilize the solution to arbitrarily low frequencies as well as the ability to simulate topography precisely. In 3-D modeling, we have produced an algorithm which computes the MT response of 3-D bodies in an arbitrarily layered host. Model computations and the interpretation of field data have led to several important conclusions:

- current-gathering in small-scale, near-surface conductive zones may distort or confuse the apparent resistivities, but not so tipper element magnitudes or impedance phases, due to larger or deeper bodies

- current-gathering in alluvium-filled valleys may be reflected in a regional distortion of the electric field affecting all stations to arbitrarily low frequencies

o interpretation with a 1-D algorithm may be invalidated by large- or small-scale current-gathering phenomena common to many basin and range geothermal areas.

A rigorous error analysis was developed for conventional and remote reference $\mathrm{MT}$ data acquisition under the assumption that noise in the $\mathrm{E}$ - and $\mathrm{H}$ field measurements is governed by a complex normal distribution. The standard unweighted least-squares estimates of apparent resistivity and tipper are not minimum variance when the measured fields are not stationary. Also the conventional weighted least-squares estimate is minimum variance provided only the E-fields are noisy. A generalized weighting procedure using signal power and multiple coherence has been derived which has greatly improved data quality of the UURI MT acquisition system.

Technology transfer has been achieved through the release of computer programs and documentation to the National Energy Software Center (Argonne National Laboratory) and by the publication and distribution of numerous reports and papers on MT theory and data interpretation.

For Additional Information:

Laboratory Contact: Philip E. Wannamaker University of Utah Research Institute

Earth Science Laboratory

391 Chipeta Way, Suite C

Salt Lake City, UT 84108

(801) 524-3422 
Sof tware Contact:

National Energy Software Center

Argonne National Laboratory

9200 South Cass Avenue

Argonne, IL 60439

(312) $972-2000$

References:

Wannamaker, P.E. et al.: Magnetotelluric Models of the Roosevelt Hot Springs

Thermal Area, Utah. University of Utah Report DOE/ET/27002-8, 1980.

Wannamaker, P.E.: "Resistivity Structure of the Northern Basin and Range."

The Role of Heat in the Development of Energy and Mineral Resources in the Northern

Basin and Range Province. Geothermal Resources Council Special Report 13: 345-362.

Wannamaker, P.E. et al.: "Electromagnetic Modeling of Three-Dimensional Bodies

in Layered Earths Using Integral Equations." Geophysics, 49: 60-74.

Wannamaker, P.E., Hohmann, G.W., and Ward, S.H.: "Magnetotelluric Responses

of Three-Dimensional Bodies in Layered Earths." Geophysics, 49 (1984): 1517-1533.

Newman, G.H., Wannamaker, P.E., and Hohmann, G.W.: "On the Detectability of Crustal Magma Chambers Using the Magnetotelluric Method." Geophysics, 50, (1985): 1144-1162.

Stodt, J.A.: "Generalized Error Analysis for Conventional and Remote Reference Magnetotellurics." Geophysics, submitted, 1985.

Wannamaker, P.E. et al.: "Secondary Field Formulation for Finite-Element Modeling of Two-Dimensional Magnetotelluric Responses." Journal of the Roval Astronomic Society, in preparation 1985.

Wannamaker, P.E., Stodt, J.A., and Rijo, L.: "Two-Dimensional Topographic Variations in Magnetotellurics Modeled Using Finite Elements." Geophysics, in preparation 1985.

Stodt, J.A.: "Weighted Least Squares Estimates of the Magnetotelluric Transfer Functions from Nonstationary Data." Geophysics, submitted 1985.

Wannamaker, P.E.: "Electrical Conductivity of Water-Undersaturated Crustal Melting." Journal of Geophysical Research, submitted 1985. 


\section{MAGNETOTELLURIC SURVEY}

Los Alamos National Laboratory conducted a regional magnetotelluric (MT) survey of Arizona and New Mexico for the Hot Dry Rock (HDR) Geothermal Project. The survey consisted of over 200 deep MT soundings along several long profiles with sounding spacings of 15 to $20 \mathrm{~km}$. The MT lines are located in areas where other geophysical and geologic studies indicate areas (local and regional) of geothermal interest. Areas of hot dry rock interest include tectonic province boundaries and late Cenozoic volcanic regions. The MT study was aimed at mapping the depth to the pervasive deep electrical conductor within the crust and/or upper mantle over a large region and then correlating this depth with terrestrial heat flow, depth to Curie point measurements, regional tectonics, and local geology. With the exception of the first 56 sites, data from all the remaining sites have been collected using the remote reference MT noise reduction technique.

Based on this study, several general conclusions can be made. No single geophysical technique is a panacea for geothermal exploration, hot dry rock in particular. However, because MT is sensitive to the crustal thermal state, it is an excellent exploration tool when used in combination with geologic and other geophysical techniques. The depth of the deep electrical conductor obtained by the MT method in general correlates with the expected crustal thermal regime as predicted by terrestrial heat flow, depth to Curie, regional tectonics, and/or local geology. In this study, mapped crustal electrical conductivity upwellings in otherwise resistive crustal rock correspond with known or suspected thermally anomalous areas. These conductivity upwellings fall into two basic categories. The first contains a resistive cap rock $(\geq 1000 \mathrm{~m})$ and appears to be associated with local thermal features. Because the cap rock is resistive, suggesting impermeable upper crust, local ground water percolation is not a likely mechanism for creating the high conductivity anomaly. Such regions, when coincident with other thermal indicators (e.g., late volcanic activity and high heat flow), may be good hot dry rock targets. The second type contains a moderately conductive cap rock $(>100 \mathrm{~m}$ ) and appears to be associated with zones of tectonic extension. These regions are probably associated with deeply circulating groundwater that causes increased conductivity. Because these regimes are usually associated with elevated thermal regions, the anomalously high electrical conductivity beneath the more resistive cap may be due to free water in the presence of elevated temperature and/or partial melt. These regions may also be important hot dry rock resource areas, but more care must be taken to evaluate the cause of the conductive anomalies.

For Additional Information:

Contact: $\quad$ M. Ander

Los Alamos National Laboratory

Mail Stop C335

Los Alamos, NM 87545

(505) 667-5061 


\title{
MAPPING FLOW PATHS IN FRACTURE-DOMINATED RESERVOIRS
}

Methods for studying the progress of fluids injected into geothermal reservoirs are undergoing rapid development. Formerly mapping the effects of injected fluids was restricted to low permeability formations where high hydraulic pressures could be applied to force failure or minute displacements in reservoir rock accessed by the fluid. Now, taking advantage of a recent discovery of seismic signals associated with the acid treatment of a subeconomic well, it is possible to study the flow of fluid in permeable, fracture-dominated formations.

Properly selected dilute acids, once injected into a formation with permeable fractures, preferentially attack mineralization which cements together fracture faces causing weakening and failure of the mineral bond between them. This ultimately results in the relative movement of rock adjoining the fracture. The movement causes signals which can be detected and their original point located, by seismic/acoustic sensors placed in one or more nearby wells. Maps of the original points of signals can then be made by making use of conventional seismic techniques that indicate the locations of the principal fractures contributing to flow through the reservoir.

As an example, signals of sufficient amplitude for mapping were observed at a distance of $2,500 \mathrm{ft}$ from a well undergoing acid treatment. In that treatment, $500 \mathrm{bbl}$ of a dilute $\mathrm{HF}$ and $\mathrm{HCl}$ mixture were injected to remove the drilling mud plugging a productive interval and to improve communication with natural fractures (a common practice in geothermal fields). A map of the resultant seismicity showed that most of the acid followed a single path away from the well undergoing treatment.

For Additional Information:

Contact:

\author{
James Albright \\ Mail Stop J981 \\ Los Alamos National Laboratory \\ Los Alamos, NM 87545 \\ (505) 667-5061
}

References:

Batra, R., Albright, J.N., and Bradley, C.: "Downhole Microseismic Monitoring of an Acid Treatment in the Beowawe Geothermal Field." Geothermal Resources Council Transactions. Vol. 8. 1984, pp. 479-484. 


\section{TRACE ELEMENT GEOCHEMISTRY OF HYDROTHERMAL SYSTEMS}

The distributions of trace and minor elements in hydrothermal systems have been shown to be important indicators of the size, shape and temperature of the system. Five distinctive elemental suites of chemical enrichment are recognized, each characteristic of a particular combination of physical and chemical conditions within the hydrothermal system. These are: (1) concentrations of arsenic, antimony, beryllium, and mercury associated with siliceous material at locations of liquid discharge, fluid mixing or boiling; (2) concentrations of manganese, barium, tungsten, beryllium, copper, cobalt, arsenic, antimony and mercury in manganese and iron oxide deposits from thermal springs; (3) high concentrations of mercury in argillized rock near fumaroles and lower concentrations in a broad diffuse halo surrounding the thermal center; (4) concentrations of arsenic and base metals in rocks surrounding high-temperature fluid-flow controlling fractures; and, (5) deposits of $\mathrm{CaCO}^{3}$ at a depth where flashing of brine to steam has occurred due to pressure release. In general, the geochemical enrichments are not, widespread, pervasively developed zones of regular form and dimension as are typical in many ore-forming hydrothermal systems.

The use of mercury, in particular, has an advantage over other geochemical indicators because it is readily and inexpensively analyzed at very low concentrations. Enrichments in mercury may be detectable even before appreciable hydrothermal alteration has occurred. The measurement of radon ${ }^{222}$ flux using alpha-sensitive dosimeters has been found to be successful in locating fault systems that communicate with the structurally controlled geothermal reservoir at Roosevelt Hot Springs, Utah.

The development of these geochemical models has been supported by the DOE/GTD. Technology transfer has been accomplished through the release of numerous reports and papers.

\section{For Additional Information:}

Contact: $\quad$ Joseph N. Moore

University of Utah Research Institute

Earth Science Laboratory

391 Chipeta Way, Suite A

Salt Lake City, UT 84108

(801) 524-3422

\section{References:}

Christensen, O.D., Capuano, R.M., and Moore, J.N.: "Trace-Element Distribution in an Active Hydrothermal System, Roosevelt Hot Springs Thermal Area, Utah." Journal of Volcanology and Geothermal Research. 16 (1983): 99-129.

Capuano, R.M., and Bamford, R.W.: Initial Investigation of Soil Mercury Geochemistry as an Aid to Drill Site Selection in Geothermal Systems. Univ. Utah Research Institute, Earth Science Lab Rep. 13, 1978.

Nielson, D.L.: Radon Emanometry as a Geothermal Exploration Techniaue: Theory and an Example from Roosevelt Hot Sprinngs KGRA, Utah. University Utah Research Institute, Earth Science Lab Rep. 14, 1978. 


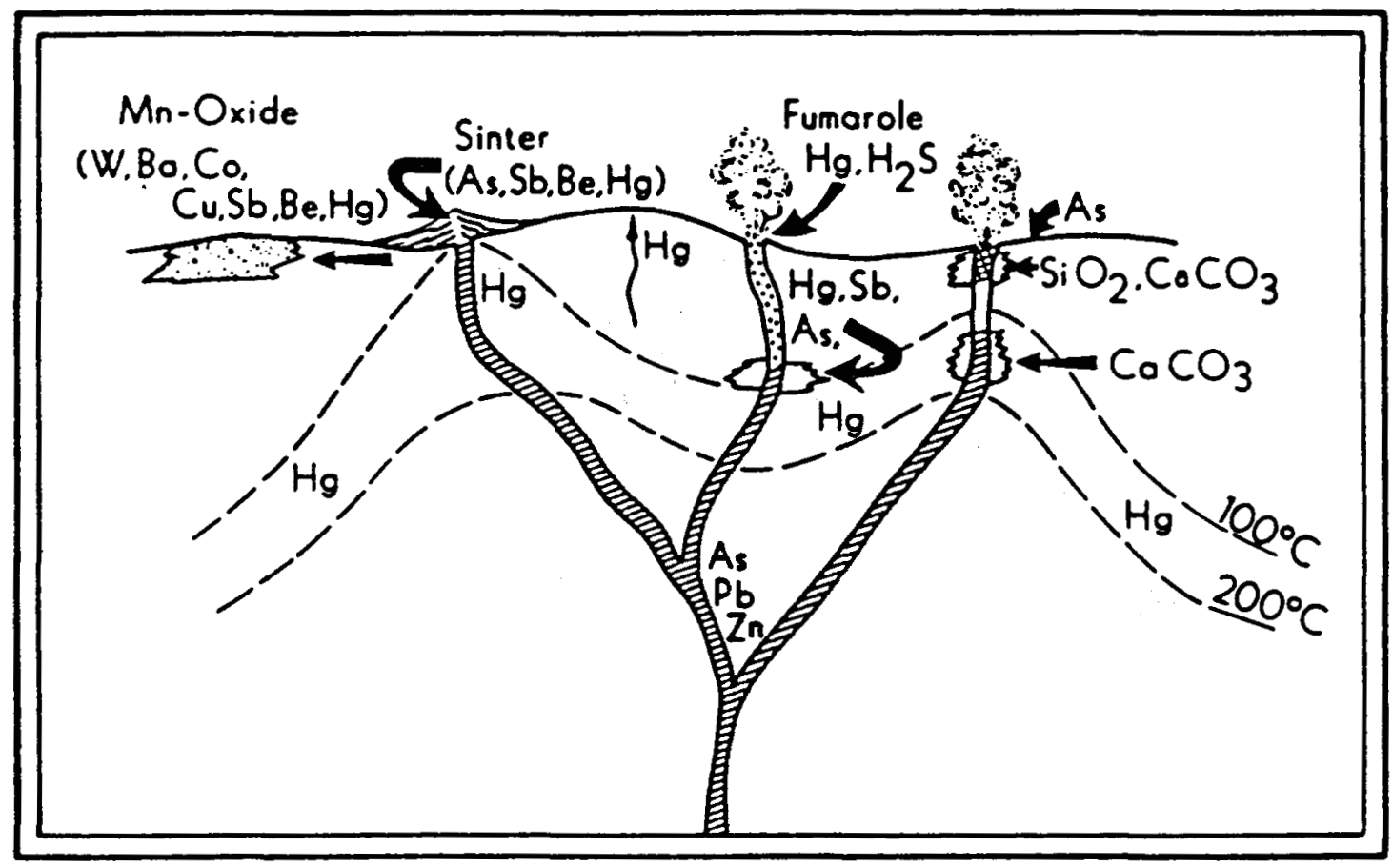

Distribution of Trace Elements and Types of Deposits in Geothermal Systems. 


\section{ACOUSTIC BOREHOLE MAPPING OF SEISMICITY ACCOMPANYING HYDRAULIC FRACTURING}

Determining the locations of microearthquakes is a technique for mapping the fluid paths in rock during hydraulic fracturing operations. By reliably locating the events, a second well can be planned to intersect the region where the fluid has permeated and a flow-through connection between the two wellbores can be established. This technique is the only method for determining the location of the fluid during hydraulic fracturing operations carried out in deep, hot geothermal regimes.

By using a network of borehole seismic observation stations, the locations of the microearthquakes can be determined to a precision of approximately 20 meters. This locational reliability is sufficient to plan a second borehole to intersect the fluid-stimulated region. The feasibility of this technique has been demonstrated by the successful completion of a flow-through path between two wellbores by the Hot Dry Rock Geothermal energy project. An alternative way to locate the microearthquakes is to use a single three component borehole seismic sensor. Data from this sensor can be used to determine the locations of the microearthquakes by the so called "hodogram" technique whereby the direction to the event is determined from the particle motion of the first arriving wave and the distance to the event is calculated from the time difference of the two seismic body wave phases ( $p$ and $s$ waves). The hodogram method is less reliable than methods that use multiple stations. Uncertainties in locations can be as much as a few hundred meters. Work is underway to improve the hodogram location techniques since it should be more cost effective than the multiple station technique.

For Additional Information:

Contact:

M. Fehler

Los Alamos National Laboratory

Mail Stop J979

Los Alamos, NM 87545

(505) 667-5061

Reference:

House, Leigh, Keppler, Hans, and Kaieda, Hideshi: "Seismic Studies of a Massive Hydraulic Fracturing Experiment." 1985 International Symposium on Geothermal Energy Transactions. Volume 9-Part II. Geothermal Resources Council, 1985, pp. 105-108. 
CHAPTER 3

DRILLING AND WELL COMPLETION

$57 / 58$ 
3.1 HARDWARE

59 


\section{ACOUSTIC BOREHOLE TELEVIEWER}

The Acoustic Borehole Televiewer is a downhole device that uses ultrasonics to produce an oriented image of the borehole wall. The technique provides information for determining location and orientation of fractures which crosscut the borehole. The televiewer was first introduced in 1968 by Mobil Research and used by several service companies for a few years until it was, for the most part, abandoned by industry. Improvements in the device were continued by the manufacturer, Simplec Manufacturing Company of Dallas, Texas, and by researchers at Amoco R\&D in Tulsa, Oklahoma, for limited specialized use. Through these efforts, the televiewer principal was eventually extended to provide a three-dimensional scan of the region beyond the wellbore.

Researchers at the Water Resource Division of the USGS, who used the instrument as a data gathering tool, made significant improvements that extended the televiewer operating temperature range. In 1979, at the suggestion of industry personnel reviewing the Sandia Program, a borehole televiewer built under the Mobil patents was purchased from Simplec Manufacturing Company to determine the feasibility of adapting it for operation in the geothermal environment. An upgrade effort was initiated with performance goals of operation at temperatures up to $275^{\circ} \mathrm{C}$ and pressures up to 5,000 psi.

The fundamental parts of the televiewer are shown in the block diagram of the figure. The downhole portion of the instrument is approximately 16 feet long with a 3-1/2 inch OD and is connected to either a 4 or 7 conductor electric wireline. The transducer is a $1 / 2$ inch diameter disc of piezoelectric material resonant at 1.3 MW which acts as both a transmitter and receiver of acoustic energy. The transducer beam width has been measured at about 3 degrees ( $3 \mathrm{~dB}$, two way) in the far field (greater than 1-1/2n from transducer). It is pulsed by a short burst of 1.3 $\mathrm{MHz}$ electrical energy at a rate of 1800 pulses/sec, generating a pressure pulse that travels to the wall and is then reflected. If the tool is properly centered in the hole by the centralizers on top and bottom so that the direction of transmission is normal to the wall, the energy will be reflected back in the direction of the transducer. This reflected pulse is received by the transducer and generates an electrical signal whose amplitude is a function of the amount of energy reflected by the illuminated spot on the wall. The time of arrival is a function of the roundtrip acoustic travel time of the pulse, hence distance to the wall.

\section{For Additional Information:}

Contact: James Uhl

Sandia National Laboratories

Geothermal Research Division

Albuquerque, NM 87185

(505) 844-1700

References:

Jagelar, A.H.: "New Well Logging Tools Improve Formation Evaluation." World Qil, March 1980, pp 89-102. 
Heard, F.E. and Bauman, T.J.: Development of a Geothermal Acoustic Borehole Televiewer. Sandia National Laboratories Report SAND83-0681, 1983.

Keys, W.S.: "The Application of the Acoustic Televiewer to the Characterization of Hydraulic Fractures in Geothermal Wells." Proceedings of the Geothermal Reservoir Well Stimulation Symposium. (1980): 176-202.

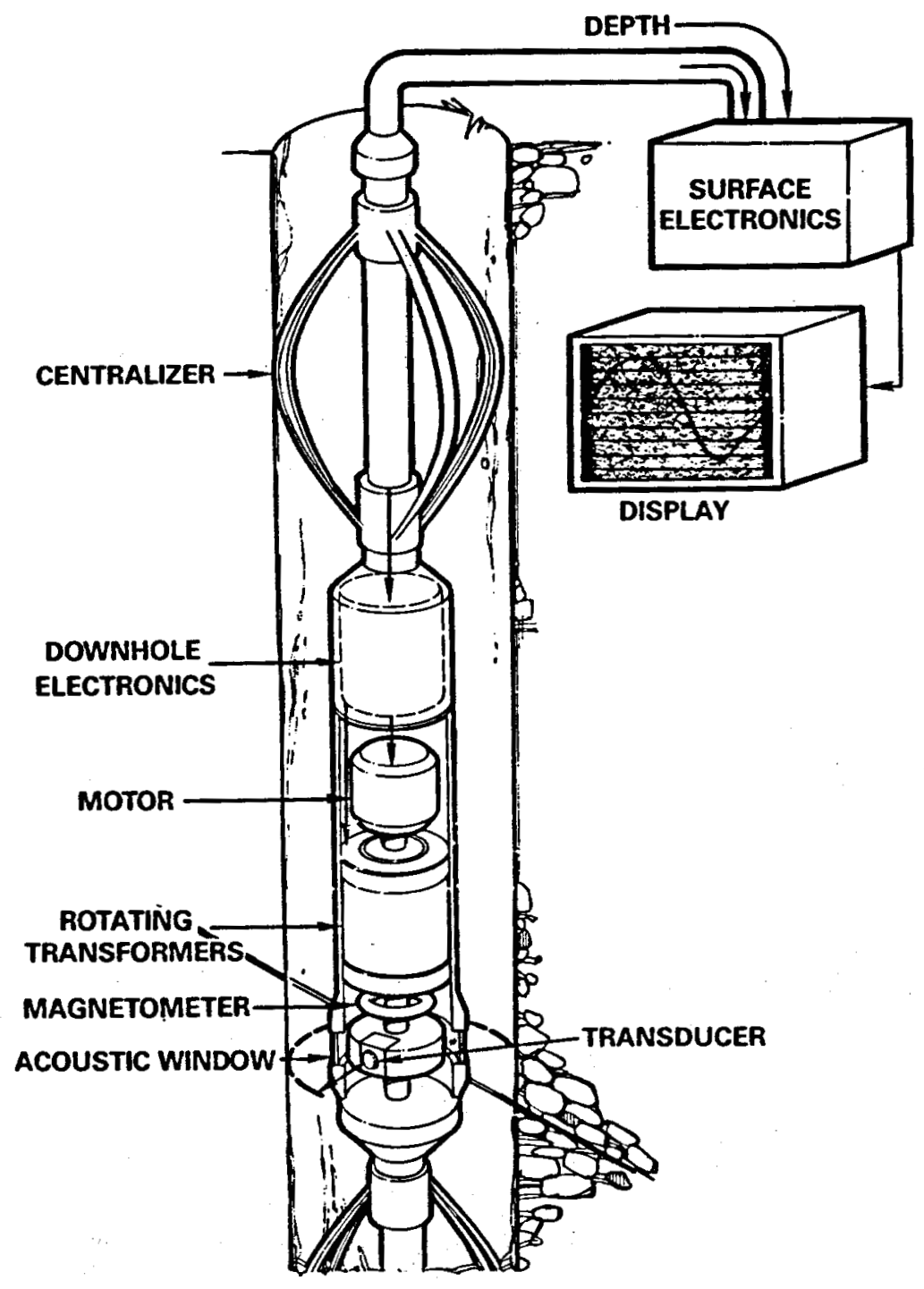

BLOCK DIAGRAM OF THE ACOUSTIC BOREHOLE TELEVIEWER 


\section{BOREHOLE FLUID SAMPLER}

The borehole fluid sampler requires three conductors of logging cable. The tool takes two separate samples of $270 \mathrm{cc}$ or one large sample of $780 \mathrm{cc}$. Chemical analysis of the fluid samples, which are taken at various depths in a borehole, can be used to determine geothermal reservoir properties. The sample size may be easily changed to accommodate quite large samples.

The DC permanent motor and planetary gears rotate a shaft that controls a hand valve mounted on the top of the container. The hand valve is normally closed, sealing the container. Valves within the container allow inlet flow but not reverse flow, thereby securing the sample. The motor current, motor running time, and shaft revolutions show on surface readouts during a sampler run. An operator controls the tool's valve-opening sequence by an upper lower clutch system and a microswitch that monitors the shaft revolutions.

\section{QPERATING ENVIRONMENT}

Temperature Rating

Fluid Pressure

Length

Diameter

Weight

Sample Size (cc) $572^{\circ} \mathrm{F}\left(300^{\circ} \mathrm{C}\right)$

$15,000 \mathrm{psi}$

89 in.

5.0 in.

229 lbs.

$780 \mathrm{cc}$

Optional -- Sample size may be increased by increasing length of sonde.

For Additional Information:

Contact: $\quad$ Bert R. Dennis

Mail Stop D448

Los Alamos National Laboratory

Los Alamos, NM 87545

(505) 667-0728

Reference:

Dennis, Bert R., Koczan, Steven P., Stephani, Evon L.: High Temperature Borehole Instrumentation: Los Alamos National Laboratory, LA-10558-HDR, 1985. 


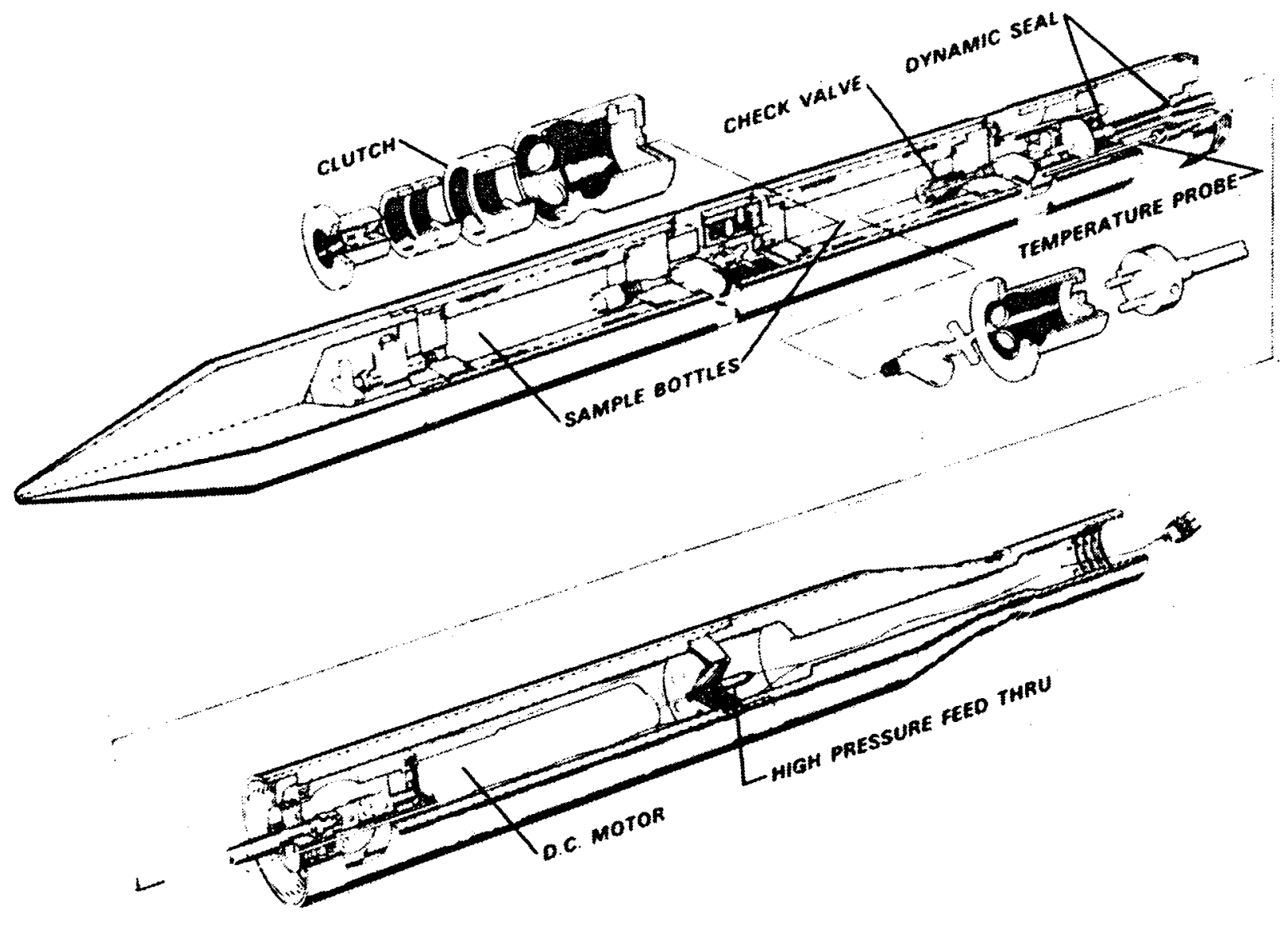

BOREHOLE FLUID SAMPLER 


\section{CALIPER TOOL}

An independent multi-arm caliper tool was designed to define the profile of geothermal boreholes such as those at Fenton Hill. Development began with the design and fabrication of a prototype 3-arm sonde, which can be modified to have six independent arms. The arms are evenly spaced circumferentially and are capable of measuring radii from $2-1 / 2$ to 7 -in. at a common depth. Arm length can be varied to measure hole diameters up to 30 inches or can be designed for maximum sensitivity at given diameters. The arms are activated by a motor and can be extended or retracted on command from the surface. Should the sonde become jammed in the borehole, the lower link will buckle and permit the arms to collapse.

\section{OPERATING SPECIFICATIONS}

Temperature Rating

Fluid Pressure

Length

Diameter

Weight

Radii $572^{\circ} \mathrm{F}\left(300^{\circ} \mathrm{C}\right)$

15,000 psi

112 in.

$3.00 \mathrm{in}$.

$154 \mathrm{lbs}$

$8-14-2$ (Change arm length)

For Additional Information:

Contact:

Bert R. Dennis

Los Alamos National Laboratory

Mail Stop D448

Los Alamos, NM 87545

(505) 667-0728

\section{Reference:}

Dennis, Bert R., Koczan, Steven P., Stephani, Evon L.: High Temperature Borehole Instrumentation: Los Alamos National Laboratory, LA-10558-HDR, 1985. 


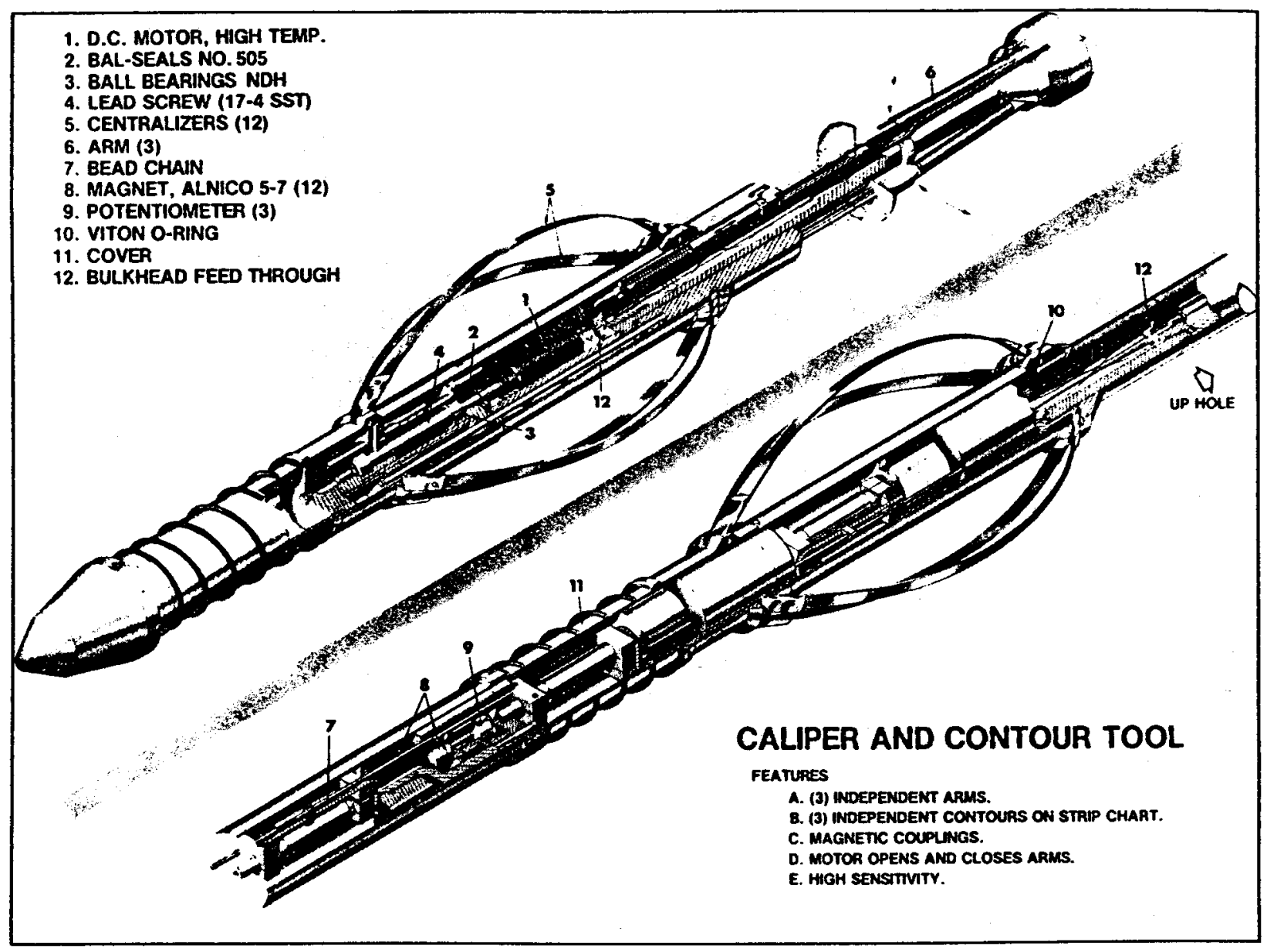




\section{CAVITATING DRILL BIT NOZZLES}

Research at Sandia National Laboratories has resulted in increased knowledge and modifications in the existing CAVIJET cavitating fluid jet nozzle designs. Conventional CAVIJET nozzles were capable of producing cavitation, using drilling mud, to a depth of about $1,200 \mathrm{~m}$ (4000 ft.) when operated at a pressure drop, AP, of about $13.8 \mathrm{MPa}(2,000 \mathrm{psi})$. However, due to the rather large size of these nozzles, the conventional CAVIJETs could only be fitted within a two-cone roller bit, a bit type which is seldom used.

The results of Sandia's study demonstrated that self-resonating cavitating jet systems were capable of providing the required performance for use in deep drilling with tri-cone bits. These results led to further investigations. Some of the conclusions drawn from these subsequent experiments were:

1. Several self-resonating CAVIJET nozzle system designs produce passive oscillations which (a) cause the jet to structure into discrete ring vortices, and thus (b) provide nozzle systems which have incipient cavitation numbers two to six times higher than obtained with either conventional CAVIJET nozzles or typical drill bit nozzles.

2. In rock cutting trials, higher incipient cavitation numbers have been correlated with greater erosivity.

3. The ORGAN-PIPE CAVIJET system is adaptable to the physical restraints of existing bits, and is the most promising concept for future bit designs.

4. The Structured Acoustically Tuned Oscillating Jet (STRATOJET ) nozzle systems will clean chips from a simulated bottomhole at a nozzle pressure drop only about 25 percent of that required for standard nozzle systems.

5. Self-resonating structured jets can be achieved either with or without cavitation. Therefore, at hole depths below where cavitation is present, a STRATOJET nozzle may still contribute to improved bottom hole cleaning.

6. The effects of several parameters on the bubble collapse process were studied, with the most interesting result being the effect of initial bubble size. As the initial bubble diameter increases, the effects of jet stagnation pressures near the wall become more pronounced. Larger bubbles collapse faster, thus the microjet that develops as a consequence of the collapse contains significantly more erosive power. This finding demonstrates the need to develop nozzle designs that produce highly structured jets in which large cavitation bubbles are formed periodically, rather than unstructured jets that produce smaller, randomly generated bubbles.

For Additional Information:

Laboratory Contact: David Glowka

Sandia National Laboratories

Geothermal Research Division

Albuquerque, NM 87185

(505) 844-3933 
Industry Contact:

Gary S. Frederick

Tracor Hydronautics

7210 Pindell School Rd.

Laurel, MD 20810

(301) 776-7454

References:

Sandia National Laboratories. Analytical and Experimental Study of the Acoustics and the Flow field Characteristics of Cavitating Self-Resonating Water Jets. Sandia Report SAND84-7142, 1984.

Sandia National Laboratories. Research and Development of Improved Cavitating Jets for Deep-Hole Drilling. Sandia Report SAND83-7461, 1984. 


\section{DOWNHOLE FLOW METER}

The downhole flow meter is an impeller-type device that measures flow velocity along the length of the wellbore. By interpreting the measured data it is possible to identify production and injection intervals, as well as detect the flash point in the well and scale buildup in the wellbore.

The flow meter has an overall length of 2 feet and a diameter of two inches. The body is constructed of stainless steel and the impeller of titanium. A standard hightemperature cablehead is used to connect the instrument to the armored cable, on which it is lowered into the well.

This instrument has been used in highly corrosive geothermal wells at temperatures up to $520^{\circ} \mathrm{F}$. Laboratory testing indicates that operation up to $572^{\circ} \mathrm{F}$ is possible.

For Additional Information:

Laboratory Contact:

Sally Benson

Earth Sciences Division

Lawrence Berkeley Laboratory

Berkeley, CA. 94720

(415) 486-5875

Producer Contact:

Ron Schroeder

Berkeley Group Inc.

1330 Broadway, Suite 1450

Oakland, CA 94612

(415) 465-1744

Reference:

Solbau, R.D., Goranson, C.B., and Benson, S.M.: "The Development and use of a High Temperature Downhole Flowmeter for Geothermal Well Logging." Proceedings of the Ninth Annual Workshop on Geothermal Reservoir Engineering, Stanford, CA. December 13-15.1983. pp. 205-210. 


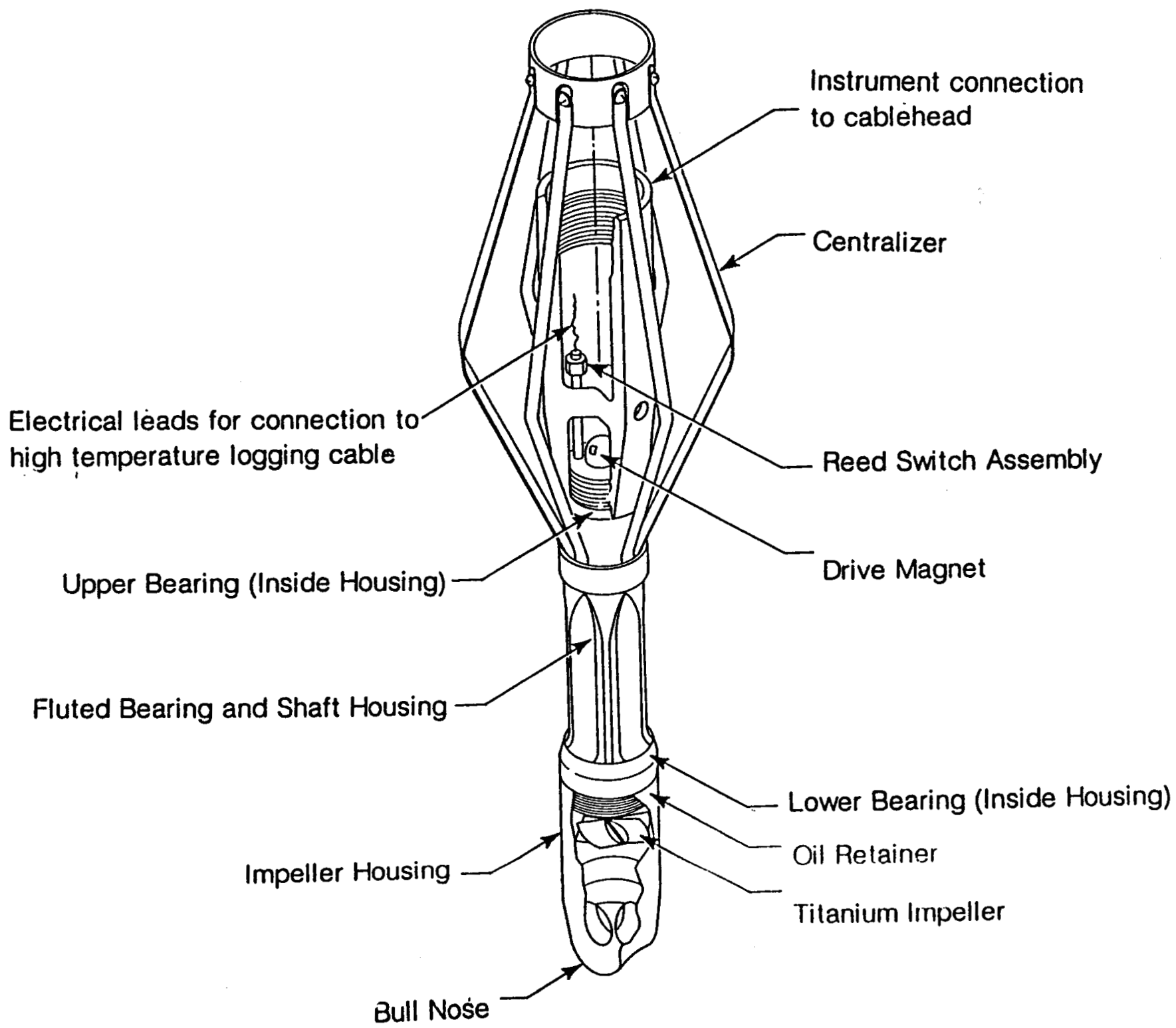

SCHEMATIC OF THE DOWNHOLE FLOW METER 


\section{DOWNHOLE INJECTOR AND GAMMA RAY DETECTOR}

Radioactive tracers injected at specific locations in the borehole show fluid circulation in the fractured geothermal reservoir. Radioactive bromine or some other radioactive tracer is injected into the injection well with the injector system developed at Los Alamos. A gamma ray detector is mounted in the same sonde as the injector. The gamma ray detector is thermally protected in a dewar flask using a cerrobend heat sink. When the sonde is positioned in the borehole at a predetermined release location, a motor-propelled rod smashes the quartz ampoule that contains the tracer. The integral gamma ray detector tracks the radioactive tracer as it leaves the injection well. A second gamma ray detector measures the arrival of the tracer in the production well. The system can be used to show fluid flow velocities and residence time of the reservoir fluid as it traverses the borehole and fractured reservoir. The gamma ray detector can be removed and operated separately from the downhole injector.

\section{OPERATING SPECIFICATIONS}

$\begin{array}{ll}\text { Temperature Rating } & 572^{\circ} \mathrm{F}\left(300^{\circ} \mathrm{C}\right) \\ \text { Fluid Pressure } & 15,000 \mathrm{psi} \\ \text { Length With Injector } & 121 \mathrm{in} . \\ \text { Length Without Injector } & 95 \mathrm{in} . \\ \text { Diameter } & 3.25 \mathrm{in} . \\ \text { Weight With Injector } & 175 \mathrm{lbs} \\ \text { Weight Without Injector } & 145 \mathrm{lbs}\end{array}$

For Additional Information:

Contact:

Bert R. Dennis

Los Alamos National Laboratory

Mailstop D448

Los Alamos, NM 87545

(505) 667-0728

Reference:

Dennis, Bert R., Koczan, Steven P., Stephani, Evon L.: High Temperature Borehole Instrumentation: Los Alamos National Laboratory, LA-10558-HDR, 1985. 


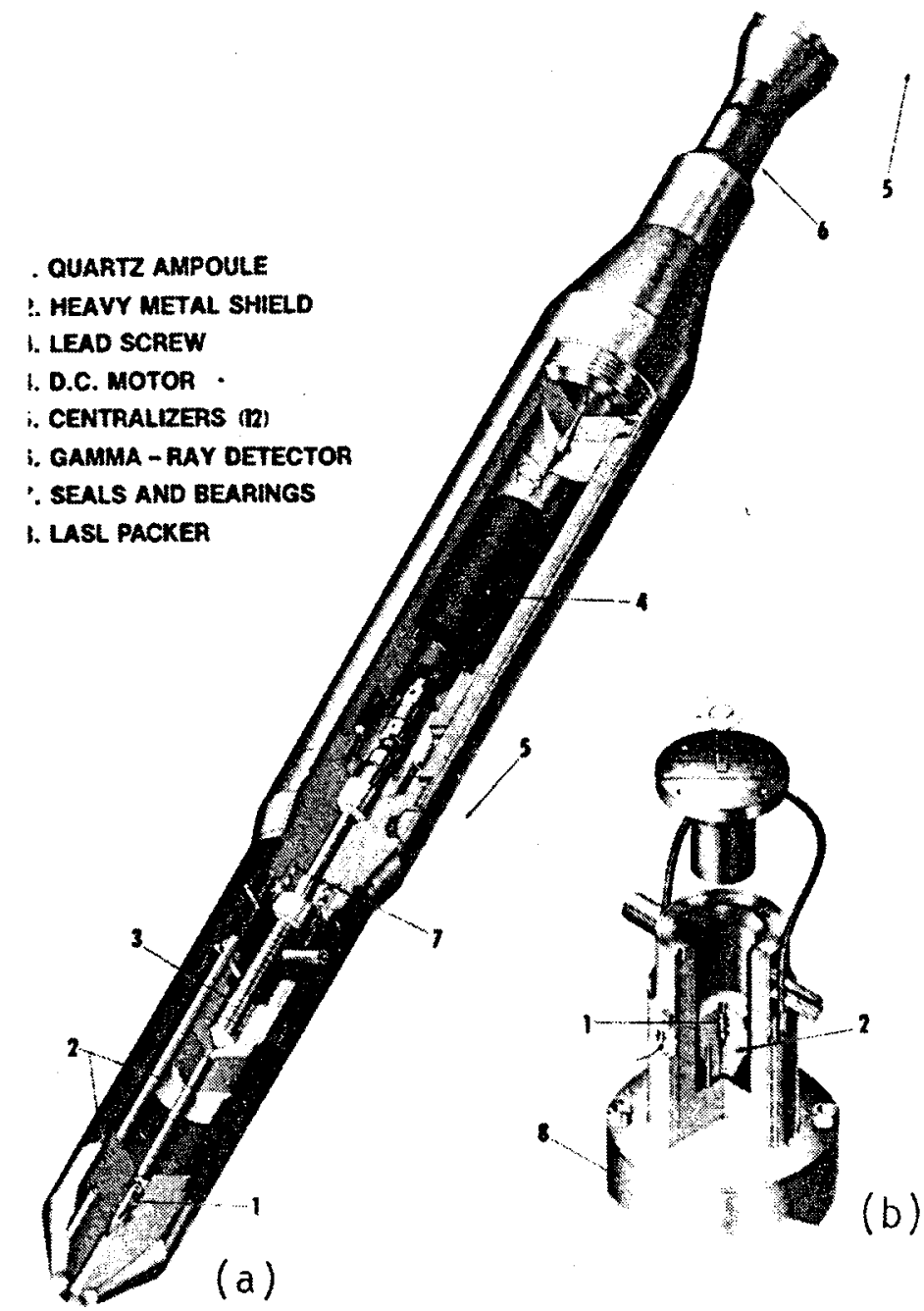

82

DOWNHOLE Br INJECTION AND GAMMA-RAY DETECTOR 


\section{CEMENT PLACEMENT TOOL}

The prototype cement placement tool is designed to provide a method of spotting cement plugs using a double wiper plug. After breaking circulation and cooling the well through the bottom of the tool, the lower sleeve catches the bottom cement wiper plug, pressures up the cementing string to a pre-determined pressure (thereby signaling the pump truck) and then shears to allow placement of the cement slurry through the lower circulation ports. After the cement is placed, the top wiper plug (displacement plug) is caught in the upper sleeve. The cement pumper is quickly shut down before the upper sleeve shears. The cementing string and placement tool are removed from the cement plug and the string is then pressured to shear the top sleeve. The tool and string are circulated clean through the upper circulation ports and removed from the well.

The placement tool is designed to be used in cement placement procedures which minimize dilution and contamination of the cement slurry as the slurry is pumped down the cementing string. It also allows for an accurate displacement of the slurry. Proper displacement volume varies with well temperature in hot wells and accurate displacement of cement requires a good estimate of average well temperature during displacement unless reliable pump down (wiper plugs) are used.

The prototype tool was run one time to spot a plug in Fenton Hill HDR well EE-3. The tool functioned perfectly using Vitton wiper plugs. After waiting on cement, a drill test was run and compared with previous tests in which drilling cement plugs had been spotted through open ended drill pipe. The cement plug spotted with the placement tool required $15,000-20,000$ lbs weight on a 8-1/2 in. bit to drill at $40 \mathrm{ft}$. per hr. Previous plugs were drilled at $69 \mathrm{ft}$. per hour with $5,000-10,000$ lbs weight on a $12-1 / 4$ in. bit.

The prototype tool was constructed for less than $\$ 5,000$. The Vitton wiper plugs and plug dropping head were purchased and rented at regular price book prices (less than $\$ 3,000$ ). A typical misrun on a high temperature cement job costs $\$ 30,000$ or more.

The prototype tool was designed by Baker Services Company. Additional runs of the tool are needed before any design improvements should be considered. The Vitton Wiper Plugs (pump-down-pumps) can be used where a wellbore can be cooled $400^{\circ} \mathrm{F}$. Design changes and high temperature testing are needed to develop a $500^{\circ} \mathrm{F}$ plug but no R\&D funds have been committed.

For Additional Information:

Laboratory Contact:

Donald S. Dreesen

Los Alamos National Laboratory

Mailstop J981

Los Alamos, NM 87545

(505) 667-5061
Producer Contact:

Rod Bennett

Baker Service Tools

9100 Emmott Road

Houston, TX 77040

(713) $466-1322$

\section{Reference:}

Dreesen, Donald S.: "Cement Plug Placement Tool." LANL Internal Memorandum $2 / 13 / 85$. 


\title{
DOWNHOLE FLUID INJECTOR
}

The fluid injector injects fluorescein dyes as chemical tracers into the fluid-filled borehole. Dye-tracer flow tests and residence-time distribution studies help geothermal investigators characterize the reservoir.

The tool delivers and ejects a metered volume of a fluid, such as a dye or acid, into the geothermal borehole at a prescribed location. The fluid to be injected, ranging from 2 to 10 gallons, is contained within a cylinder at the bottom of the tool.

The lower end of the cylinder is sealed. The upper end cap contains the discharge ports and flapper-type check valves, which allow flow out of the container during injection but prevent loss during insertion. The latching system holds the reservoir cylinder and the piston and rod assembly together until injection when the release mechanism unlatches the container. The cylinder then drops over the rod and piston, thereby discharging fluid through the openings at the cylinder's end cap.

\section{OPERATING SPECIFICATIONS}

Temperature Rating

Fluid Pressure

Length

Diameter

Weight

No. of Conductors $572^{\circ} \mathrm{F}\left(275^{\circ} \mathrm{C}\right)$

15,000 psi

$121 \mathrm{in}$.

3.25 in.

175 lbs.

3

\section{Additional Information:}

Contact:

\author{
Bert R. Dennis \\ Los Alamos National Laboratory \\ Mailstop D448 \\ Los Alamos, NM 87545 \\ (505) 667-0728
}

\section{Reference:}

Dennis, Bert R., Koczan, Steven P., Stephani, Evon L.: High Temperature Borehole Instrumentation: Los Alamos National Laboratory, LA-10558-HDR, 1985.

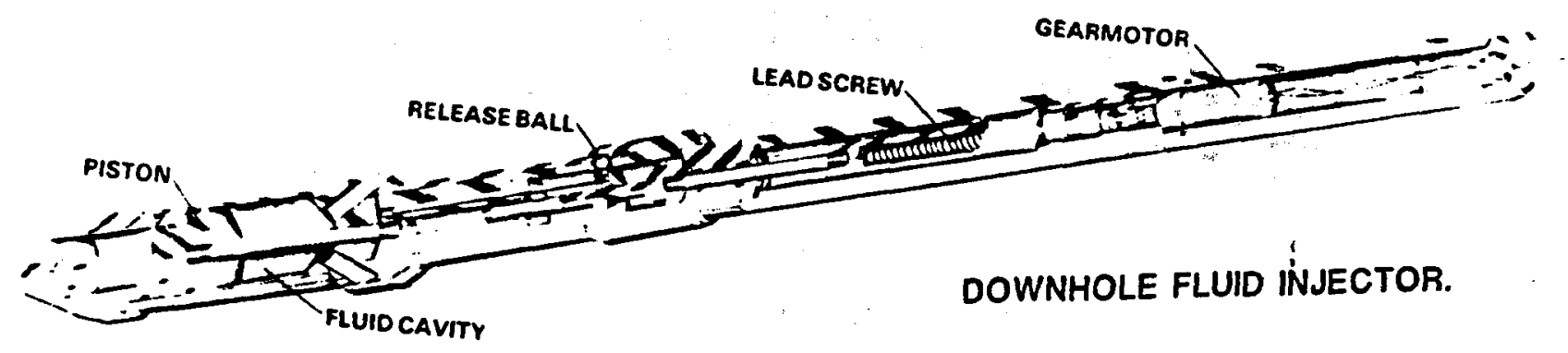




\section{DRILL PIPE SEVERING DEVICE}

The drill pipe severing device uses a shaped lens to provide an explosive cutting tool that leaves a clean circumferential edge where it cuts the drill pipe or casing. The downhole firing unit and high-temperature detonator are the same as those used in the string shot and multiple fire detonator tool. The lens and shaped charge must be designed for each size pipe or casing in the wellbore.

\section{OPERATING SPECIFICATIONS}

$\begin{array}{ll}\text { Temperature Rating } & 320^{\circ} \mathrm{C} \\ \text { Fluid Pressure } & 15,000 \text { psi } \\ \text { Length } & 96 \mathrm{in} . \\ \text { Diameter } & 2.5 \mathrm{in} . \\ \text { Weight } & 100 \mathrm{lbs}\end{array}$

For Additional Information:

Contact: $\quad$ Bert R. Dennis

Los Alamos National Laboratory

Mailstop D448

Los Alamos, NM 87545

(505) 667-0728

Reference:

Dennis, Bert R., Koczan, Steven P., Stephani, Evon L.: High Temperature Borehole Instrumentation: Los Alamos National Laboratory, LA-10558-HDR, 1985.

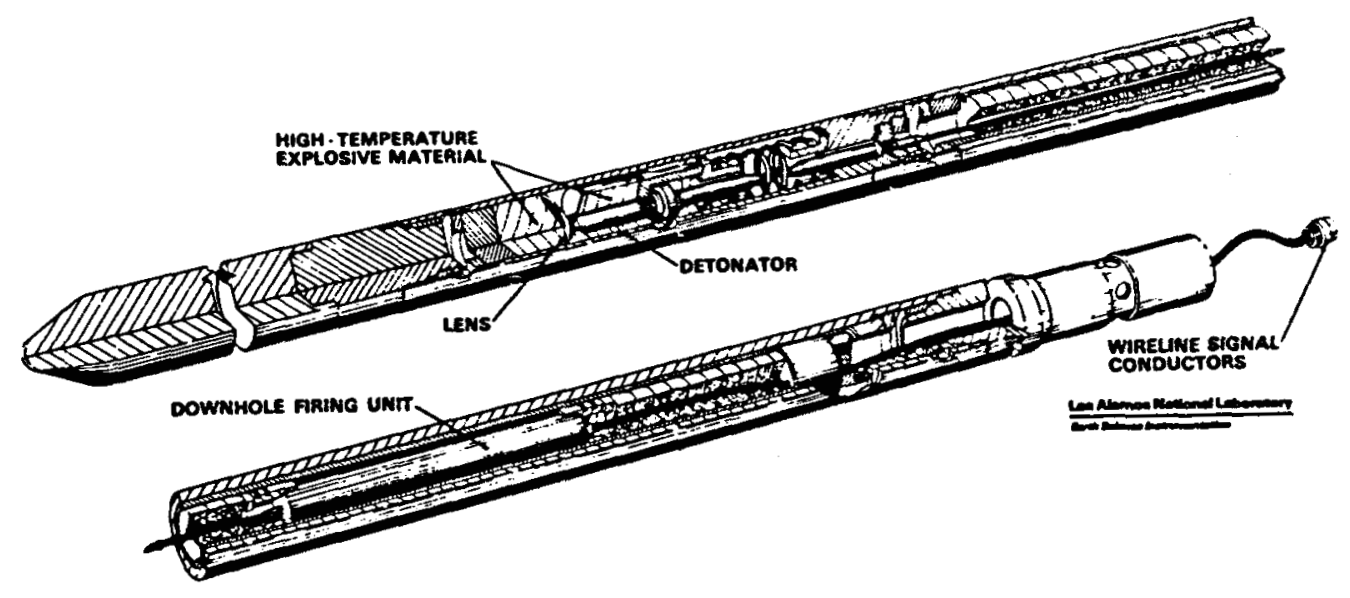

DRILL PIPE SEVERING DEVICE 


\section{EXPLOSIVE FRACTURE INITIATION TOOL}

The explosive fracture initiation tool deploys and detonates a small explosive charge at a pre-selected position in the openhole section of a geothermal wellbore. Detonation of the shaped charge can initiate fractures in the selected zone after which hydraulic pressurization extends the fractures into the formation. The downhole firing unit, detonators and explosives are of the same types used in all the explosive tools.

\section{OPERATING SPECIFICATIONS}

Temperature Rating

Fluid Pressure

Length

Diameter

Weight

$$
\begin{aligned}
& 320^{\circ} \mathrm{C}\left(608^{\circ} \mathrm{F}\right) \\
& 10,000 \mathrm{psi} \\
& 225 \mathrm{in} . \\
& 3.25 \mathrm{in} . \\
& 310 \mathrm{lbs}
\end{aligned}
$$

For Additional Information:

Contact:

Bert R. Dennis

Los Alamos National Laboratory

Mailstop D448

Los Alamos, NM 87545

(505) 667-0728

Reference:

Dennis, Bert R., Koczan, Steven P., Stephani, Evon L.: High Temperature Borehole Instrumentation: Los Alamos National Laboratory, LA-10558-HDR, 1985.

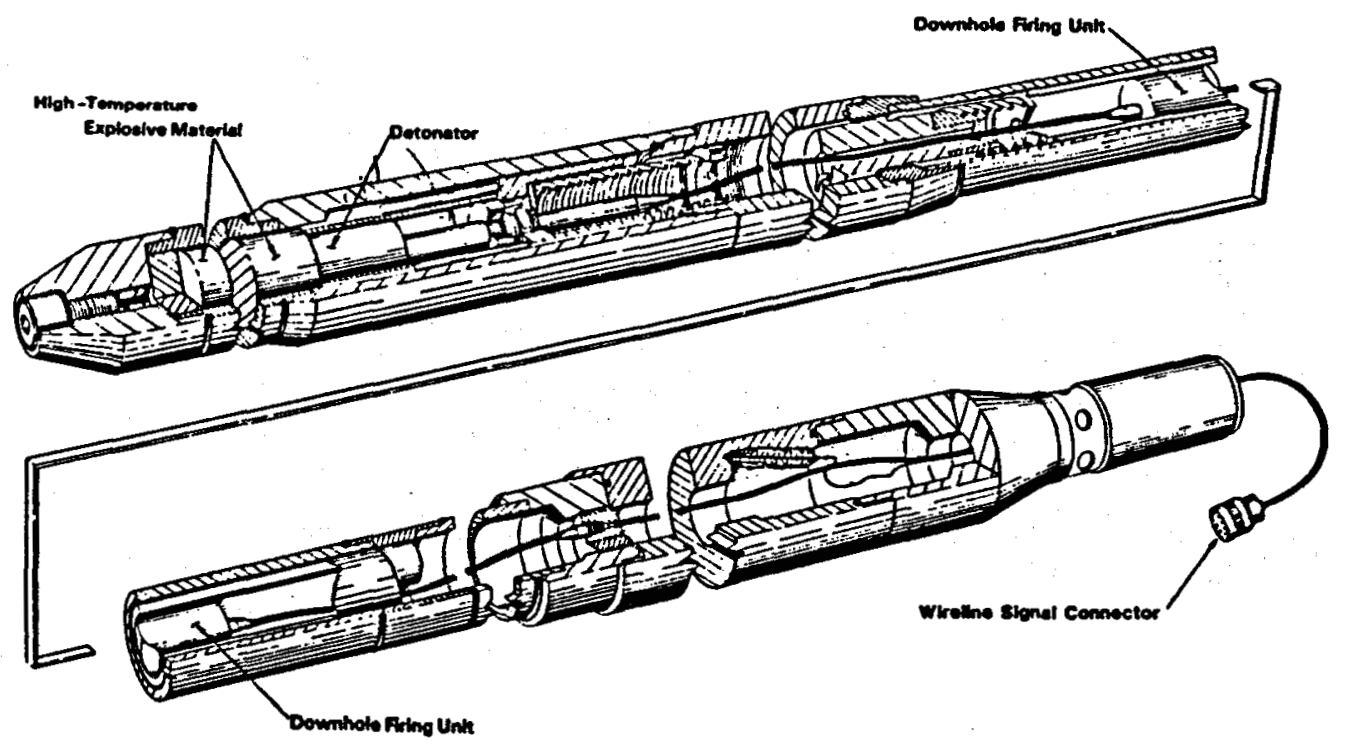

EXPLOSIVE FRACTURE INITIATION TOOL 


\section{EXPLOSIVE SIDE TRACKING TOOL}

This tool uses an explosive shaped charge to create a bell shaped cavity of rubble in the borehole which provides a side-tracking ledge in the hard granitic rock. This ledge will allow the drill bit with bent sub-assembly to side-track from the low side of the borehole.

\section{OPERATING SPECIFICATIONS}

Temperature Rating $320^{\circ} \mathrm{C}$

Fluid Pressure $\quad 15,000$ psi

Length $250 \mathrm{in.}$

Diameter 5.0 in.

Weight $215 \mathrm{lbs}$.

For Additional Information:

Contact: Bert R. Dennis,

Los Alamos National Laboratory

Mailstop D448

Los Alamos, NM

(505) 667-0728

\section{Reference:}

Dennis, Bert R., Koczan, Steven P., Stephani, Evon L.: High Temperature Borehole Instrumentation: Los Alamos National Laboratory, LA-10558-HDR, 1985.

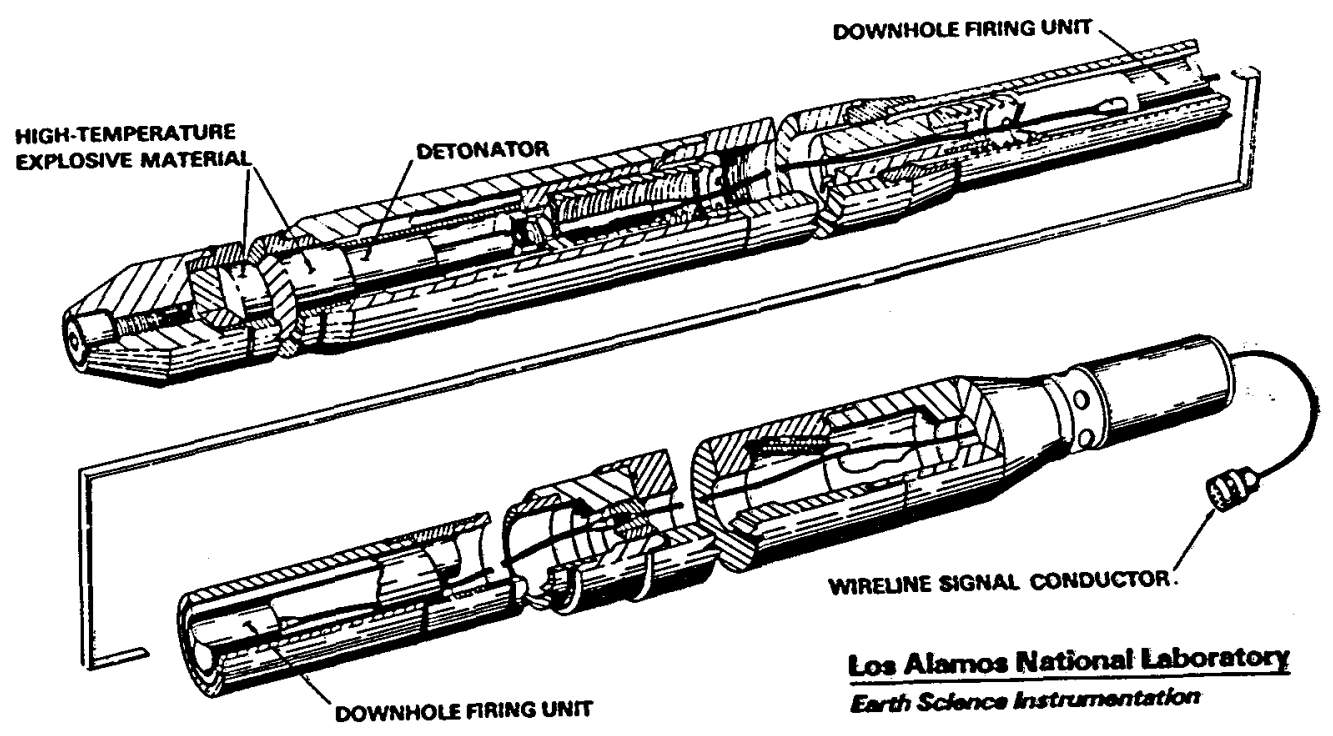

\section{EXPLOSIVE SIDE-TRACKING DEVICE}




\section{HARD ROCK GEOTHERMAL DRILL BIT}

Consistent and reliable hard rock drill bit performance is difficult to achieve, especially in high-temperature and abrasive crystalline rock. A primary contributor of ten encountered in severe reduction in bit life is a rapid reduction in the diameter (gauge wear) of the bit. This excessive bit gauge wear is aggravated in deviated boreholes because the bit is subjected to increased lateral contact force with the borehole wall.

Gauge wear causes a tapered, decreasing borehole diameter, and requires reaming by the subsequent bit run in the hole, therefore compounding the gauge wear problems and significantly reducing bit life and effective penetration rates.

Drilling in hot, hard, abrasive rock involves low penetration rates and relatively short bit lives. Comparative tests during drilling of the first two wells suggested several ways in which the carbide-insert, three-cone, roller bits normally used in hard-rock rotary drilling could be improved. Working with a commercial bit manufacturer and testing bits at Fenton Hill, the HDR Program assisted in the development of an improved geothermal bit that incorporated better bearings in the roller cones, harder carbide inserts especially in the gauge (outside) rows on the cones -- and wear protection on the legs and skirt of the bit provided by hard facing and carbide inserts there. The higher cost of these special bits is more than balanced by their improved performance, and they are now widely used throughout the geothermal industry.

These bits gave a reliable bit life of above $100 \mathrm{~m}$ at the $8-3 / 4 \mathrm{in} .(22.2 \mathrm{~cm})$ size in the deepest, $35^{\circ}$ inclined portion of the borehole at temperatures from 500 to $600^{\circ} \mathrm{F}$ ( 260 to $320^{\circ} \mathrm{C}$ ). The bits were also very successful in directional drilling with a low speed, high torque turbodrill.

For Additional Information:

Laboratory Contact: J. Rowley

Los Alamos National Laboratory

Mailstop D462

Los Alamos, NM 87545

(505) 667-5061

R\&D Contact: W.C. Baker

Smith Tool Company

1207 34th St.

Bàkersfield, CA 93301

(805) 323-0656 


\section{FLUID VELOCITY (SPINNER) PROBE}

The fluid velocity probe yields accurate data about complete fluid-flow patterns in a borehole. A typical borehole will have fractures in several zones. The fluid velocity, as measured by the sensor, can help characterize the man-made reservoir by determining the nature and location of the fractures, where and how much fluid leaves or enters the borehole, and the relative contribution of each fracture to the total reservoir. The impeller size was increased and interface electronics were designed to provide better resolution and to increase the analog output from $10 \mathrm{mV}$ to $10 \mathrm{~V}$ full scale. This tool can $\log$ the borehole vertically in either direction.

Information regarding flow rates at various positions in the borehole, combined with data from the caliper tool, ascertains the location of hydraulic fractures and volumetric contributions from each fracture.

\section{OPERATING SPECIFICATIONS}

Temperature Rating

Fluid Pressure

Length

Diameter

Weight

Option
Standard

$272^{\circ} \mathrm{F}\left(300^{\circ} \mathrm{C}\right)$

15,000 psi

100 in.

$4.0 \mathrm{in.}$

$200 \mathrm{lbs}$

Temperature
Slimline $272^{\circ} \mathrm{F}\left(300^{\circ} \mathrm{C}\right)$ 15,000 psi 101 in. 2,875 in. $70 \mathrm{lbs}$ Temperature

For Additional Information:

Contact:

Bert R. Dennis

Los Alamos National Laboratory

Mailstop D448

Los Alamos, NM 87545

(505) 667-0728

Reference:

Dennis, Bert R., Koczan, Steven P., Stephani, Evon L.: High Temperature Borehole Instrumentation: Los Alamos National Laboratory, LA-10558-HDR, 1985. 


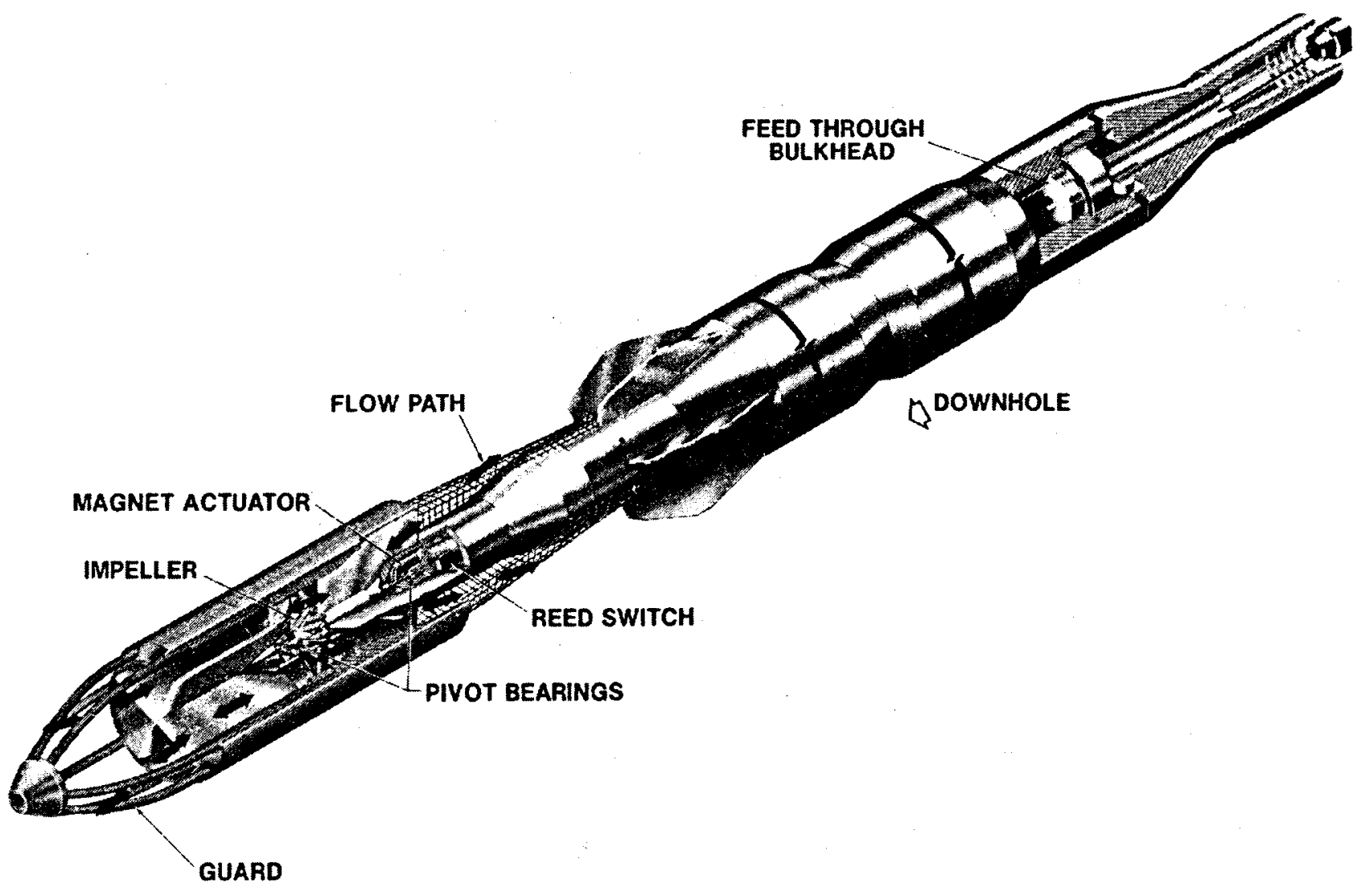

FLUID VELOCITY (SPINNER) PROBE. 


\section{HIGH TEMPERATURE CASING PACKER}

A recently improved, high temperature casing packer is a critical component in a casing completion system. The packer is rated for service to $5000 \mathrm{psi}$ differential pressure in either direction at $500^{\circ} \mathrm{F}$. A Y267 EPDM element with backup rings form the casing seat. Wedge type retractible slips anchor the packer. It is a retrievable, single set packer which can be run in conjunction with an internal expansion joint to provide for tubing expansion and contraction.

The packer has a pressure rating equivalent to that of high temperature permanent or drillable packers. It allows for a retrievable well completion systems to be designed for high pressure injection, stimulation, and production in $500^{\circ} \mathrm{F}$ wells.

Massive hydraulic fracturing has been successfully accomplished using the packer set in 9-5/8 in. $40 \mathrm{lb} / \mathrm{ft}$ casing, 11,350 ft deep in Fenton Hill HDR well EE-2. After a 7 day soak at temperatures between $400^{\circ} \mathrm{F}$ and $475^{\circ} \mathrm{F}$, the packer and a $40 \mathrm{ft}$ expansion joint were exposed to differential pressures up to $450 \mathrm{psi}$ with cool down to $80^{\circ} \mathrm{F}$. Over 5.5 million gallons of water were injected at surface pressures up to $7000 \mathrm{psi}$ at an average injection rate of $40 \mathrm{BPM}$.

The installed cost of the retrievable packer system is about $1 / 2$ to $1 / 3$ that of a permanent or drillable packer system with equivalent expansion joint and premium hightemperature seals. The cost to remove the retrievable packer is also about $1 / 3$ the cost of milling and retrieving a drillable system.

OTIS Engineering is in the process of transferring this packer system from their R\&D group and prototype shop to their regular product manufacturing and marketing groups.

\section{For Additional Information:}

Laboratory Contact: Donald S. Dreesen

Los Alamos National Laboratory

Mailstop J981

Los Alamos, NM 87545

(505) 667-5061

R\&D Contact: $\quad$ D. Taylor

OTIS Engineering

P.O. Box 819052

Dallas, TX 75381

(214) 323-3694

Producer Contact: D. Taylor

OTIS Engineering

P.O. Box 819052

Dallas, TX 75381

(214) 323-3694

Reference:

Dreesen, D.S., and Nicholson, R.W.: "Well Completion and Operations for MHF of Fenton Hill HDR EE-2." Geothermal Resources Council Transactions, Vol 9, Part II, 1985, pp. 89-94. 


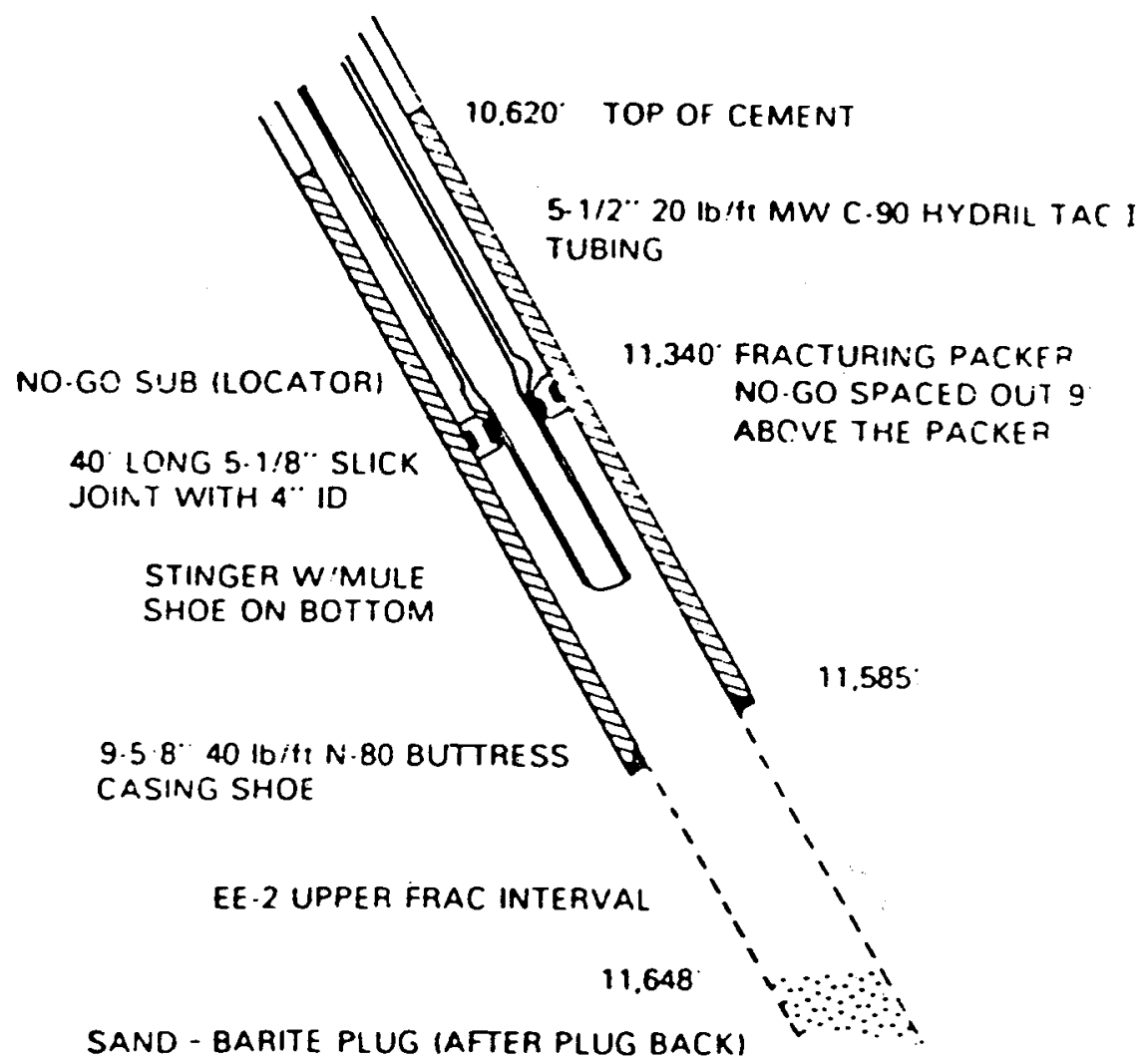

BOTTOM-HOLE INJECTION ASSEMBLY FOR THE EE-2 MHF 


\section{HIGH TEMPERATURE DOWNHOLE FLUID SAMPLER}

Downhole fluid samplers provide a means of collecting relatively undisturbed samples of formation fluids. The high temperatures, corrosive fluids, and high pressures in geothermal wells prevent use of conventional downhole samplers. A downhole sampler has been developed for geothermal use. The specifications of this tool are listed below.

Sampler type: $\quad$ Downhole flow-through

Length: $\quad 125$ in.

Diameter: $\quad 2.25$ in.

Weight: $\quad 70$ lbs.

Sample volume: $\quad 2,000 \mathrm{ml}$

Material: $\quad$ MP35N alloy (all parts in contact with sample)

Sampler pressure

(internal): $\quad 10,000 \mathrm{psi}(70 \mathrm{MPa})$

Temperature limit: $\quad 350^{\circ} \mathrm{C}$

Power requirement: $\quad 40 \mathrm{ma} \mathrm{dc}$

For Additional Information:

Contact: Ray Solbau

Earth Sciences Division

Lawrence Berkeley Laboratory

Berkeley, CA 94720

(415) 486-4000 


\section{HIGH TEMPERATURE DRILLING JARS}

High temperature, hydraulic jarring tools were developed as the result of collaborative efforts between Los Alamos National Laboratory and two firms. Fishing jars are used to retrieve drill pipe or drilling tools stuck in the hole. A jarring tool is inserted at the bottom of the drill string which is then tripped into the well and attached to the stuck fish. By means of the jarring tool, impact is applied to the stuck section to loosen it so that it can be removed. Tools of this type are a standard item of drilling hardware and are used frequently, usually with good results. In addition to these "fishing jars," drilling jars are commonly included in the bottom-hole drilling assemblies used at the Los Alamos Hot Dry Rock geothermal site (Fenton Hill, NM). These tools can of ten be used to prevent stuck drilling assemblies because they can be applied when the first signs of tight hole conditions are detected and therefore prevent lengthy and costly fishing operations. The HDR Program worked with two manufacturers to develop hydraulically actuated jarring tools that would operate reliably at temperatures above $200^{\circ} \mathrm{C}\left(400^{\circ} \mathrm{F}\right)$. Both companies now market those tools as a commercial rental service available to the geothermal and petroleum drilling industry.

For Additional Information:

Laboratory Contact: J. Rowley

Los Alamos National Laboratory

Mailstop D462

Los Alamos, NM 87545

(505) 667-5061

R\&D Contact: $\quad$ D. Webb

Houston Engineering

Houston, TX

Producer Contact: D. Webb

Houston Engineering

Houston, TX

Bower Tools, Inc.

Houston, TX 


\section{HIGH TEMPERATURE ELECTRONICS AND INSTRUMENTATION}

Sandia National Laboratories was conducting research toward development of geothermal well logging instrumentation. The DOE-sponsored program was directed toward development of key high-temperature instrumentation technologies and components; demonstration of the technologies; and their transfer to industry.

Included in these activities are:

- Hybrid Circuits - inks, capacitors and active devices for temperatures up to $500^{\circ} \mathrm{C}$.

- Armor materials for logging cable (Tefion TFE, and Teflon PFA).

- High-temperature electronic devices - integrated circuits, thin-film components, compound semiconductor, and high-temperature transformer material.

- Transducers.

For Additional Information:

Contact: $\quad$ Richard Traeger

Sandia National Laboratories

Geothermal Research Division

Albuquerque, NM 87185

(505) 844-2377

Reference:

Veneruso, A.F., Simpson, R.S., and Arnold, C.: High Temperature Electronics and Instrumentation Seminar Proceedings. Sandia National Laboratories Report SAND80-0834C, 1980. 


\section{PASSIVE THERMAL PROTECTION SYSTEM}

A passive thermal protection system has been used successfully in hot geothermal wellbores. The system thermally protects delicate electronic components placed inside a tool sonde whose thermal life time is about 11 hours at $230^{\circ} \mathrm{C}$, or four times longer than the previous system used.

The improvement in thermal residence time at $230^{\circ} \mathrm{C}$ was achieved by replacing the brass mounting hardware in the electronic compartment with heat pipes. The condenser end of each heat pipe was designed to protrude into the heat sink base. The heat pipes were constructed using brass tubing for the wall material, methanol as the working fluid and internal threads on the inside tube wall instead of a separate work material. The heat sink material was changed from commonly used Woods' Metal to ice. This lowered the heat sink melting point and resulted in a large increase in thermal potential for heat flow from the electronics into the heat sink. Ice also increases the thermal mass of the volume limited system by increasing the amount of energy absorbed as enthalpy change and energy absorbed in changing phase from solid to liquid.

\section{For Additional Information:}

Contact:

G. Bennett

Los Alamos National Laboratory

Los Alamos, NM 87545

(505) 667-5061

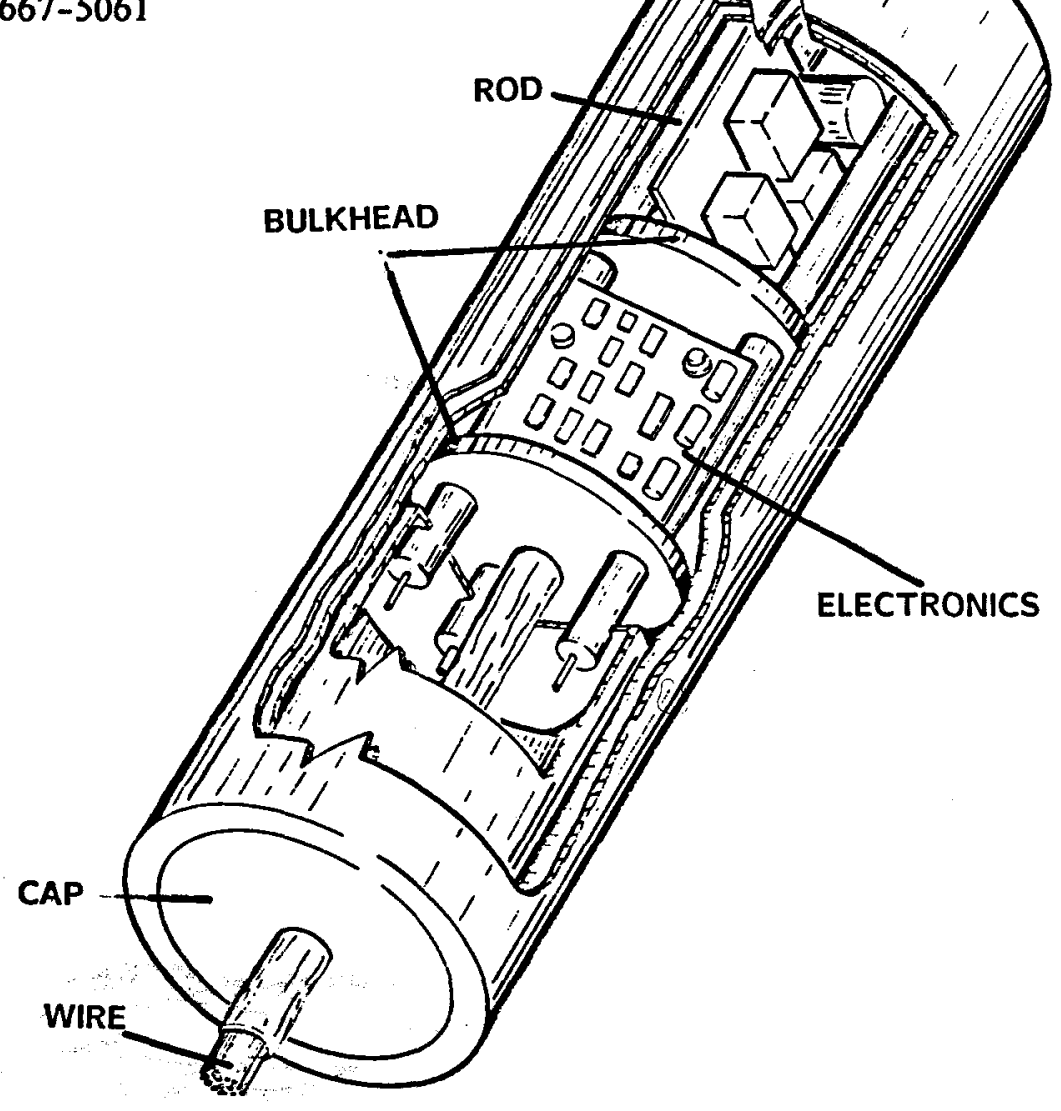

Passive Thermal Protection System 


\section{HIGH TEMPERATURE, HIGH PRESSURE CABLEHEAD}

The cablehead assembly provides a cable-to-sonde electromechanical coupling device, which protects the electrical conditions from the high-pressure/high-temperature area from the downhole fluid, high pressure environment to a dry, low-pressure instrument chamber. The cablehead assembly is a protected area for splicing the cable conductor ends to the high-temperature bulkhead.

Should the instrument sonde become lodged in the wellbore, the cablehead is designed to allow separation of the sonde and cable. The fishing bell housing then provides a positive gripping area for overshot fishing tools for retrieval from the borehole.

\section{OPERATING SPECIFICATIONS}

$\begin{array}{ll}\text { Temperature Rating } & 662^{\circ} \mathrm{F}\left(350^{\circ} \mathrm{C}\right) \\ \text { Fluid Pressure } & 15,000 \mathrm{psi} \\ \text { Length } & 35 \mathrm{in} . \\ \text { Diameter } & 2.125 \text { in. } \\ \text { No. of Conductors } & 7+\text { Armor }\end{array}$

For Additional Information:

Contact: $\quad$ Bert R. Dennis

Los Alamos National Laboratory

Mail Stop D448

Los Alamos, NM 87545

(505) 667-0728

Reference:

Dennis, Bert R., Koczan, Steven P., Stephani, Evon L.,: High Temperature Borehole

Instrumentation: Los Alamos National Laboratory, LA-10558-HDR, 1985. 


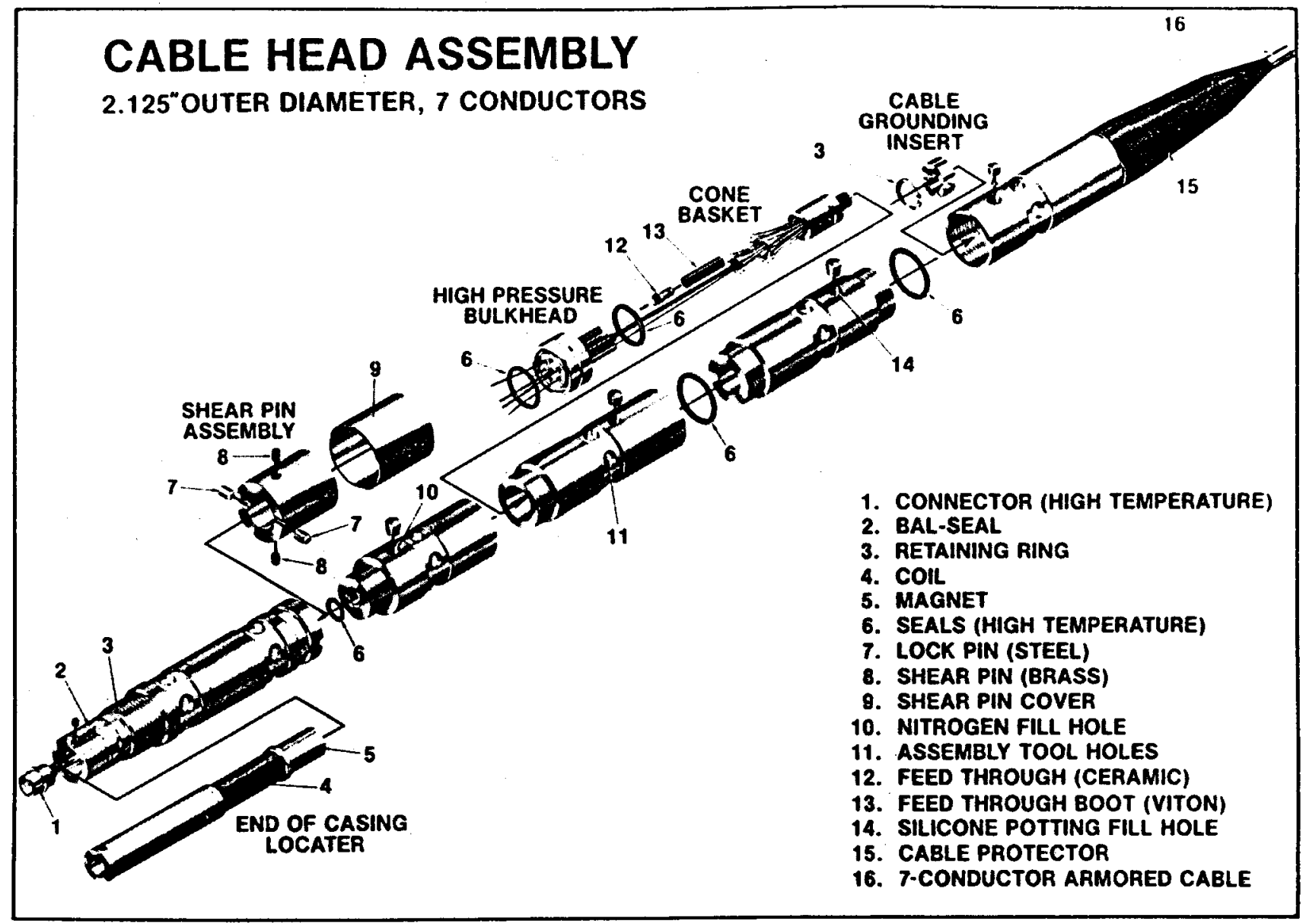




\section{HIGH TEMPERATURE OPEN HOLE PACKERS}

An inflatable element open hole packer and prototype packer running assembly (see figure) have been used for massive hydraulic fracturing in Fenton Hill HDR Well EE-3A. The packer has a steel-rib reinforced, high temperature EPDM element with both high pressure seal and anchor sections. The anchor consists of exposed steel reinforcing ribs which contact the open hole formation as the packer is inflated. The inner tube and seal section are mandrel wrapped with high temperature rated EPDM elastomer. The packer running assembly includes an expansion joint, inflate and release assembly, a fluid compensator system and a gage carrier sub for chart type bottom hole pressure and temperature gauges.

The successful use of high temperature, high pressure, open hole packers for fracturing and injection testing has had a positive impact on the drilling, evaluation and well completion of Fenton HDR Well EE-3A. Work that would have previously required $1-1 / 2$ to 3 years to complete has been completed in 4 months. Using previous techniques, the EE-3A wellbore would have had a set of scab liners cemented in and a major wash over and milling operation to prepare the wellbore for the final completion. Using the open hole packers, damage to the wellbore has been minimal and no permanent equipment has been left in the well.

Seven packer runs have resulted in five successful runs and two misruns (one misrun packer had to be washed over and fished out). On 3 of those runs over one million gallons of water were injected at differential pressures on the packer up to $5000 \mathrm{psi}$. All of the packers were exposed to temperatures above $400^{\circ} \mathrm{F}$ prior to inflation and one packer was exposed to $475^{\circ} \mathrm{F}$. Using the fluid compensation system the packers have been kept inflated through bottom-hole cool downs exceeding $350^{\circ} \mathrm{F}$ but additional design modifications are needed to keep the packer elements from rupturing during thermal recovery. The expansion joint has performed well during the trip in, packer inflation and injection. Drill pipe contraction exceeded $22 \mathrm{ft}$ on one run. Some modification is needed to reduce damage to the expansion joint.

The cost of zone isolation using an open hole packer assembly is about $1 / 4$ the cost of cementing in a scab liner. If liner removal costs are included, the open hole packer assembly is estimated to be about $1 / 8$ to $1 / 10$ of the total cost of the liner.

The packer element developed by Baker Production Technology (formerly Lynes, Inc) is reliable in competent formations (granadiorite) for service to $5000 \mathrm{psi}$ and to $500^{\circ} \mathrm{F}$. Service parameters for the element in less competent formations will have to be determined in field tests. The running assembly needs further development for massive hydraulic fracturing service. Its present configuration is suitable for mini-frac service, and it can be easily modified to serve as a retrievable open hole bridge plug. The expansion joint was designed for LANL by Baker Services Company. OTIS Engineering also provided technical support to convert the expansion joint to a slick OD expansion joint using spare parts for a $9-5 / 8$ in. steam packer.

\section{For Additional Information:}

\section{Laboratory Contact:}

Donald S. Dreesen

Los Alamos National Laboratory

Mail Stop J981

Los Alamos, NM 87545

(505) 667-5061 
Producer Contact:

C. MacRae

Baker Service Tools

9100 Emmott Rd.

Houston, TX 77040

(713) $466-1322$

Reference:

Dreesen, D.S.: "Development of an Open Hole Packer for High Pressure Service in

a $500^{\circ} \mathrm{F}$ Precambrian Wellbore." Los Alamos National Laboratory report (in prep).

TOP

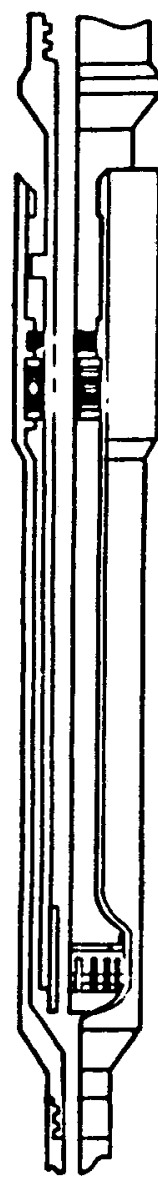

Drill Pipe

Tool Joint

Connecting Joint

"J.Trpe"

Soal Unit

36ft Expansion Joint

Tool Joint

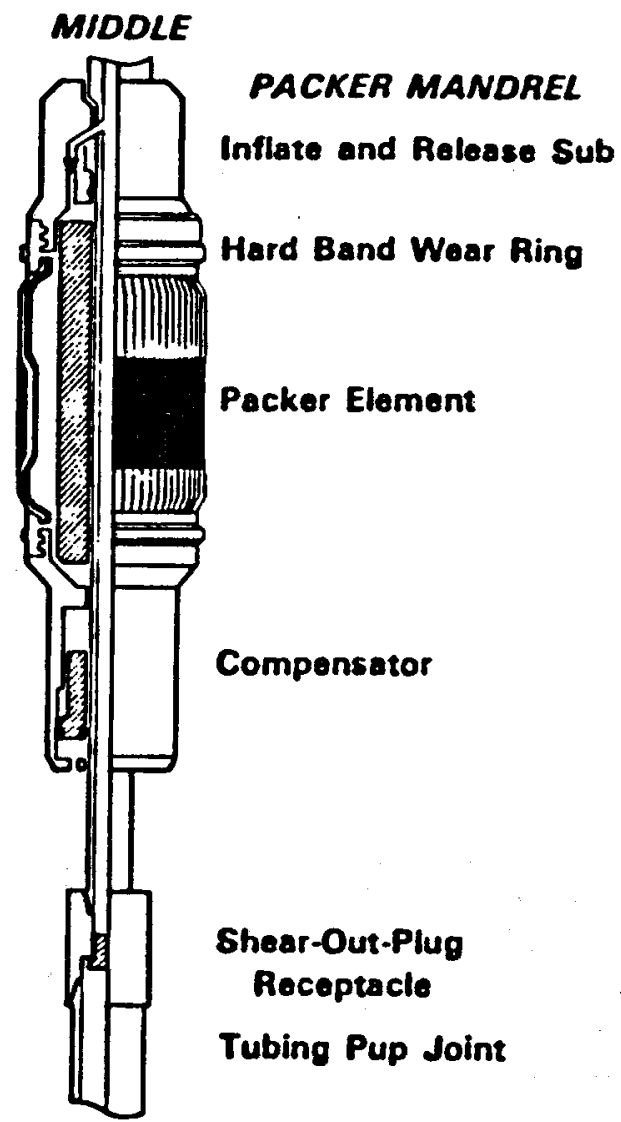

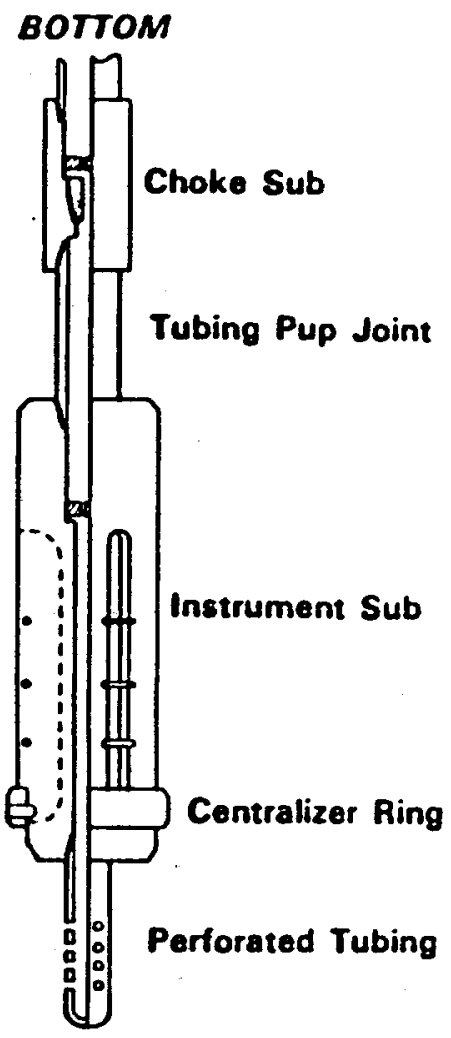




\section{HIGH TEMPERATURE TURBODRILL}

A high temperature turbodrill serves as the critical component in directional drilling systems designed to drill in deep, hot granite formations. Successful field operations have demonstrated that the turbodrills are capable of drilling to $15,200 \mathrm{ft}$. $(4.7 \mathrm{~km})$ depths and at rock temperatures up to $630^{\circ} \mathrm{F}\left(320^{\circ} \mathrm{C}\right)$. Two sizes of these downhole drilling motors were developed: $7-3 / 4$ in. $(19.7 \mathrm{~cm})$ and $5-3 / 8$ in. $(13.7 \mathrm{~cm})$ diameter units for directional drilling in $12-1 / 4$ in. $(31.1 \mathrm{~cm})$ and $8-3 / 4$ in. $(22.2 \mathrm{~cm})$ diameter holes, respectively.

Additional components in such directional drilling systems include:

o a bent sub to provide side or lateral load on the drill bit

o a steering tool or wireline-conveyed guidance sensor (e.g., magnetometer and inclinometer combinations) used to set up and monitor the required direction of drilling

o a turbodrill rotational speed indicator (pressure pulser)

o a shock-absorber subassembly to protect the system, especially the turbodrill bearings, from excessive shock and vibration loads.

Power for the turbodrill is supplied by the flow of drilling fluid, usually clear water, provided by the mud pumps of the drill rig.

Drilling in a prescribed direction proceeds by lowering the directional-drilling system into the well on the drill string, orienting the drill motor direction (compass heading) by the use of the steering tool in relation to the angle of the bent sub, setting the proper load on the bit with the rig hook and weight indicator, initiating pump flow, and monitoring/altering direction with the steering tool as drilling progresses.

The development was conducted in collaboration with Maurer Engineering Inc., a firm located in Houston, Texas. In laboratory tests, the turbodrills drilled granite blocks with the bit sizes and types to be used in the field application. Detailed drilling performance data were developed for the turbodrills from these tests. This latter data, combined with the dynamometer results, was used to establish, direct, and monitor the field performance of the actual directional drilling operations. Thus, field performance charts for drilling granite were available to serve as an operational guide during actual use.

Initial field trials were successfully conducted at about a $5,000 \mathrm{ft} .(91.5 \mathrm{~km})$ depth in a granite geothermal well. The typical performance of the 7-3/4 in. $(19.7 \mathrm{~cm})$ turbodrill in the $12-1 / 4$ in. $(31.8 \mathrm{~cm})$ portion of this well at $10,500 \mathrm{ft} .(3.5 \mathrm{~km})$ and $410^{\circ} \mathrm{F}\left(220^{\circ} \mathrm{C}\right)$ indicated a successful angular change of $4^{\circ}$ in $119 \mathrm{ft}$. $(36 \mathrm{~m})$ drilled, in $4-1 / 2 \mathrm{in}$. The turbodrill speed of $350 \mathrm{rpm}$ was achieved with a fluid flow of $360 \mathrm{gal} / \mathrm{min}\left(0.25 \mathrm{~m}^{3} / \mathrm{min}\right)$. A bit load of $20,000 \mathrm{lb}(9,100 \mathrm{~kg})$ and a bent sub angle of $1 / 2-$ to $1-1 / 2^{\circ}$ were used.

For Additional Information:

Laboratory Contact:

J. Rowley

Los Alamos National Laboratory

Los Alamos, NM 87545

(505) 667-5061
Producer Contact:

W.C. Maurer

Maurer Engineering, Inc.

2916 West P.C. Jester

Houston, TX 77071

(713) 683-8227 


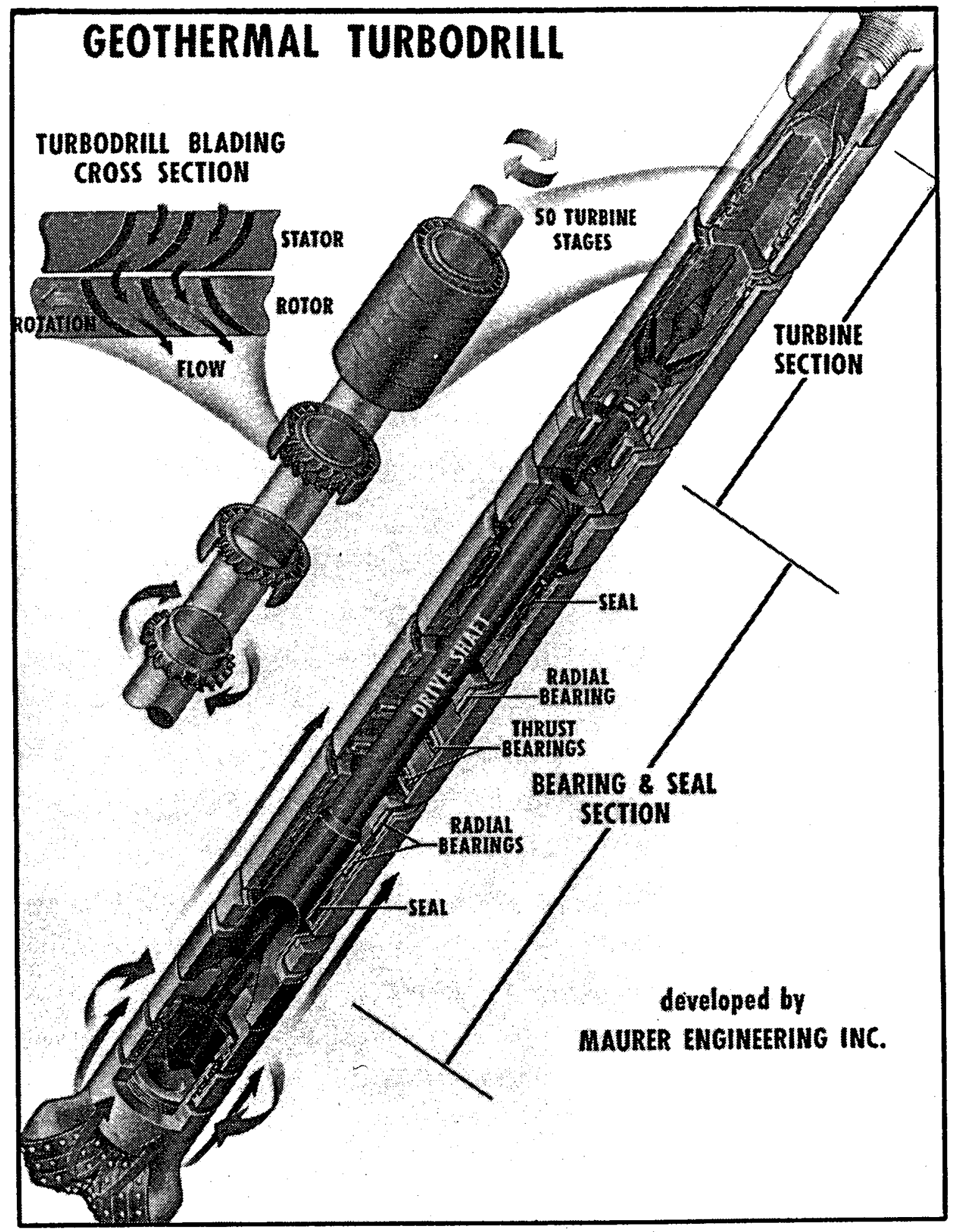




\section{PDC DRILL BITS}

Polycrystalline Diamond Compact (PDC) drill bits are a specialized "drag bit" using man-made PDC cutting elements (STRATAPAX) originally developed by the General Electric Company. PDC inserts, due to their superior hardness, greatly enhance the cutting tool life as compared to cemented tungsten carbide tools or single crystal diamond tools.

Since 1976, Sandia has been involved in the design and development of advanced drag bits employing PDC cutting elements. The development of design criteria for these bits has consisted of a coordinated plan of experimental and analytic studies carried out in collaboration with the General Electric Company Corporate Research and Development Laboratories and various commercial bit manufacturers and users. The experimental program included single point tests of individual cutters, laboratory tests of full-size prototype bits, and field tests of full-scale bit designs based on laboratory data. In an effort to characterize some of the fundamental aspects of rock cutting by PDC tools, finite-difference and finite element numerical codes have been used to simulate the behavior of the rock-tool mechanical interaction.

For Additional Information:

Contact: $\quad$ David Glowka

Sandia National Laboratories

Geothermal Research Division

Albuquerque, NM 87185

(505) 844-3933

Reference:

Ortega, A. and Glowka, D.A.: Studies of Frictional Heating of Polycrystalline Diamond Compact Drag Tools During Rock Cutting. Sandia National Laboratories Report SAND80-2677, 1982. 


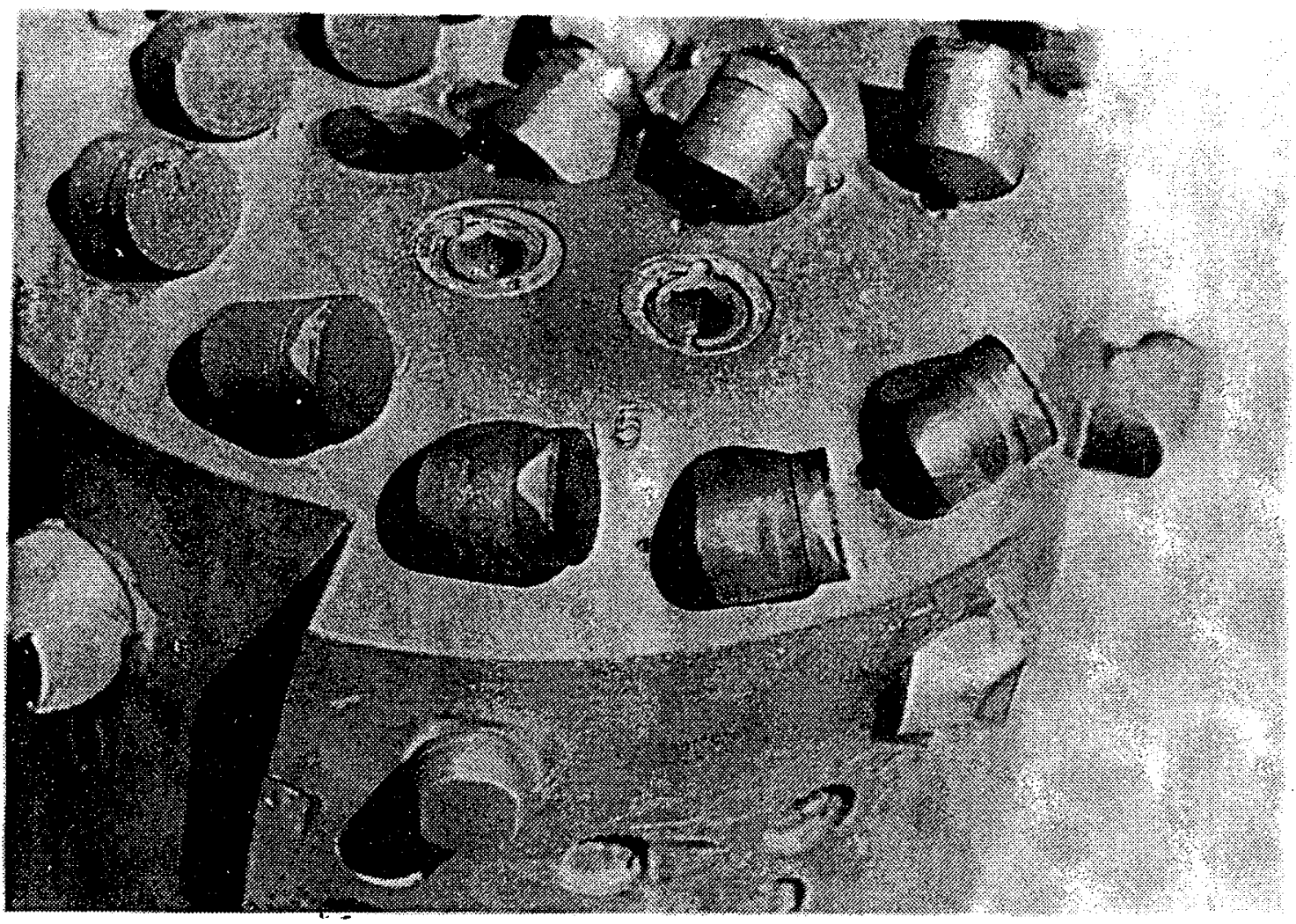

66-1/2" Sandia PDC Drag Bit After Cutting in Crab Orchard Sandstone and Sierra White Granite - Water Cooling 


\section{SPINNER/TEMPERATURE/PRESSURE WITH COLLAR LOCATOR}

This combination fluid velocity (spinner)/temperature/pressure tool also incorporates a collar locator. The temperature sensor is a standard thermistor used in other temperature probes. The spinner is identical to the fluid velocity probe and the pressure transducer is a Model CEC $1000-09$ rated at $343^{\circ} \mathrm{C}\left(650^{\circ} \mathrm{F}\right)$, compensated temperature range $24^{\circ} \mathrm{C}\left(75^{\circ} \mathrm{F}\right)$ to $315^{\circ} \mathrm{C}\left(600^{\circ} \mathrm{F}\right)$. The combination of special temperature compensation and careful calibration can provide accurate pressure measurements and still maintain infinite resolution.

Operating Specifications

Temperature rating

$572^{\circ} \mathrm{F}\left(300^{\circ} \mathrm{C}\right)$

Fluid Pressure

Length

Diameter

10,000 psi

138 in.

Weight

3.00 in.

$140 \mathrm{lbs}$.

For Additional Information:

Contact: Bert R. Dennis

Los Alamos National Laboratory

Mail Stop D448

Los Alamos, NM 87545

(505) 667-0728 


\section{TEMPERATURE PROBES}

Borehole temperature surveys provide diagnostic measurements and geothermal reservoir characterization. The measurements determine the thermal gradient along the borehole, locate borehole-fracture intersections, and measure thermal drawdown and recovery rates of the circulating systems. The temperature probes give diagnostic data during drilling, cementing, pressurization, and hydraulic fracturing operations. The sonde incorporates a high-temperature collar locator to tag casing signatures used to correct cable length.

The high-temperature probes, fabricated in various sizes, are wellbore survey tools that are readily fielded and allow online analysis of changing borehole conditions. All LANL temperature sondes use a thin-walled, stainless steel thermistor probe as the sensor.

\section{OPERATING SPECIFICATIONS}

$\begin{array}{llll} & \text { Standard } & \text { Slimline } & \text { Heavy Duty } \\ \text { Temperature Rating } & 662^{\circ} \mathrm{F}\left(350^{\circ} \mathrm{C}\right) & 662^{\circ} \mathrm{F}\left(350^{\circ} \mathrm{C}\right) & 662^{\circ} \mathrm{F}\left(350^{\circ} \mathrm{C}\right) \\ \text { Fluid Pressure } & 15,000 \mathrm{psi} & 15,000 \mathrm{psi} & 15,000 \mathrm{psi} \\ \text { Length } & 73 \mathrm{in} . & 112 \mathrm{in} . & 117 \mathrm{in} . \\ \text { Diameter } & 2.625 \mathrm{in} . & 2.0 \mathrm{in} . & 2.0 \mathrm{in} . \\ \text { Weight } & 84 \mathrm{lbs} & 76 \mathrm{lbs} & 230 \mathrm{lbs} \\ \text { No. of Conductors } & 4 & 6 & 4 \\ \text { Options } & \text { Collar Locator } & \text { Collar Locator } & \text { Collar Locator }\end{array}$

*For use in pressurized boreholes through flow control packoffs.

For Additional Information:

Contact: $\quad$ Bert R. Dennis

Los Alamos National Laboratory

Mail Stop D448

Los Alamos, NM 87545

(505) 667-0728

Reference:

Dennis, Bert R., Koczan, Steven, P., Stephani, Evon L.: High Temperature Borehole Instrumentation: Los Alamos National Laboratory, LA-10558-HDR, 1985.

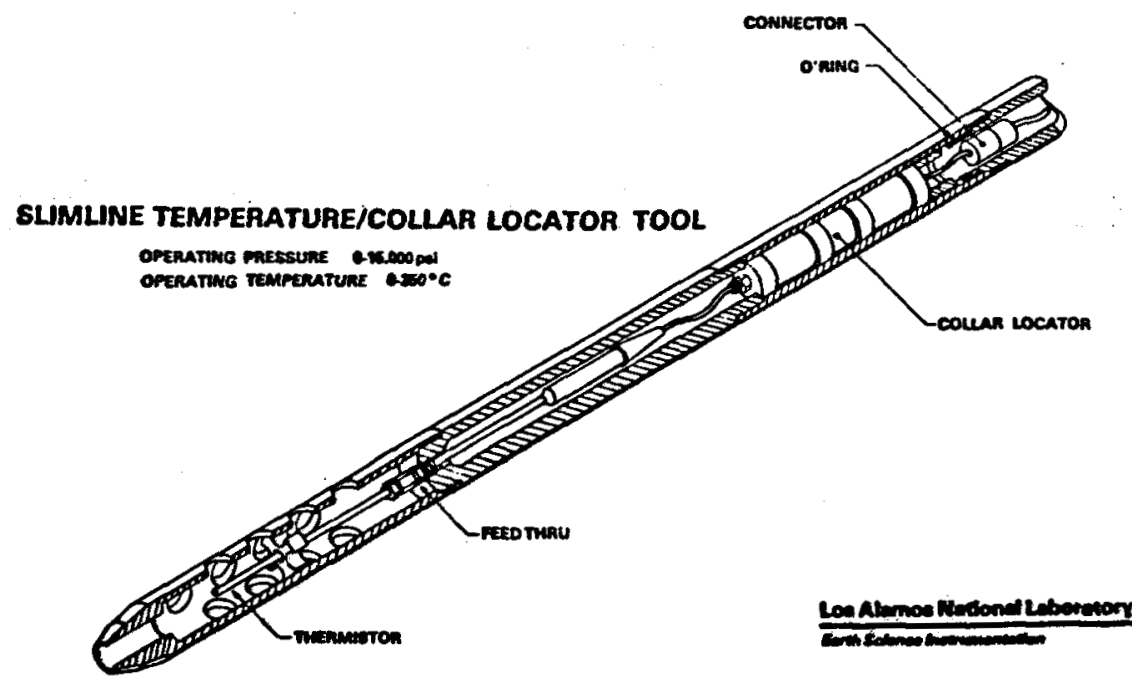




\section{WELLBORE INERTIAL NAVIGATION SYSTEM}

The Wellbore Inertial Navigation System (WINS) was developed and successfully tested by Sandia National Laboratories. Developed for directional surveying of geothermal, oil, and gas wells, the system uses gyros and accelerometers to obtain survey errors of less than 10 ft. $(3 \mathrm{~m})$ in a $10,000-\mathrm{ft}(300 \mathrm{~m})$ well. The concept and hardware is based on a system developed for flight vehicles, the Roll-Stabilized Inertial Measurement System (RIMS).

The WINS concept involves using a three axis inertial navigation system that is stopped periodically during a wellbore survey. The system is mechanized as a small diameter platform having a single gimbal to provide platform stabilization against rotation around the longitudinal axis. This platform and associated electronics represent the surveying tool. An associated uphole digital computer performs navigation and other computations.

Including its pressure barrel, the WINS is 4 in. $(10 \mathrm{~cm})$ in diameter and $20 \mathrm{ft} .(6.1 \mathrm{~m})$ long. Its battery pack has enough capacity for about 4 hours of operation.

The output of accelerometers and gyroscopes is manipulated to determine velocity and displacement. Cable length does not have to be measured and accuracy is not affected by misalignments between the system and the borehole. Another advantage is that the calculated velocity is useful for calibration purposes.

The system uses a single-gimbal platform, the advantages of which include the potential for small size, for mechanical simplicity, and for ease in calibrating the system. Also, compared to fully strapped-down systems, it is insensitive to high angular rates of the survey tool about its longitudinal axis. Site.

In March 1982, a WINS was successfully tested in a well at the DOE's Nevada Test

For Additional Information:

Contact: $\quad$ Stewart M. Kohler

Guidance and Control Division I 2334

Sandia National Laboratories

Albuquerque, NM 87185

(505) 844-5678

\section{References:}

Sandia National Laboratories. Inertial Navigation System for Directional Surveying. Sandia report SAND82-1668, 1982.

Sandia National Laboratories. The Wellbore Inertial Navigation System (WINS) Software Development and Test Results. Sandia report SAND 82-1954, 1982. 


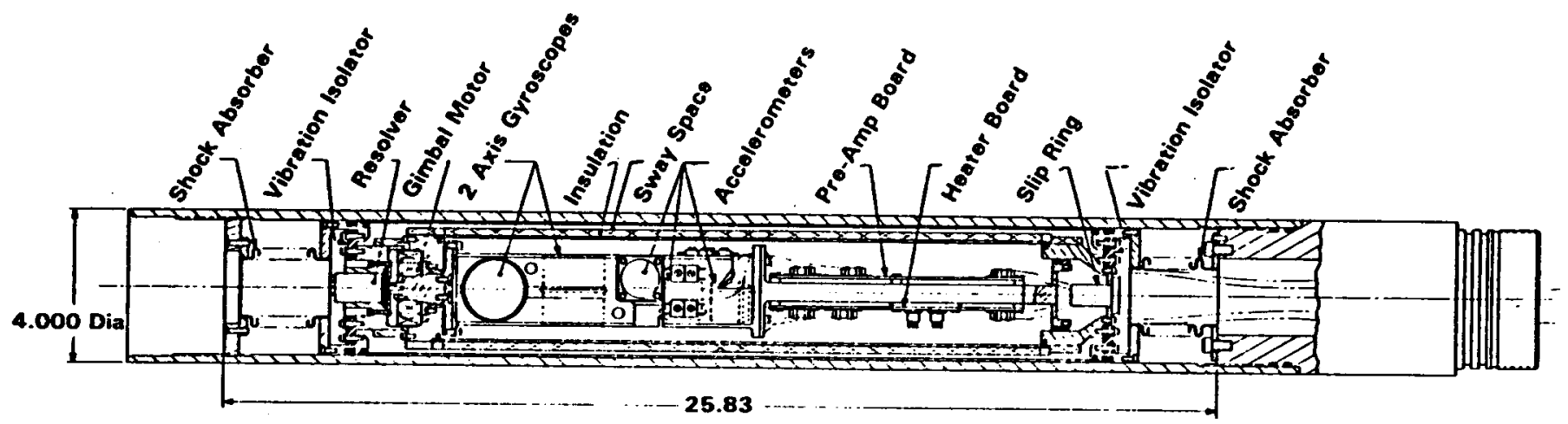

WINS SINGLE-GIMBAL PLATFORM 


\subsection{SOFTWARE}





\section{COMPUTER MODEL}

The CCC model (Conduction-Convection-Consolidation) numerically solves coupled heatand mass-flow equations for a liquid saturated porous or fractured medium, and computes one-dimensional consolidation of the simulated system. The model employs the integrated finite difference method in discretizing the saturated medium and formulating the governing equations. The deformation of the medium is calculated using the one-dimensional consolidation theory of Terzaghi.

The program requires fairly detailed input data. Included in the data requirements are information related to node geometry, initial conditions at the nodes, and the properties of the rock materials and the fluid. The code allows specification of up to twelve different materials. For each material the porosity, permeability, specific storage, thermal conductivity, heat capacity and density of the solid must be specified. These parameters may be constant or may vary with temperature and/or effective stress. The porosity and specific storage can vary with the effective stress, the permeability with both temperature and effective stress, and the thermal conductivity and heat capacity with temperatures only. These relations are specified by tables, which are interpolated during each time step.

Input parameters for fluid properties include viscosity, heat capacity, density and compressibility of water. A constant value of the compressibility must be specified; other fluid properties may also be assumed constant. However, the code provides the option of specifying the viscosity and heat capacity as a function of temperature, and density as a function of temperature and pressure. An empirical formula is used for the density function, while the code interpolates input tables for the appropriate value of the viscosity and heat capacity during each time step.

Output is provided according to specified times or specified time steps. The pressure, temperature, and first and second order derivatives are printed for each node, as is the total nodal pore volume reduction (consolidation). The fluid and energy fluxes are given for each node connection. The mass and the energy balance are also included in the output.

The computer code CCC has been carefully validated and applied successfully to problems related to geothermal energy, radioactive waste management and aquifer thermal energy storage.

For Additional Information:

Contact:

M. Lippmann

Earth Sciences Division

Lawrence Berkeley Laboratory

Berkeley, CA 94720

(415) 486-5035 


\section{References:}

Lippmann, M.J., Tsang C.F., and Witherspoon, P.A.: "Analysis of the Response of Geothermal Reservoirs Under Injection and Production Procedures." Society of Petroleum Engineers Paper 6537, presented at the 47th Annual California Meeting, SPEAIME, Bakersfield, CA, 1977.

Mangold, D.C., Lippmann, M.J., and Bodvarsson, G.S.: CCC User's Manual. Lawrence Berkeley Laboratory report LBL-10909, Prepared for the U.S. Department of Energy under contract W-7405-ENG-48, 1980.

Mangold, D.C., Tsang, C.F., Lippmann, M.J., and Witherspoon, P.A.: "A Study of a Thermal Discontinuity in Well Test Analysis." Journal of Petroleum Technology. Vol. 33, No. 6, 1981, pp. 1095-1105.

Tsang, C.F., Buscheck, T., and Doughty, C.: "Aquifer Thermal Energy StorageA Numerical Simulation of Auburn University Field Experiments." Water Resources Research. Vol. 17, No. 3, 1981, pp. 647-658. 


\section{ANALYZE COMPUTER CODE}

ANALYZE is a history matching program designed for the analysis of both interference tests and production tests in single phase, fluid saturated, hydrothermal reservoirs. The model operates to minimize the difference between a set of measured pressure points and a set of calculated pressure points, and then returns values for the reservoir transmissivity, storativity, and distance to a single linear reservoir boundary. The technique allows for simultaneous analysis of pressure data from up to twenty observation wells, each influenced by the production (and/or injection) of as many as $\mathbf{2 0}$ wells, with arbitrarily varying flow rates. An analytic solution calculates pressure responses in an isothermal, isotropic, homogeneous, porous media of constant thickness and infinite areal extent. The production well is modeled as a fully penetrating line source.

For Additional Information:

Laboratory Contact: Sally Benson

Earth Science Division,

Lawrence Berkeley Laboratory

Berkeley, CA 94720

(415) 486-5875

Sof tware Contact:

National Energy Software Center

9700 South Cass Ave.

Argonne, Illinois 60439

(312) $972-2000$

References:

McEdwards, D.G., and Benson, S.M.: ANALYZE User's Manual. Lawrence Berkeley Laboratory report LBL-10907, prepared for the U.S. Department of Energy under contract W-7205-ENG-48, 1980.

McEdwards, D.G., and Tsang, C.F.: "Variable Rate Multiple Well Testing Analysis." Proceedings, Invitational Well-Testing Symposium, Berkeley, October 19-21. 1977. Lawrence Berkeley Laboratory Report LBL-7027, pp. 92-99. 


\section{DEGEOWEL TWO PHASE FLOW COMPUTER MODEL}

A computer model of two phase (steam/water) flow in a geothermal well has been programmed and validated. Model predictions were compared with actual field test data taken from flowing geothermal wells throughout the western US. The model is written in FORTRAN IV for an IBM Series I minicomputer, but should be easily transferred to any machine with a comprehensive FORTRAN compiler. The model output consists of fluid temperature, pressure, quality (fraction of steam in the total fluid flow), and flow regime at successive stations up the wellbore to the surface.

The prediction of pressure drop in a two phase flow is much more complicated than in a single phase flow. Current techniques use empirical models that define the fluid state in terms of a flow regime, or pattern. The contribution of friction pressure drop and "holdup" (hydrostatic head term) to the overall pressure drop are the formulated for specific low regimes. The model was developed with several alternative correlations for friction and holdup, which were used to make prediction for wells that had been logged under flow conditions. Comparisons were made and the correlations that best matched the field data selected for final inclusion in the model.

The model also goes a step further in sophistication by incorporation the effect of fluid chemistry on the two phase flow characteristics of the well. Dissolved solids and particularly dissolved gases can have a significant impact on the onset of two phase flow, as well as on the transition points to other flow regimes. A water equilibrium program known as WATEQ has been added as a subroutine to predict chemical equilibrium in the brine as a function of pressure and temperature. This allows a user with a detailed analysis of the chemistry of a particular well to get more accurate predictions from the model.

A complete listing of the code is published in a report entitled "Two Phase Flow in Geothermal Wells," prepared for DOE by the Denver Research Institute. The model was created by Coury and Associates under subcontract to DRI.

For Additional Information:

Laboratory Contact:

James Butz

ADA Technologies

Honeywell Center, Suite 480

304 Inverness Way South

Englewood, CA 80112

(303) 792-5615

R\&D Firm Contact: G. Coury

Coury \& Associates

10088 West 32nd Avenue

Lakewood, CO 80211

(303) 232-3823 


\section{GEOPHYSICAL WELL LOG DATA BASE MANAGEMENT}

A suite of geophysical well logs is generally recorded in each geothermal exploration or development well. The interpretation of these logs may be difficult since the lithologies, alteration, fluids, and structures are generally different from the petroleum well $\log$ environment. The interpretation of a geothermal well $\log$ suite is facilitated by plotting all logs at a uniform downhole scale on a single chart for easy comparison with lithologic logs. The multiple $\log$ responses viewed simultaneously reduce the ambiguity of the geologic interpretation.

WELLOG is a sof tware system developed by the University of Utah Research Institute/Earth Science Laboratory to plot digitized data files, and manage these files in such a way to permit side-by-side plotting of multiple logs and cross plotting of up to three logs. The program is written for a PRIME 400 computer but can be modified for other systems. Several well $\mathrm{log}$ suites from high-temperature geothermal wells have been interpreted and the methodology and results disseminated.

Program WELLOG has been submitted to the National Energy Software Center (Argonne National Laboratory) for distribution at reproduction and handling charges. Additional technology transfer has been effected through the publication of technical reports and papers.

For Additional Information:

Laboratory Contact: Philip E. Wannamaker University of Utah Research Institute Earth Science Laboratory 391 Chipeta Way, Suite C Salt Lake City, UT 84108 (801) 524-3422

Sof tware Contact: National Energy Software Center Argonne National Laboratory 9700 South Cass Avenue Argonne, IL 60439 (312) $972-2000$

References:

Plotting Well Log Data. University of Utah Research Institute/Earth Science Laboratory Report ESL-45, 1980.

Glenn, W.E., Ross, H.P., and Atwood, J.W.: "Review of Well Logging in the Basin and Range Known Geothermal Resource Area." Journal Petroleum Technology. (May 1982): 1104-1118. 


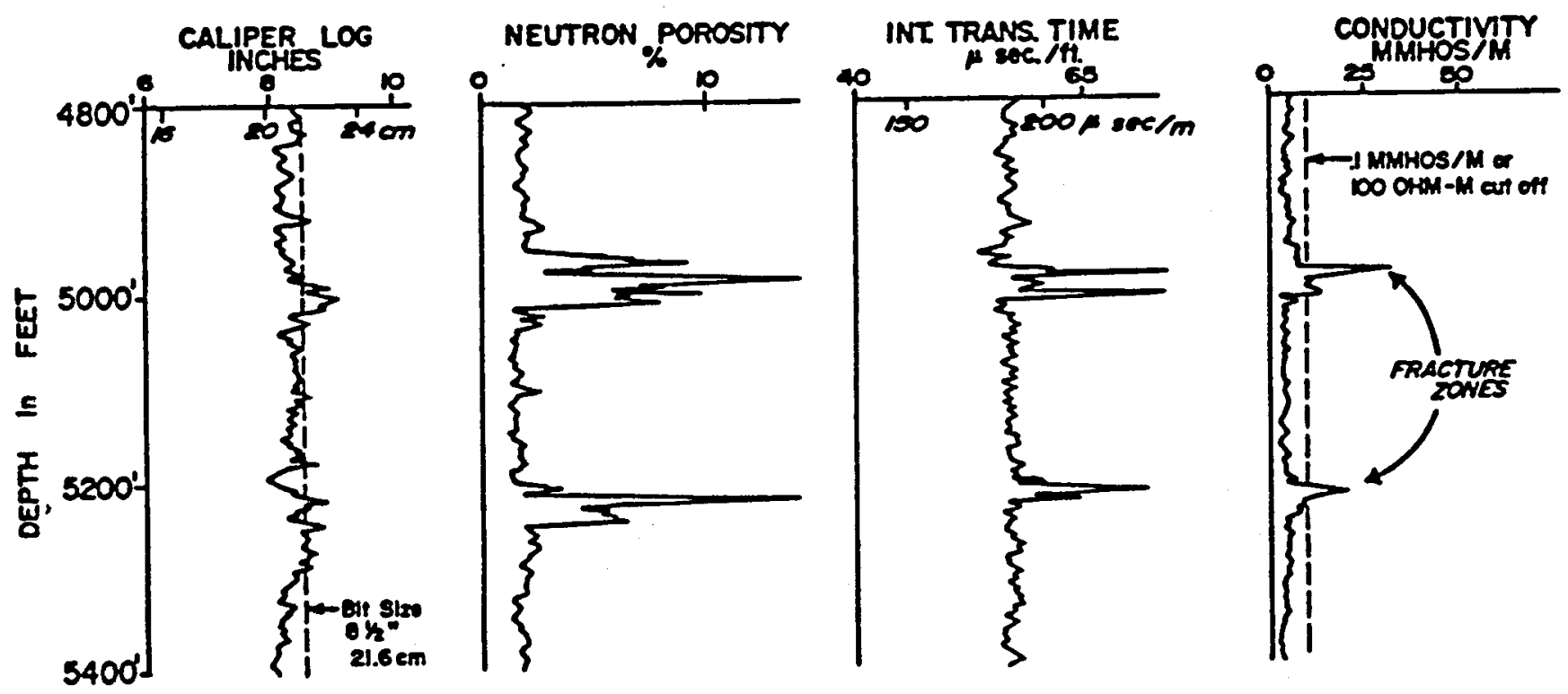

Selection of well logs from AHS Well 14-2, UT, illustrating induction log saturation and fracture response. 


\section{GEOTEMP2 COMPUTER MODEL}

GEOTEMP2 is a wellbore thermal simulator designed for geothermal well drilling and production problems. It is an extensively modified version of a previous model called GEOTEMP. Principal improvements incorporated into GEOTEMP2 include the ability to consider variable tubing flow areas; multiple fluids in the wellbore; deviated wellbore; air or nitrogen drilling; mist drilling; and two-phase steam production/injection. The major technical features and capabilities of GEOTEMP2 include:

1. The flowing stream energy balance is fully transient, that is, temperature predictions are accurate for short time intervals. The thermal analysis is not "steady state."

2. The thermal properties of the wellbore are fully described, including the steel, cement, and fluids in real well completions. The program is sufficiently general to describe most wells.

3. The temperature calculations in the wellbore and the surrounding formation are directly coupled.

4. The code has been designed with enough flexibility so that the complete life of a well from drilling to production, shut-ins for workovers, injection, etc. can be simulated in one computer run.

5. Several different wellbore fluids can be specified, such as drilling muds, packer fluids, cements, and production fluids. Further, more than one fluid may be in the wellbore at the same time, and the displacement of one fluid by another is automatically determined.

6. Two-phase steam production and injection can be simulated with GEOTEMP2. Flowing stream properties and flow types (e.g. slug flow) are determined as well as flow temperatures.

7. Air, nitrogen, and mist drilling can be simulated. GEOTEMP2 can switch between air and mud drilling at any time desired.

A major part of the GEOTEMP2 wellbore thermal simulator is the gas drilling/mist drilling capability. Previously, one of the few models available for gas drilling applications was that developed by R.R. Angel in the 1950's. The GEOTEMP2 gas drilling simulator goes far beyond previously available analyses by including a balance of aerodynamic drag and buoyancy forces on the cuttings, a fully described bottom-hole assembly, and the effects of mist addition and water influx.

The other major component of GEOTEMP2 is the two-phase steam injection and production model. The empirical flow correlations used to develop the flow model were based on the Orkiszewski vertical two-phase flow equations. These correlations are based on field data from over 200 wells and have been further verified by other measurements. The accuracy of the model is considered to be better than 10 percent. The steam thermodynamic correlations use the equations of state published by Keenan and Keyes in their current edition of steam tables.

The data required to fully describe a GEOTEMP2 problem include the following: tubing and casing interval depths and diameters; wellbore total depth, true vertical depth, depth of 
deviation, and maximum hole diameter; surface, bottomhole and intermediate depth temperatures; drilling fluid densities, plastic viscosities, and yield points.

The output from GEOTEMP2 is a temperature profile (temperature vs. depth) of the production/injection fluid in the wellbore at user-specified times and flow rates.

Temperature profiles are also given for five radial positions: the tubing and annulus temperatures, the first two formation temperatures, and the undisturbed temperature. All temperatures are given at depth increments of 200 feet.

GEOTEMP2 has been written in FORTRAN IV. Efforts have been made to keep the programming as conventional as possible so that GEOTEMP2 will run without modification on most computers. GEOTEMP2 was developed on a Prime $\mathbf{5 5 0}$ minicomputer, and clearly should run on most mainframe computers. Smaller 16 bit mini and micro computers probably will not be suitable because of the programs size.

For Additional Information:

Laboratory Contact:

Len Duda

Sandia National Laboratory

Geothermal Research Division

Albuquerque, NM 87185

(505) 844-2377

R\&D Contact:

R. Mitchell

Enertech Engineering and Research Co.

5847 San Felipe Road, Suite 1000

Houston, TX 77057

(713) $789-0055$

Sof tware Contact: National Energy Software Center

Argonne National Laboratory

9700 South Cass Ave.

Argonne, IL 60439

(312) $972-2000$

References:

Mitchell, R.F.: Advanced Wellbore Thermal Simulator GEOTEMP2 Research Report. Sandia National Laboratories report SAND 82-7003/1, 1982.

Wooley, G.R.: Wellbore and Soil Thermal Simulation for Geothermal Wells Development of a Computer Model and Acquisition of Field Temperature Data. Sandia National Laboratories report, 1978.

Mondy, L.A., and Duda L.E.: Advanced Wellbore Thermal Simulator GEOTEMP2 User Manual. Sandia National Laboratories report SAND84-0857, 1984. 


\section{GRITS COMPUTER MODEL}

The model is designed to perform preliminary economic evaluations of direct use geothermal energy applications. This enables the user to compare various designs and tradeoffs in performing various feasibility studies.

The model was designed as part of a study of geothermal energy development in the eastern United States and hence considers primarily low- and moderate-temperature resources. The user inputs the resource characteristics--temperature, flow rate, drawdown (these can be input as functions of time). The reservoir itself can be optionally modeled in terms of the pumping cycle, heat storage, transmissivity, and well radius to determine pumping energy and drawdown. The field can be designed for a single or multiple well system, with or without reinjection. Well costs are a function of depth. Downhole pumps are sized and costed, in terms of required flow rate and drawdown. Included is a resource assessment phase for which the user selects the cost and duration. During the utilization phase, the wells are considered to be drilled during the first year. The option exists of modeling in either a resource limited or demand limited mode.

The model is capable of analyzing both district heat and process applications, in either a single system or binary mode. There are options for a fossil fuel boiler as a topping system and a storage tank for load leveling. The user inputs the transmission system and cost, the number of houses, buildings, or required process loads. For heating applications, the demand is determined by hourly temperature data (available for 134 cities, or input by user). The capital costs are calculated based on sizes and designs of the items. Lifetimes of capital components are input. In the case of district heating, the rate of system construction can be varied. Operation and maintenance costs are a percentage of capital costs. Maximum project life is $\mathbf{3 0}$ years.

The program either calculates levelized cost of Btu's, or the net present value of the system and discounted payback period. The debt structure and interest rates are inputs, as is the discount rate. For comparison purposes as well as in determining yearly expenses, the user defines price trends for the costs of fuel and electricity. Taxes are not considered. Constant or current dollars may be used.

The program is interactive and allows the creation of a base case from which parameters may be varied for sensitivity studies. GRITS, Version 9 incorporates a number of earlier models developed in connection with the same study, including DSM, GREES, and BIGMAC. The program is written in FORTRAN.

The program is available as a listing or on tape from JHU-APL. Versions of the code have been written for IBM, DEC, and VAX systems. The latest edition of the user's guide is available through NTIS (order number PV 82246026). 


\section{For Additional Information:}

Contact:

F. Paddison

John Hopkins University

Applied Physics Laboratory

Laurel, MD 20810

(301) $953-5170$

References:

Weissbrod, R. et al.: Economic Evaluation Model for Direct Use of Moderate Temperature (up to $250^{\circ} \mathrm{F}$ ) Geothermal Resources in the Northern Atlantic Coastal Plain. JHU/APL, QM-79-124, June 1979.

Kroll, P., Barron, W., and Toth, W.: The Demand Specified Model for Direct Applications of Geothermal Energy: A User's Guide. JHU/APL, QM-80-131, December 1980.

Kroll, P. et al: BIGMAC: Basic Interactive Geothermal Model with Aquifier Characterization, a User's Guide. JHU/APL, QM-81-089, October 1981.

Kroll, P., and Kane, S.M.: GRITS (Version 9): Model Description and User's Guide. JHU/APL, QM-81-112, October 1981.

Kane, S.M., Kroll, P., and Nilo, B.: Sensitivity Analysis - Cost of Geothermal Energy. JHU/APL, QM-82-004, December 1982.

Kane, S.M. et al.: "GRITS - A Computer Program For Economic Evaluation of Geothermal Energy." ASHRAE Transactions, 88 Part I, (1982): 1323-1336. 


\section{PT COMPUTER MODEL}

The numerical simulator PT (for Pressure and Temperature) solves the mass and energy balance equations for saturated porous and/or fractured media. It also calculates rock deformation (subsidence) using the one-dimensional consolidation theory. The model is fully three-dimensional and uses the integral finite difference method for formulating the governing equations and discretizing the flow domain.

PT solves the governing equations simultaneously using Gaussian elimination. The model is very general, allowing for temperature dependent rock properties (such as permeability, thermal conductivities, and heat capacities), pressure and temperature dependent fluid properties, and arbitrary source or sink rates. It also has the option of solving very efficiently only one of the equations; the mass balance equation for isothermal problems, and the energy equation when the fluid flow is steady. The simulator has been validated against many analytic solutions and field experiments.

For Additional Information:

Contact: $\quad$ Gudmundur Bodvarsson

Earth Sciences Division

Lawrence Berkeley Laboratory

University of California

Berkeley, California 94720

(415) 486-4789

\section{References:}

Bodvarsson, G.S.: "Mathematical Modeling of the Behavior of Geothermal Systems Under Exploitation." Ph.D. thesis, University of California, Berkeley, 1982.

Bodvarsson, G.S., and Doughty, C.: PT - Users Manual. Lawrence Berkeley Laboratory report LBL-17896, 1985.

Lippmann, M.J., and Bodvarsson, G.S.: "The Heber Geothermal Field, California:

Natural State and Exploitation Modeling Studies," JGR Vol. 90, No. B1, p. 745-758.

Tsang, C.F., and Doughty, C.F.: Detailed Validation of a Liquid and Heat

Flow Code Against Field Performance. Lawrence Berkeley Laboratory report LBL-18833, 1985. 
NW

SE

NOWLIN NO.I

HULSE No.I

J.D.JACKSON No.I

GTW No.5

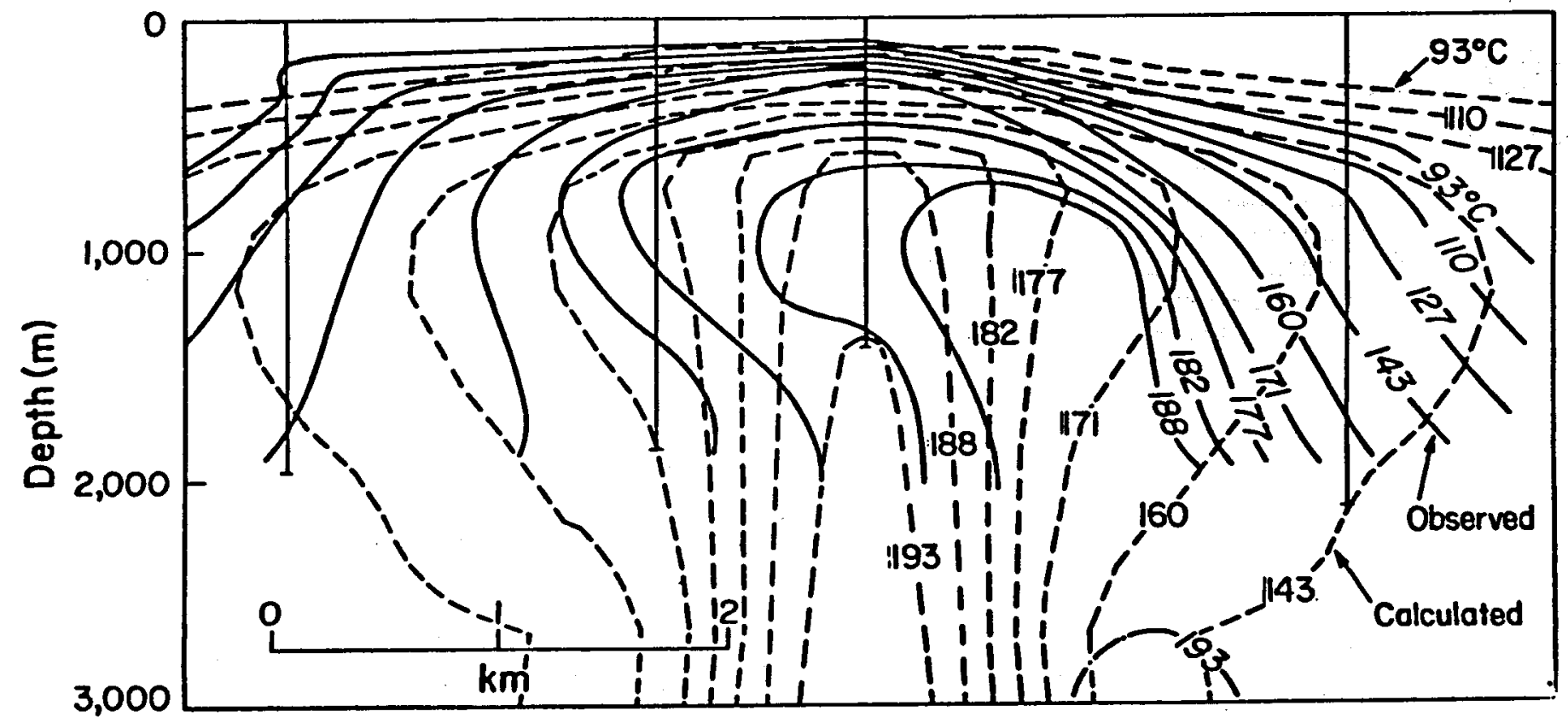

Comparison between observed and computed temperature distribution for the Heber geothermal field using the PT code. 


\section{PTC COMPUTER MODEL}

The two dimensional numerical simulator PTC was developed to analyze coupled hydrological-thermal-chemical process encountered in subsurface geological formations. PTC was developed from the code PT, which is capable of modeling three dimensional, coupled fluid and heat transport processes in Porous/fractured media. In addition to fluid and heat transport, the code PTC can simulate one component chemical transport processes, including the effects of convection, dispersion, and kinetics of mineral-water reactions.

To improve the accuracy of the numerical code, a numerical method consisting of a combination of the second-order Godunov method (explicit, monotonized upwind/central difference method) and operator splitting technique is introduced to solve the convectiondiffusion type equations arising from heat and chemical transport in porous media. Various test cases have been conducted to verify the accuracy of the numerical method. The results show that, in contrast to the conventional finite difference method, the present method greatly reduces numerical diffusion errors and guarantees no oscillations near fronts for high Peclet numbers. In particular, the method significantly reduces grid orientation effects. The code has been applied to some fundamental and practical problems including theoretical studies of natural convection in porous media, and kinetic reactions of silica water in geothermal systems.

For Additional Information:

Contact: Cheng Hsien Lai/Gudmundur Bodvarsson

Earth Sciences Division

Lawrence Berkeley Laboratory

University of California

Berkeley, CA 94720

(415) 486-4000

\section{References:}

Lai, C.H., Bodvarsson, G.S., and Witherspoon, P.A.: Numerical Studies of Silica Precipitation/Dissolution. Lawrence Berkeley Laboratory Report, LBL-18440, 1985.

Lai, C.H., Bodvarsson, G.S., and Witherspoon, P.A.: A Second-Order Upwind Differencing Method for Nonisothermal Chemical Transport in Porous Media. Lawrence Berkeley Laboratory Report LBL-19998, 1985. 


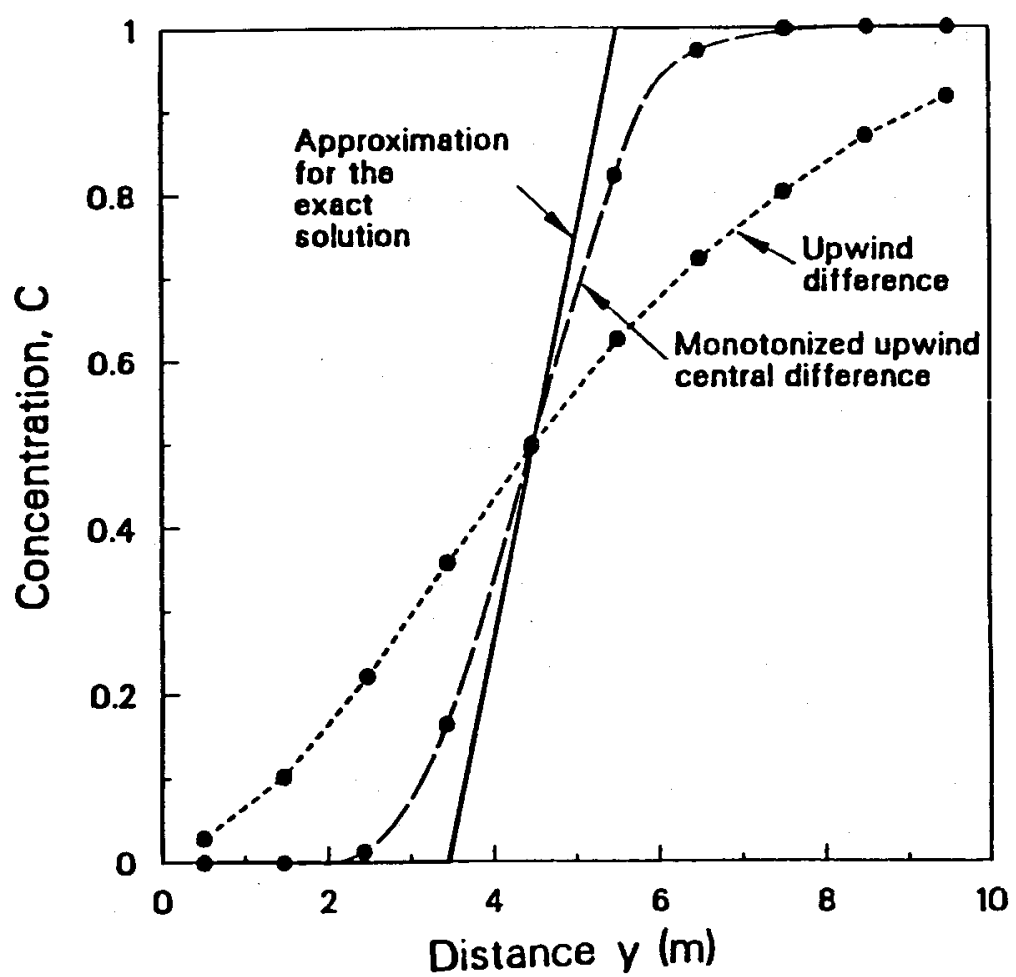

XCG $968-281$

Comparison of numerical solutions and the approximate solution for the grid orientation problem.

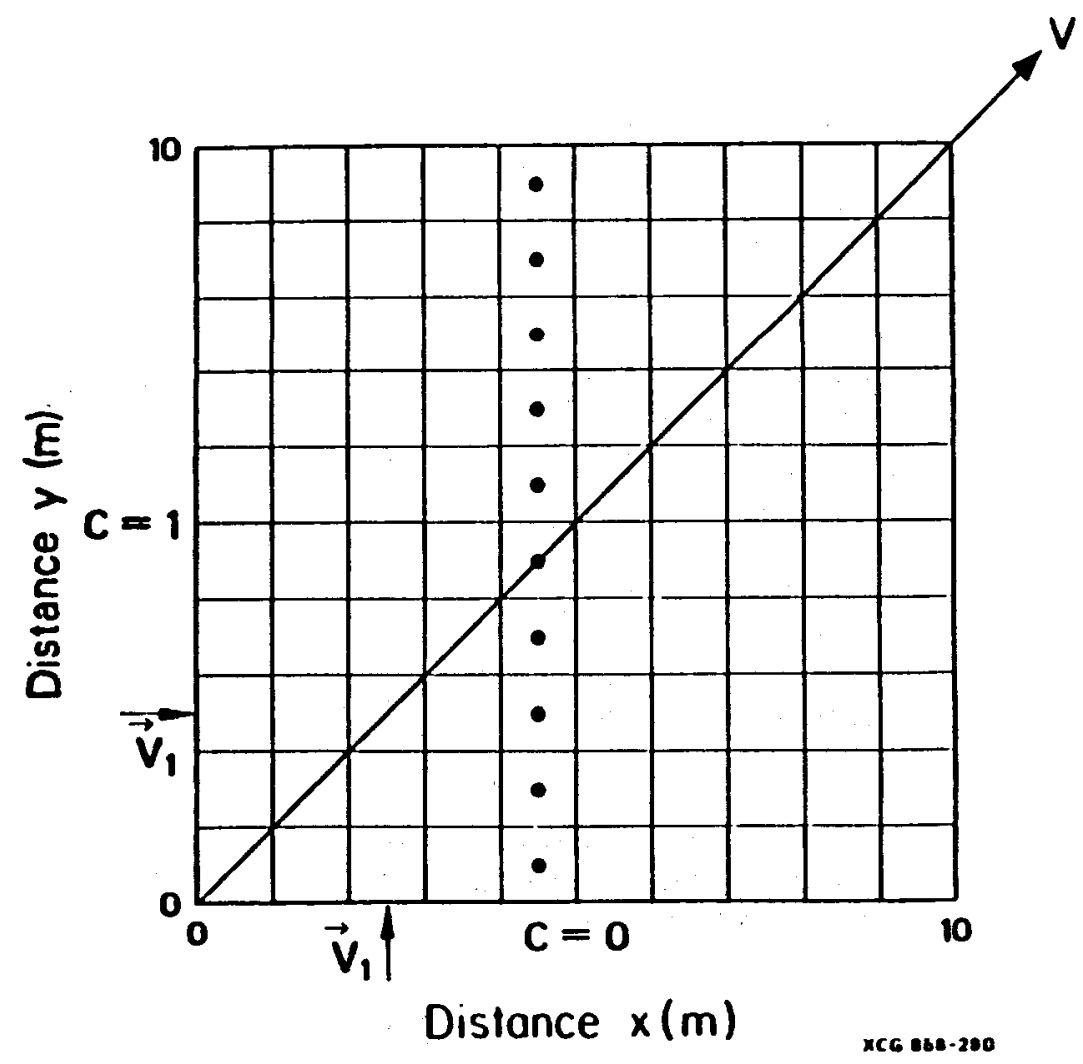

Schematic illustration of the benchmark problem for a flow field oblique to the computational grid at $45^{\circ}$. 


\section{SHAFT79 AND TOUGH COMPUTER SIMULATION MODELS FOR SINGLE- AND TWO-PHASE GEOTHERMAL RESERVOIRS AND NONISOTHERMAL GROUNDWATER FLOW}

SHAFT79 is a computer program for two-phase non-isothermal flow in permeable media. Based on an integral finite difference methodology, the program was originally developed for porous media flow. However, the recently developed method of "multiple interacting continua" (MINC) makes it possible to apply SHAFT79 to flow in fractured porous media, using simple preprocessing of geometrical data.

The numerical techniques used in SHAFT79 were designed to handle the strong coupling present between fluid and heat flow in two-phase systems and the extreme non-linearities encountered in phase transitions. All mass and energy balance equations are solved simultaneously, using Newton-Raphson iteration. The linear equations arising at each iteration step are solved by direct Gaussian elimination, using sparse storage techniques. Fully implicit time discretization is used, with all fluxes evaluated at the new time level. The thermophysical properties of water are interpolated from steam tables.

SHAFT79 has been verified against known analytical and numerical solutions. It has been applied to a variety of geothermal reservoir problems.

Recently a successor to SHAFT79 known as TOUGH has been completed, which in addition to geothermal reservoir evaluation is being used for studies of nuclear waste isolation in fully or partially saturated fractured media.

For Additional Information:

Laboratory Contact:

Karsten Pruess

Earth Sciences Division

Lawrence Berkeley Laboratory

Berkeley, CA 94720

(415) 486-4000

User Contact:

M.L. Jester

Bechtel Power Corp.

50 Beale Street

San Francisco, CA 94105

(415) 768-1234

Anthony Menzies

Geothermex, Inc.

5221 Central Avenue, Suite 201

Richmond, CA 94804

(415) 527-9876

Sof tware Contact:

National Energy Sof tware Center

Argonne National Laboratory

9700 South Cass Avenue

Argonne, IL 60439

(312) $972-2000$ 


\section{References:}

Pruess, K., and Schroeder, R.C.: SHAFT79 User's Manual. Lawrence Berkeley Laboratory report LBL - 10861, 1980.

Pruess, K.: GMINC - A Mesh Generator for Flow Simulations in Fractured Reservoirs. Lawrence Berkeley Laboratory report LBL-15227, 1983.

Pruess, K.: TOUGH Users Guide, Nuclear Regulatory Commission, Report NUREG/ CR-4645, June 1987. 


\section{TERZAGI COMPUTER MODEL}

TERZAGI is an integrated finite-difference computer program which solves for transient and steady-state fluid potentials in one-, two- or three-dimensional, saturated, deformable, confined systems having isothermal flow. It is applicable to artesian aquifers or petroleum reservoirs. The system can be made up of porous or fractured materials and can have complex geometry. The flow region can be heterogeneous, and anisotropy can be handled by orienting surfaces of volume elements normal to principal axes of permeability. Wellbore storage effects can be included as part of the flow region. The material properties such as permeability and matrix compressibility can be functions of pressure. Boundary conditions can be functions of potential or time. The program has been applied to problems related to ground subsidence, flow in fractured rocks, and hydraulic fracturing and has been extensively validated. The program is based on the integrated finite-difference method of Narasimhan and Witherspoon, and uses a mixed explicit-implicit iterative technique for solving the confined system flow problem.

TERZAGI is a saturated-flow version of the more general program TRUST (TRansient flow in Unsaturated and STrained porous media) which solves for both saturated and unsaturated flow in porous media.

Reservoir geometry can be specified in one, two or three dimensions, employing rectangular, cylindrical, axial or spherical symmetry. The volumetric properties of each grid block and the geometric properties of each node connection must be input. Each grid block can be assigned a different material, and the permeability and fluid storage coefficient of each material can either be specified as constants or calculated by the program using usersupplied functions relating these parameters to effective stress, void ratio or co-efficient of compressibility. The water density, viscosity and compressibility are all required inputs, as are the volumetric fluid generation rate from sources and sinks, initial pressure head, preconsolidation stress, and boundary conditions.

The value of pressure head and its time derivative at a selected node and the pressure heads and fluxes of all the grid blocks can be output at regular time intervals or cycles. Separate graphic programs can be used to process the output data.

The computer code is written in FORTRAN IV. The program was developed on the CDC 7600, but has been adapted to a number of computer systems. 106,000 octal words of memory are required for execution.

The TERZAGI model is available on magnetic tape from the National Energy Software Center. Program listings of the general model, TRUST, can be obtained from Lawrence Berkeley Laboratory.

\section{For Additional Information:}

Contact: $\quad$ T. Narasimhan Lawrence Berkeley Laboratory

Earth Sciences Division

Berkeley, CA 94720

(415) $486-4000$ 


\section{References:}

Narasimhan, T.N.: Program TERZAGI User's Manual. Lawrence Berkeley Laboratory report LBL 10908, 1980.

Narasimhan, T.N., and Witherspoon, P.A.: "An Integrated Finite Difference Method for Analyzing Fluid Flow in Porous Media." Water Resources Research, 12:1 (1976): 57-64.

Narasimhan, T.N., and Witherspoon, P.A.: "Numerical Model for SaturatedUnsaturated Flow in Deformable Porous Media, 1. Theory."Water Resources Research, 13:3 (1979): 657-667.

Narasimhan, T.N., Witherspoon P.A., and Edwards, A.L.: "Numerical Model for Saturated-Unsaturated Flow in Porous Media, 2. The Algorithm." Water Resources Research, 14:2 (1978): 255-261. 


\section{WELLBORE COMPUTER MODEL}

WELLBORE is a computer code for simulating transient, one-dimensional two-phase or single-phase non-isothermal fluid flow in a wellbore. The program uses a practical, implicit method to solve the finite difference approximation of the Navier-Stokes equations of mass, momentum, and energy conservation. Terms that would impose a severe time restriction, such as the compressibility terms, are evaluated implicitly while other terms are expressed in an explicit manner. The convection effects are represented with a conserving upwind finite difference. Both the slip between the phases (when the flow is two-phase) and the frictional losses are given as empirical correlations. The primary thermodynamic variables used in solving the equations are pressure and specific energy. An equation of state subroutine provides the density, quality, and temperature. The heat loss out of the wellbore is calculated by solving a radial diffusion equation for the temperature changes outside the bore. The code has been coupled with a single-phase radial flow reservoir model, and a version of the wellbore code coupled with the two-phase reservoir model was also developed (Miller et. al., 1982).

The important difference between this program and other reported wellbore models is that a steady state is not assumed, i.e., the mass into the well does not necessarily equal the mass out of it. Nevertheless, a steady state solution can be obtained. The transient wellbore model, with or without the reservoir model is useful in understanding well test results. The response of the fluid in the well can be eliminated in the analysis of well test data, i.e., given the wellhead flow rate or wellhead pressure and the downhole pressure, and sandface flow rate can be calculated. By knowing the actual reservoir flow, reservoir properties can be determined by using a variable well test analysis technique to reduce the transient pressure data. Also, one can solve for the flow in the bore during a complete shut-in to determine the effects of phase redistribution, which is not possible with a steady state model.

The heat loss out of the wellbore is a function of time. For each nodal point defined in the well, the temperature change in the surrounding rock is calculated by solving a finite difference approximation of the radial conduction equation, using a constant linear thermal gradient which is provided as input. The temperature in the rock is solved as a function of depth and radial position.

The single phase reservoir model provided with the program solves a finite difference approximation of the radial pressure diffusion equation using a variable grid as in the rock temperature calculation. The linking between the reservoir calculations and the wellbore calculation is done explicitly. The flow changes in the wellbore are calculated implicitly using the calculated value of the sandface reservoir pressure. Then the reservoir pressure is recalculated using the new value of the downhole pressure in the well, but the old value of the reservoir pressure. The exact mass flow rate that entered the wellbore leaves the reservoir in that time step calculation.

The initial conditions needed to start a problem with WELBORE are the downhole pressure, the specific energy flowing in from the reservoir and the mass flow rate out of the well. This is sufficient to give a steady state solution. For a transient calculation, either the bottom-hole pressure as a function of time must be known or the reservoir model can be used, keeping the pressure far from the well constant. In either case, it is necessary to provide the pressure, mass flow rate, or volume flow rate, as a function of time, at the wellhead. Other input parameters include the radius and length of the wellbore, the thermal conductivity and diffusivity of the surrounding rock, and the maximum and minimum temperatures of the geothermal gradient. If the reservoir model option is 
executed, the permeability, porosity, compressibility and thickness of the reservoir must be provided, along with the viscosity of the reservoir fluid.

The change in downhole and wellhead pressure is given for every other time step of the simulation. At user-specified time increments, the fluid properties in the wellbore are printed as a function of depth. These include pressure, energy, density, velocity and equilibrium density. In the case of two-phase flow, the steam and liquid velocities and the quality in place are also provided--again as a function of depth. At the same user\#specified times, the temperature profile in and around the bore, as well as the reservoir pressure around the bore, are given as functions of both depth and radial position.

WELBORE is written in FORTRAN IV and was developed on a CDC 7600. It has also been run on the CYBER 175. 55,000 octal words of storage are required for execution.

The WELBORE program including the single-phase radial flow reservoir model is available, along with associated documentation, from the National Energy Sof tware Center. An updated version of this code, for use on a personal computer, is distributed by Berkeley Group Inc. (BGI).

The version of WELBORE which includes the two phase reservoir model is obtainable from Lawrence Berkeley Laboratory.

For Additional Information:

Laboratory Contact:

Sally Benson

Earth Sciences Division

Lawrence Berkeley Laboratory

Berkeley, CA 94720

(415) 486-5875

R\&D Contact:

Ron Schroeder

Berkeley Group, Inc.

1330 Broadway, Suite 1450

Oakland, CA 94612

(415) $465-1744$

Sof tware Contact: National Energy Sof tware Center

Argonne National Laboratory

9700 South Cass Avenue

Argonne, IL 60439

(312) $972-2000$

References:

Miller, Constance W.: WELBORE User's Manual. Lawrence Berkeley Laboratory report LBL-10910. Prepared for the U.S. Department of Energy under contract W7405-ENG-48, 1980.

Miller, Constance W. et al.: "Wellbore Effects on the Analysis of Two Phase Geothermal Well Tests." Society of Petroleum Engineers Journal, June 1982. 


\section{VARFLOW COMPUTER CODE}

The VARFLOW computer program was developed to calculate the reservoir pressure response (drawdown) to geothermal production/injection. It is particularly useful in those applications where drawdown cannot otherwise be easily calculated: where more than one well is flowing and/or brines are also being injected, or where the flow rate from a well is not held constant. VARFLOW can be used to calculate the anticipated pressure response at up to ten observation wells because the flows occur at this number of production and/or injection wells.

The complete fortran code for VARFLOW is listed in the reference given below.

For Additional Information:

Contact: $\quad$ Sally Benson

Earth Sciences Division

Lawrence Berkeley Laboratory

Berkeley, CA 94720

(415) 486-5875

References:

EG\&G Idaho, Inc., and Lawrence Berkeley Laboratory. Low-to-Moderate

Temperature Hydrothermal Reservoir Engineering Handbook. Report ID0-10099.

Prepared for the U.S. Department of Energy under contract DE-AC07-76ID01570, 1982. 
3.3 PROCESSES/PROCEDURES 


\section{HYDRAULIC FRACTURING}

With increasing depth below the earth's surface, the combination of increasing pressure, temperature, and rates of most chemical reactions, tends to reduce the porosity, permeability, and free-water content of the formations encountered. Therefore, when temperatures high enough for commercial use are reached, the deeply buried rock is usually almost impermeable and substantially dry. The obvious and most economical method of extracting heat from such "hot, dry rock" is to somehow circulate water through it. This, however, requires creation of flow passages with a very large surface area for contact of water with the rock. The starting point of the U.S. Hot Dry Rock Program was the conclusion - since confirmed by studies in other countries - that the simplest, safest, and least expensive means of creating this type of permeability was hydraulic fracturing.

Hydraulic fracturing is done by using high-pressure pumps at the surface to develop sufficient pressure downhole to split the wall of the hole, just as excessive internal pressure splits a metal or plastic pipe. Once a crack is formed in the wall of the hole, it is easier to extend that crack than to form a new one. Therefore, once produced, a hydraulic fracture can be extended outward from the hole for hundreds of feet simply by continuing to pump water into it. The method is used hundreds of times a week all over the world to increase the flow of oil, natural gas, or water into production wells. However, it is usually done in relatively weak, sedimentary rock, at temperatures not much above atmospheric. Accomplishing it in dense, strong rock at very high temperatures is much more difficult and has required development of improved downhole equipment and fracturing techniques. Since very little of the water pumped into the well leaks off into the surrounding rock, controlled experiments of types never before attempted are possible. These are adding greatly to our understanding of the mechanisms of hydraulic fracturing and crack extension.

In order to produce hydraulic fractures at a particular depth, it is necessary to pressurize only a short section of the hole, requiring that section to be isolated from the rest of the hole above and below it. This isolation is usually accomplished by the use of packers, which seal against pressures of several hundred to a few thousand pounds per square inch and survive at temperatures that destroy rubber and most elastomers. An important contribution of the Hot Dry Rock Program is the development of packers that seal successfully for long periods against differential pressures of more that 5000 pounds per square inch at temperatures above $500^{\circ} \mathrm{F}$. These are of two types, one to seal against the relatively smooth inner surface of steel casing and the other to seal against the rough wall of an uncased well. Both types are finding industrial use outside the Hot Dry Rock Program in steam-flooding for recovery of petroleum and in stimulation of hot natural gas wells by hydraulic fracturing.

At depths of geothermal interest, hydraulic factures are expected to be vertical, substantially planar, and, in any given locality, oriented in a specific direction (determined by the stress field at depth in that area) Limited information from hydraulic=fracturing operations in oil and gas fields indicates that this is usually the case and, in the Hot Dry Rock Program, it has been true in fracturing experiments at depths between 2500 and 10,000 feet. At greater depths down to 14,000 feet, however, the fracture systems produced have been three-dimensional rather than planar and inclined rather than vertical. This unexpected fracturing behavior is attributed to the effects on the local stress field of a cooling magma body under an old volcano near the experimental site and to the presence in the granitic reservoir rock of a three-dimensional array of weakly sealed ancient fractures. If the reopened fractures are well connected, this array should be ideal for very large-scale heat extraction. Its physical nature and heat-transfer characteristics are currently being investigated by a variety of methods. 
For Additional Information:

Contact: Hugh Murphy

Los Alamos National Laboratory

Mail Stop J979

Los Alamos, NM 87545

(505) 667-3185 


\section{HOT DRY ROCK DRILLING TECHNOLOGY}

Drilling in a program to develop Hot Dry Rock geothermal energy technology has included drilling in granitic basement rock to temperatures as high as $315^{\circ} \mathrm{C}\left(600^{\circ} \mathrm{F}\right)$ and depths to $15,000 \mathrm{ft}$.

The drilling has been accomplished with modified petroleum industry rotary and positive displacement motor equipment and attention to the different downhole conditions.

Early drilling was done with treated water. A sepiolite mud used in the most recent redrilling campaign is given credit for better hole cleaning and drill string lubrication. Larger cuttings accompanied better penetration rates. Reduced torque and drill pipe wear were also experienced. However, temperature limitations for sepiolite were encountered. High temperature resistant properties of some materials have been improved since the first drilling experience. Continued improvement is still needed. Special designs of downhole stimulation hardware have been developed, in cooperation with manufacturers, to meet specific needs including casing and open hole packers. Different coring bits have been used with very promising results from a hybrid (rotary tungsten-carbide plus polycrystalline diamond compacts) bit.

\section{For Additional Information:}

Contact: $\quad$ Robert Hendron

Los Alamos National Laboratory

Mail Stop J979

Los Alamos, NM 87545

(505) 667-5061

References:

Smith, Morton C.: Major Accomplishments of the Hot Dry Rock Program 1970-1982. Los Alamos National Laboratory, 1983, LALP-82-37.

Smith, Morton C.: The Transfer of Hot Dry Rock Technology. Requested by, and submitted to, the U.S. Department of Energy-for possible publication in 1986. 


\section{SCALE CONTROL FOR GEOPRESSURED-GEOTHERMAL WELLS}

The precipitation of calcium carbonate (scale) when producing large amounts of hydrocarbons and saturated brine is a commonly encountered problem in production operations.

As part of an effort to understand the relationship between these operational problems, the saturation index usually assigned to wells, and the brine flow rate; a series of lab and field tests were conducted by the Gas Research Institute under contract to the DOE Geothermal Technology Division (GTD). The results showed that:

- there was a direct correlation between saturation index values and the precipitation rate that caused the operational problems;

- there was, conditionally, a direct correlation between the brine flow rate and scale formation; (no scale formed when the flow rate was under $15,000 \mathrm{~b} / \mathrm{d}$ );

- it was possible to remove scale formed on surface piping, and to prevent it from re-forming at higher flow rates, by pumping or 'squeezing' an acidic $15 \% \mathrm{HCl}$ 'inhibitor pill' through the pipes.

Further research was conducted in order to treat scaling that continued to form downhole. In June 1985 an experimental inhibitor pill made up of 300 barrels (B) of $15 \%$ w $\mathrm{NaCl}, 100 \mathrm{~B}$ of $6 \%$ inhibitor in $15 \% \mathrm{w} \mathrm{NaCl}, 100 \mathrm{~B}$ of $15 \% \mathrm{NaCl}, 100 \mathrm{~B}$ of $10 \mathrm{ppg} \mathrm{CaCl}$, and $20 \mathrm{~B}$ of $15 \% \mathrm{w} \mathrm{NaCl}$ was pumped incrementally into the Gladys McCall well formation. Production flow rate was gradually increased to $31,000 \mathrm{~b} / \mathrm{d}$ in July with no adverse effects. For the next seven months, more than 3.4 million barrels of brine was produced before scaling reoccured in the low pressure side of the system. A small amount of inhibitor was added to this side of the system allowing an additional 2 million barrels of brine to be produced.

In February 1986, a second inhibitor pill consisting of 100 barrels of $3 \%$ phosphonate solution was pumped downhole. Over 10 million barrels of brine has been produced since then with no apparent scaling. The average cost per barrel for the first 16.25 million barrels produced was $\$ 0.0043$ - a minimal amount compared to replacing or cleaning affected pipes everytime scaling occured.

The success of the scale control inhibitor represents an important technological triumph for the drilling and production community in general, as it is the first of its kind to be conducted in a quartz sand formation containing no calcite, and is another excellent example of successful cooperation between the GTD and private industry.

\section{For Additional Information:}

Contact: Susan Stiger

EG\&G Idaho Inc.

P.O. Box 1625

Idaho Falls, ID 83415

(208) 526-0457 


\section{SCALE INHIBITOR EFFECTIVENESS: THE INJECTION-BACKFLOW TECHNIQUE}

Mineral deposition in the wellbore and the adjacent reservoir rocks during injection of geothermal brines is a major concern of geothermal developers. The injection-backflow technique has been used at East Mesa to test the effectiveness of a calcite scale inhibitor and study the deposition of silica under actual injection conditions. The technique involves injecting thermal fluids into the reservoir, allowing the fluids to remain for a specified length of time and then backflowing the well. Chemical analysis of the waters is used to determine the extent of mineral deposition and inhibitor effectiveness.

This technique has several advantages over flow through (two-well) tests. These include the ability to assure recovery of injected fluids and to vary the effects of time. In addition, the tests are conducted under actual operating conditions, a feature not possible to duplicate in the laboratory.

DOE/GTD has supported research on the use and interpretation of data from injectionbackflow testing. The technique has been described in numerous reports.

For Additional Information:

Contact: $\quad$ Phillip M. Wright

University of Utah Research Institute

Earth Science Laboratory

391 Chipeta Way, Suite C

Salt Lake City, UT 84108

(801) 524-3422

References:

Adams, M.C.: "Tracer Stability and Chemical Changes in an Injected Geothermal Fluid During Injection-Backflow Testing of the East Mesa Geothermal Field." 10th Workshop of Geothermal Reservoir Engineering. Stanford (1985): 247-252.

Wright, P.M., Capuano, R.M., Adams, M.C., and Moore, J.N.: "Uses of Geochemistry with Injection-Backflow Testing in Geothermal Reservoir Studies" Geothermal Resources Council Transactions, Volume 8. (1984): 349-354. 


\section{TRACER INVESTIGATIONS FOR GEOTHERMAL INJECTION}

Tracers provide essential information to the geothermal developer on the rate of movement of thermal brines during production of a field. This information is needed to determine the rates of thermal decay of the field. Few non-isotopic tracers are currently available for use in high-temperature thermal systems, and, of those in use, little data is available on their stabilities.

DOE/GTD is currently supporting research and laboratory experiments designed to test the stabilities of a potentially new class of high-temperature tracers, the fluorinated hydrocarbons. Because of the large number of different possible fluorinated hydrocarbons, these compounds are ideally suited as tracers. The tracers are being tested at temperatures and in fluids typical of natural geothermal systems. Additional studies are being conducted on the stabilities of the organic dyes currently in use as tracers. Technology transfer on the tracer stability tests has been accomplished through reports and presentations.

For Additional Information:

Contact: Joseph N. Moore

University of Utah Research Institute

Earth Science Laboratory

391 Chipeta Way, Suite A

Salt Lake City, UT 84108

(801) 524-3422

References:

Adams, M.C.: "Tracer Stability and Chemical Changes in an Injected Geothermal Fluid During Injection-Backflow Testing at the East Mesa Geothermal Field." 10th Workshop on Geothermal Reservois Engineering. Stanford Univ. (1985): 247-252.

Capuano, R.M., Adams, M.C., and Wright, P.M.: "Tracer Recovery and Mixing from Two Geothermal Injection-Backflow Studies." Proceedings, Ninth Workshop on Geothermal Reservoir Engineering. Stanford Univ. 1983. 


\subsection{TEST FACILITIES}

$128 / 129$ 


\section{LOST CIRCULATION TEST FACILITY}

The DOE geothermal Lost Circulation Test Facility (LCTF) is located at Sandia National Laboratories in Albuquerque, New Mexico. The purpose of the facility is to test lost circulation materials under simulated conditions encountered in a geothermal well.

The LCTF consists of four parts: (1) a vessel, where testing is performed, plus the associated accumulators; (2) a mixing system; (3) a heating and pumping system; and (4) a pressurizing system. All of the components to the system allow the independent control of the test variables in order to simulate wellbore conditions.

The test vessel is a unit that can be heated independently of the circulating fluid and can accommodate a test core or simulated wellbore and formation up to $51 \mathrm{~cm}$ (20 inches) in diameter and $81 \mathrm{~cm}$ (32 inches) in length. Various formation conditions can be simulated in the vessel such as varying configurations of fracture and matrix permeability. Three "accumulators" are used to maintain the desired pressure in the wellbore and formation. An annulus accumulator controls the pressure in the wellbore, and the pressure of the fluid circulating system, and accomodates any increase in fluid volume due to heating. A filtrate accumulator controls pressure on the formation side of the test core and received that part of the LCM and fluid mixture which passes through the formation. A charge accumulator provides a "slug" of LCM and fluid to the test vessel. A nitrogen gas bottle system is used for pressurization.

A high-pressure mud pump, modified for use in high-temperature environments, is used to circulate the test fluid. The circulation fluid is heated in a tube and shell heat exchanger that uses 125 psi plant steam, and is rated at $850 \mathrm{~kW}\left(2.9 \times 10^{6} \mathrm{Btu} / \mathrm{hr}\right)$.

Two basic test modes, or combinations thereof, possible are:

- Slugging - A prepared fluid LCM is loaded into the charge accumulator and then forced through the core in the test vessel. The annulus accumulator received the fluid from the annulus, and the filtrate accumulator catches the fluid that passes through the simulated formation until an effective plug is created by the LCM.

o Circulating - The mud pump is used to pump the test fluid through the test vessel, mud tank, heat exchanger, and back to the mud pump. The function of the annulus and filtrate accumulators in this mode are the same as during "slugging."

All system functions are designed to be operated remotely from a control room either manually or by a computer system. A graphic representation of the system is shown as a schematic on a control/display board in the control room. The display board is equipped with monitor lights, digital meters, and control switches that allow the operator to monitor the status of motors, valves, pressures, fluid levels, and circulation rates. Test operations are normally controlled by the computer system.

In addition to testing LCM on formation configurations and properties, the facility may have applications in the following areas:

1. Mud Rheology -- a study of the effects of aging, temperature, pressure, and shear rate. 
2. Formation Damage -- a study of the effects of forward and reverse flow on LCM plugs, proppants, and drilling solids in different formulations.

3. Foam Properties -- a study of foam rheology in a borehole/drilling environment. Develop foams suitable for use as LCM media.

\section{For Additional Information:}

Contact: Glen Loeppke

Sandia National Laboratories

Geothermal Research Division

Albuquerque, NM 87185

(505) 846-0301

\section{Reference:}

Loeppke, G. and Caskey, B.: "Lost Circulation Test Facility." Geothermal Technology Development Program Annual Progress Report. October 1983. Kelsey, J. R. (ed). Sandia National Laboratories Report SAND 84-1028 (1984): 122-132.

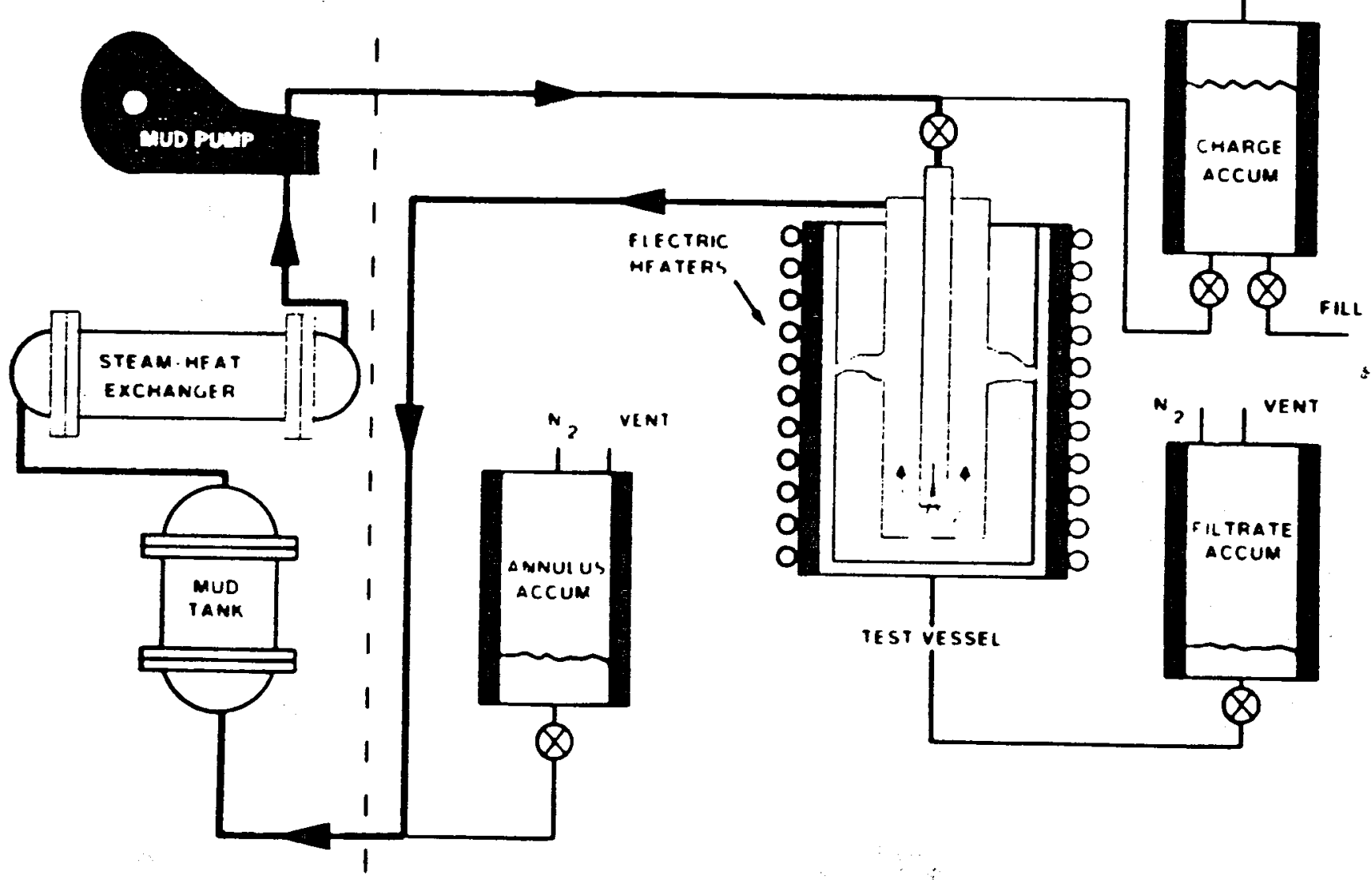

Lost Circulation Test Facility Flow Schematic 


\section{MAGMA SIMULATION FACILITY}

The purpose of the Magma Simulation Facility is to provide a unique facility to study the basic physical, electrical, and thermal properties of various molten rock types. The facility has been constructed in support of DOE's Magma Energy Program.

The facility is used for providing a high-temperature $\left(1600^{\circ} \mathrm{C}\right)$, high-pressure $(60,000$ psi) environment to study molten rock samples at in situ magma conditions. The facility has a sample chamber with a uniform hot zone $10 \mathrm{~cm}$ in diameter by $10 \mathrm{~cm}$ in height with a volume of 0.8 liter. Inert gas working pressure is 60,000 psi supplied by a two-stage intensifier. The pressure vessel is $56 \mathrm{~cm}$ in diameter, $109 \mathrm{~cm}$ in height and weighs $2273 \mathrm{~kg}$. Recording of data and operation of the facility are controlled through a remote computer station. Basic properties which can be measured are viscosity, electrical conductivity, and thermal conductivity.

For Additional Information:

Contact: James C. Dunn

Sandia National Laboratories

Geothermal Research Division

Albuquerque, NM 87185

(505) 844-4715

Reference:

Colp, J.L.: Magma Energy Research Project - Final report. Sandia National Laboratories report SAND 82-2377, 1982.

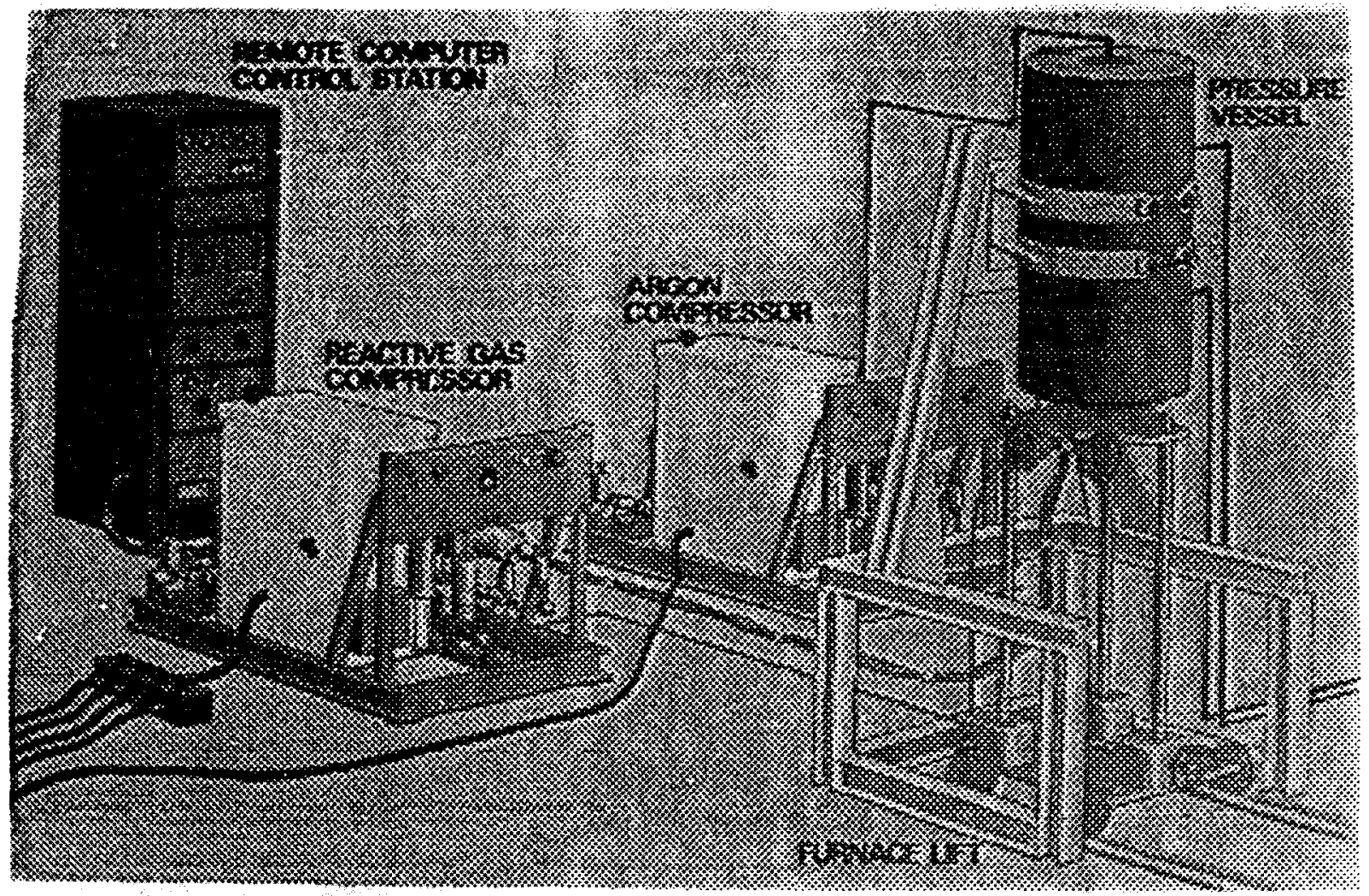




\subsection{HANDBOOKS}

133 


\section{GEOTHERMAL WELL DESIGN HANDBOOK}

This handbook presents a simplified procedure for estimating the performance of geothermal wells produced by natural flows. The user can determine wellhead fluid conditions (pressure, temperature and quality) using a hand-held calculator.

The user furnishes data on five parameters: (1) wellbore diameter, (2) depth of the well to the top of the producing zone, (3) temperature of the fluid at the top of the producing zone, (4) total mass flow rate of fluid in the well, and (5) pressure drawdown of the producing zone. Following the procedure (see figure), the user calculates what the condition of the thermal fluid at the wellhead would be, including fluid pressure, fluid temperature, and steam quality, or the percent by weight of steam in the flowing fluid.

It is expected that the data will be used most of ten in economic analyses to determine the feasibility of geothermal energy projects. Such analysis may include the examination of the number, size, and relative costs of several combinations of wellbore diameters and the determination of the required conditions to supply sufficiently high wellhead temperatures and pressures to a specific energyconversion process.

The procedure is based on parametric runs of a computer model that considers the flow of two phases (water and steam) in a well. The model had continually evolved as data from field test was used to validate the selection of flow correlations.

\section{For Additional Information:}

Contact:

James Butz

ADA Technologies

Honeywell Center, Suite 480

304 Inverness Way South

Englewood, CO 80112

(303) $792-5615$ 


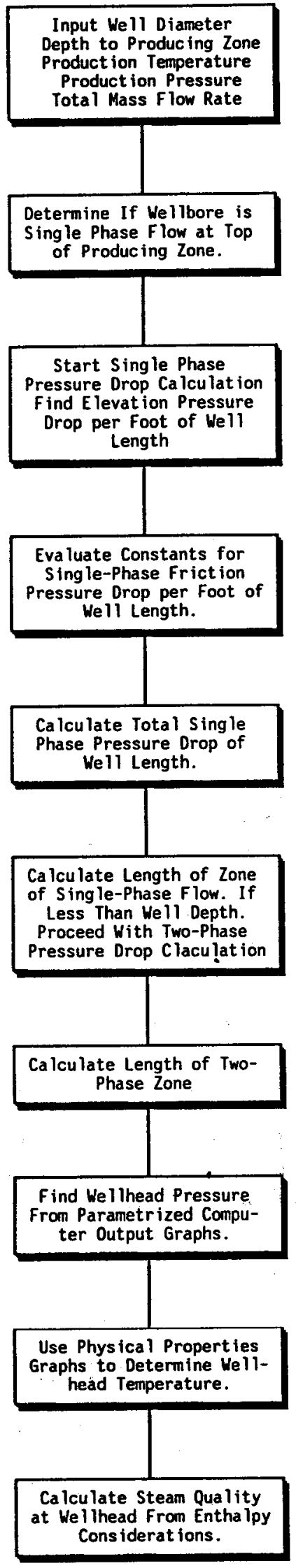

Procedure for finding conditions at a plamed geothermal wellhead is shown above. The procedure makes extensive use of reference graphs of physical properties. 


\section{CORROSION HANDBOOK FOR DOWNHOLE COMPONENTS}

This handbook summarizes the performance of materials and components used in downhole applications, with regard to the effects of corrosion, thermal degradation, and physical/mechanical properties problems caused by the geothermal environment. Discussion is limited primarily to materials and components developed and tested during specific research efforts, many of which have been governmentsponsored. Geothermal resources considered are hydrothermal (liquid and steamdominated), geopressured, and hot dry rock.

Materials and components described include equipment used over the entire lifetime of a well, as well as equipment that may be used over relatively short periods of time or intermittently. Long-term equipment includes casing, cement, and downhole production equipment. Short-term equipment includes equipment used during actual drilling and completion operations as well as during logging and evaluation of the resource. Only equipment which contacts the chemical environment of the geothermal well is considered.

For both long-term and intermittent use, limitations for current and proposed downhole equipment technology are defined from a materials perspective. Conclusions are based upon results of current research and may aid in the identification of areas where available well technology is still deficient.

Materials performance considerations based upon results of this generic research have applications to all of these resources. However, since the possible commercialization of geopressured and hot dry rock resources is still being investigated, use of this information will be most beneficial for application to liquid- and steam-dominated hydrothermal resources. These resources are currently being exploited commercially for thermal energy recovery and electrical power generation.

The handbook considers only materials for downhole use. It does not include a detailed technical description of the various activities involved in drilling, completion, logging, and production of a geothermal well. It is not a review of current downhole technology as used in the oil and gas industry, although materials problems and research efforts are discussed to point out the limitations of direct transfer of such technology to the geothermal environment. Economic assessment is also considered beyond the scope of this document.

For Additional Information:

Laboratory Contact:

L.E. Kukacka

Brookhaven National Laboratory

Upton, NY 11973

(516) 282-3065
R\&D Contact:

P.F. Ellis

Radian Corporation

8501 Mo-Pac Blvd.

Austin, TX 78759

(512) 454-4797

Reference:

U.S. Department of Energy. Corrosion Reference for Geothermal Downhole Materials Selection. Report No. DOE/SF/11503-1, 1983. 


\section{CHAPTER 4}

\section{MATERIALS AND BRINE CHEMISTRY}


4.1 HARDWARE 


\section{CEMENTS FOR GEOTHERMAL WELLS}

High-temperature hydrothermally cured cement formulations have been developed and field tested for use in geothermal well completion systems. Formulations meeting the following criteria are desired:

1. placement ability (that is, pumpability for 3 to 4 hours before hardening);

2. compressive strength greater than $1,000 \mathrm{psi}\left(6.9 \times 10^{5} \mathrm{~N} / \mathrm{m}^{2}\right)$ after 24 hours;

3. bond strength to steel casing greater than $10 \mathrm{psi}\left(6.9 \times 10^{3} \mathrm{~N} / \mathrm{m}^{2}\right)$;

4. permeability to water less than $10^{-4}$ darcy;

5. retention of impermeability and strength under prolonged exposure at $400^{\circ} \mathrm{C}$ to brine, flashing brine or dry steam;

6. compatibility with the drilling mud; and

7. noncorrosiveness to the steel casing.

The program represented the most comprehensive and thorough examination of the geothermal cementing problem undertaken thus far. It consisted of four phases: (1) problem definition, (2) cement research and development, (3) property verification, and (4) downhole testing.

To date, Phases 1 through 3 and downhole testing for 1 year in flowing brine at $214^{\circ} \mathrm{C}$ have been completed. The latter represents the first known test of cement samples downhole in a flowing geothermal well. However, downhole testing at a temperature of at least $300^{\circ} \mathrm{C}$ is considered essential before definitive conclusions regarding the hydrothermal stability at economically attractive well conditions can be made.

The results from the field test showed that 9 of the 16 cements exposed satisfied the test criteria. One was composed of an organic siloxane polymer and sand. The other eight formulations consisted of commercially available cements with high silica contents. The high silica content (44.8 to 60.7 parts by weight of cement solids) and low water content (40 to 50 parts per 100 parts by weight of cement solids) appear to be important factors leading to successful performance. The lowest weight cement to pass all tests had a slurry weight of $1.63 \mathrm{~g} / \mathrm{ml}(13.6 \mathrm{lb} / \mathrm{gal})$.

For Additional Information:

Laboratory Contact:

L.E. Kukacka

Brookhaven National Laboratory

Upton, NY 11973

(516) 282-3065

\section{Reference:}

"API Work Group Reports Field Tests of Geothermal Cements." Oil and Gas Journal 94 (February 11, 1985): 93-97.
Producer Contacts:

Halliburton Services

E.B. Nelson

Dowell Schlumberger

Houston, TX
D.K. Smith 


\section{HIGH TEMPERATURE ELASTOMERS}

The development of Y267 EPDM (ethylene propylene diene methylene) in 1979 by L'Garde, Inc. under DOE sponsorship, increased the operating limits for elastomeric parts from the ranges of $149^{\circ}-204^{\circ} \mathrm{C}$ and $260^{\circ}-316^{\circ} \mathrm{C}$. Based upon extensive testing by $L^{\prime}$ 'Garde and over 25 other organizations during the past 6 years, no better elastomer for geothermal service has been discovered. Cost reductions of up to several hundred times compared to those of other high temperature elastomers have resulted. Over 15 laboratory and 20 field case histories have been documented. Current uses include seals in logging tools, casing packers, gate valves, BOP rams, shock subs and jars.

In addition, the Y267 EPDM has been found to be a good candidate for service in high temperature oils, sour well conditions, Arctic climates at $-51^{\circ} \mathrm{C}$, and high temperature hydrocarbon gases.

At least three commercial sources of the material currently exist.

A promising chemical coupling system for bonding the Y-267 EPDM to steel has been identified. This system survives the Y-267 EPDM process very well and also survived brine aging at $260^{\circ} \mathrm{C}$ for 166 hours with respectable levels of adhesion.

For Additional Information:

Laboratory Contact:

L.E. Kukacka

Brookhaven National Laboratory

Upton, NY 11973

(516) 282-3065

R\&D Contact:

A. Hirasuna

L'Garde, Inc.

15181 Woodlawn Ave.

Tustin, CA 92681

(714) 259-0771

Producer Contact:

BJ-Hughes Rubber, Parker Seals, Precision Rubber Products

User Contact:

Donald Dressen

Los Alamos National Laboratory

Los Alamos, NM 87545

(505) 667-5061

References:

U.S. Department of Energy. Geothermal Elastometric Materials Technology Applications (GEM-TA) Program. DOE/SF/11537-1, (DE85003232) August 1984.

Brookhaven National Laboratory. Geothermal Elastometric Materials Technology Transfer (GEM-TT) Program. BNL 32936, March 1983.

Brookhaven National Laboratory. Elastomer Liners for Geothermal Tubulars. Y-267 EPDM Liner Program. BNL 40946, December 1987. 


\section{HIGH TEMPERATURE DRILLING MUD}

Muds typically used in drilling operations tend to gel at high temperatures. Also, their performance is significantly affected by additives and contaminants. Hence, there is a fundamental need to develop criteria for improving or defining new formulations for drilling, completing, and cementing geothermal wells. In addition, an improved understanding of the process of clay-cement conversion should lead to a better realization of the problems of displacing mud by cement in a geothermal wellbore.

The study of high-temperature clay-based drilling fluids began in FY 1979 at Texas Tech University Clay and Drilling Fluids Laboratories. Initial investigations included $\mathrm{x}$-ray and microscopic studies of the effects of various salts and elevated temperatures on clay morphology, specifically on the stability of attapulgite and the extent of attapulgite-tosmectite conversion. In FY 1980, studies were expanded to include sepiolite, saponite, and bentonite-the last of these is the most common clay additive in conventional drilling muds. The original project studying temperature-induced chemical, physical, and rheological changes of these clays was completed in 1981. Drilling fluids based on fibrous clays were found to be promising for geothermal drilling. Studies resulted in the formulating of muds which, to $800^{\circ} \mathrm{F}\left(420^{\circ} \mathrm{C}\right)$

o do not gel,

o retain adequate viscosity, and

o control fluid loss.

One of these mixtures is sepiolite/Wyoming bentonite/high- and low-molecular weight sodium-polyacrylate (SPA). The findings of this research has led to the marketing of a drilling mud by NL Baroid.

The follow-on effort to the initial study was an investigation of clay-tocement conversion with the possible goals of using mud-in-place as cement or of alleviating the restriction of complete mud displacement by cement. This effort was concluded in 1983 . By controlling the additives in the mud, it should be possible to design the mixture to "set up" in the casing borehole annulus. This idea has not met with wide industrial approval because of potential problems with the mud hardening too fast, etc. A different, more acceptable, approach would be to use the clay-cement conversion to advantage in providing the capability of good cement jobs even without total mud displacement. If the mud which remained as channels in the cement would, in time, turn to cement, the casing would be adequately supported.

Current work is studying additives that may improve the high-temperature properties of bentonite based muds and determining the high-temperature characteristics of saponite.

For Additional Information:

Laboratory Contact: Len Duda

Sandia National Laboratories

Geothermal Research Division

Albuquerque, NM 87185

(505) 844-5678 
R\&D Contact:

N. Guven

Texas Tech University

Lubbock, TX

\section{References:}

U.S. Department of Energy. Geothermal Technology Development Program Annual Progress Reports--FY 1980. FY 1981, and FY 1982.

Guven, N. et al.: Clay Based Geothermal Drilling Fluids. Sandia National Laboratories Report SAND82-7037, 1982. 


\section{IMPROVED WELL CASING MATERIAL}

Rapid corrosion of well casing is a serious problem in the development of many geothermal resources. One possible solution to this problem is the application of a high alloy protective liner to the inner surface of conventional casing material. A recently developed high nitrogen-bearing stainless steel may be an excellent candidate for this application.

At Brookhaven National Laboratory, the pitting resistance of a series of experimental stainless steels with varying amounts of nickel, chromium, molybdenum, manganese, and nitrogen and several commercial stainless steels and nickel based alloys was studied in highly concentrated chloride media. One of the experimental alloys (designated Alloy 30) with a nominal composition (wt\%) of $20 \mathrm{Ni}, 24 \mathrm{CR}, 6 \mathrm{Mo}, 0.44 \mathrm{~N}$, and balance Fe has been shown to have exceptional resistance to localized corrosion. This resistance is superior to that of commercial $\mathrm{Fe}-\mathrm{Cr}-\mathrm{Ni}$-Mo alloys and at least equal to that of more expensive Ni-Mo$\mathrm{Cr}$ alloys such as Alloy C-276. Alloy 30 also shows significant improvement over laboratory stainless steels with somewhat lower Mo and $\mathbf{N}$ concentrations.

For Additional Information:

Contact: $\quad$ D. van Rooyen

Brookhaven National Laboratory

Upton, NY 11973

(516) $282-4050$

Reference:

National Association of Corrosion Engineers. Properties of Nitrogen - Containing Stainless Alloy Designed for High Resistance to Pitting, Corrosion. Corrosion-NACE, Vol. 41, No. 4, April 1984. 


\section{POLYMER CONCRETE PIPE}

Polymer concrete (PC) is a composite material which has strength and durability characteristics greatly superior to those of portland cement concrete and better durability in geothermal fluids than steel and some high alloy steels. It has been successfully tested in the laboratory and in the field in brine, flashing brine, and steam at temperatures up to $260^{\circ} \mathrm{C}$ for exposure periods up to 960 days. Industry tests have confirmed the results.

When used in conjunction with glass fiber reinforcement, low weight piping suitable for service at $125^{\circ} \mathrm{C}$ and 125 psi can be produced at a cost comparable to or less than that for Schedule 40 steel. Connections can be made with slip joints for very low-pressure applications and flanged joints for higher pressure service.

For service at temperatures above $125^{\circ} \mathrm{C}, \mathrm{PC}$ liners centrifugally cast on carbon steel pipe are recommended. Processes were developed for applying the liners on straight pipe sections and fittings, and for closure of field joints.

As part of the economic study, a full-scale production plant capable of producing about $3000 \mathrm{ft}$ of lined 12-in. diameter pipe per day was outlined. The capital cost of the plant was estimated to be about $\$ 8.6$ million with a calculated return on investment of $15.4 \%$. Cost of piping a geothermal plant with PC and PC-lined steel pipe was calculated to be \$1.21 million, which compares favorably with a similar plant piped with alloy steel piping at a cost of $\$ 1.33$ million. Life-cycle cost analysis indicated that the cost of PC-lined steel pipe would be $82 \%$ of that of carbon steel pipe over a 20 -year plant operating life.

For Additional Information:

Laboratory Contact:

L.E. Kukacka

Brookhaven National Laboratory

Upton, NY 11973

(516) 282-3065

R\&D Contact:

Albert O. Kaeding
Quazite Corporation
5515 Gasmer
Houston, TX 77035
(713) $723-5310$

References:

Design and Fabrication of Polymer-Concrete Pipe for Testing in Geothermal Energy Processes. Final Report. BNL 33130, July 1981.

Design and Fabrication of Polymer-Concrete-Lined Pipe for Testing in Geothermal Energy Processes. Final Report. BNL 33019, July 1981.

Concrete Polymer Materials as Alternate Materials of Construction for Geothermal Applications. Field Test Evaluations. BNL 25957, 1979. 
4.2 TEST FACILITIES

$147 / 148$ 


\section{TWO-PHASE FLOW FACILITY}

Experimental tests on two-phase flow in geothermal wells in the past have been performed on either flowing wells or as laboratory tests using small-diameter tubes with flowing air-water mixtures. Tests in flowing wells are severely limited in range and accuracy because of the practical difficulties involved in field operations. The laboratory air-water mixtures are technically two-component two-phase flows, and lack evaporation and condensation present in a true single substance two-phase flow. The purpose of the facility is to more closely model a natural system in the lab and improve accuracy over the field tests.

The Two-Phase Flow Research Facility is specifically designed to address flow problems of relevance to the geothermal industry. The facility, or flow loop, allows the study and analysis of the flow of fluid at or near its saturation point and in the two-phase region. The important feature of the facility is that it is dedicated to two-phase flow of a single substance as opposed to two component two-phase flow. Experiments are performed at low temperatures and pressures using Freon R-114 as the working fluid. Extrapolations are then made to approach steam-water systems by using dynamic similitude.

Fluid can flow in horizontal, vertical or inclined directions. Visual observations of the flow patterns and the determination of frictional pressure losses can be made in a wide range of flows, from purely liquid, through two-phase flows of varying quality, to pure vapor flow. Investigations of flow in a typical geothermal well can be made including the step changes in area that occur as the well casing diameter changes.

For Additional Information:

$\begin{array}{ll}\text { R\&D Contact: } & \text { P.F. Maeder } \\ & \text { Brown University } \\ & \text { Providence, RI }\end{array}$

Reference:

Hanold, R.J.: Geothermal Well Stimulation Program. Geothermal Pump Program. EFP System for Carbonate Scale Control. Two-Phase Flow Program Progress Report and Status Review. Los Alamos National Laboratory, unpublished report, 1983. 


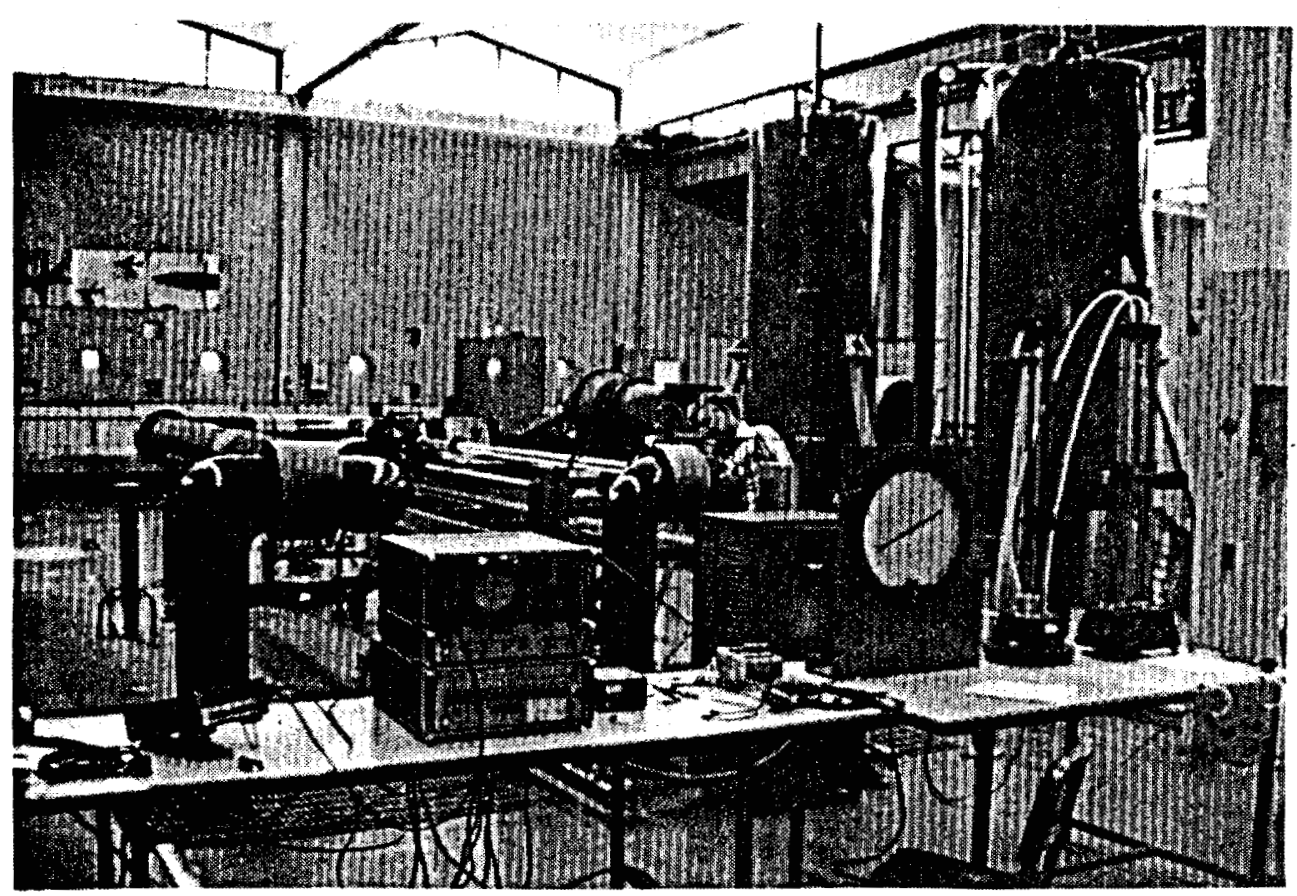

Photograph of the Two-Phase Flow Research Facility 


\subsection{HANDBOOKS}

$$
151 / 152
$$





\section{GEOTHERMAL MATERIALS SELECTION HANDBOOK}

This handbook is a collection and interpretive summary of data on materials performance in various geothermal fluids. The information may alleviate lengthy testing of large numbers of materials at each new geothermal site. It provides help in screening potential construction materials using past experience, and provides some guidelines for selecting materials for surface equipment of future geothermal energy systems.

The handbook also establishes a framework of background information that defines an approach to materials selection. It identifies the utilization modes and equipment used to produce electricity and process heat, discusses the importance of fluid chemistry, and defines the forms and mechanisms of corrosive attack that have been observed in geothermal process streams.

Materials performance in liquid- and steam-dominated world resources, with maximum temperatures within the economic electric power generation and direct utilization ranges is summarized. Predictions about the corrosiveness of fluids from these resources can be made based on the fluid characteristics. Fluid and steam transmission lines, separators, heat exchange and energy conversion equipment, heat rejection equipment, and surface components of disposal systems are considered.

Useful data on materials performance are the results of process industries operations using saline fluids as well as geothermal power plants and direct utilization systems. Materials performance data are available for seawater desalination plants, foreign operating geothermal power plants (in Iceland, Italy, Japan, Mexico, and New Zealand), and The Geysers, a U.S. power plant utilizing a steam-dominated resource. Materials performance data are also available from direct utilization systems in the United States and abroad. The selection of suitable materials which will withstand a specific corrosive environment is technologically and economically complex. This manual provides technological guidance for such materials selection in above-ground systems when used, as shown in the figure.

Economic assessment is outside the scope of this manual.

For Additional Information:

Laboratory Contact:

L.E. Kukacka

Brookhaven National Laboratory

Upton, NY 11973

(516) 282-3065

R\&D Contact:

P.F. Ellis

Radian Corporation

8501 Mo-Pac Blvd.

Austin, TX 78759

(512) 454-4797

References:

U.S. Department of Energy. Materials Selection Guidelines for Geothermal Energy Utilization Systems. Report No. DOE/RA/27026-1, 1981. 


\section{CHAPTER 5}

\section{DIRECT USE}

$154 / 155$ 
5.1 DATA BASES

$156 / 157$ 


\title{
DIRECT USE INFORMATION SERVICES
}

Under a U.S. Department of Energy program, the Geo-Heat Center (GHC) has available for distribution topical papers (36), technical reports (20), and direct use feasibility studies (73) covering space and domestic water heating, space cooling, district heating, greenhouses, aquaculture, industrial processing, and small scale binary power generation. The GHC Geothermal Technology Library has available, on a loan basis, nearly 4,000 technical volumes, resource maps, equipment supplier catalogs, and videos (tapes and slides). This collection constitutes one of the largest sources of technical direct use information available.

A GHC Quarterly Bulletin informs the geothermal technical community and the public on progress in research and development activities of the users of low and moderate temperature geothermal resources. This periodical provides valuable "how to" articles on various geothermal applications and equipment. It has been published since 1975 and currently has over 2,000 subscribers. Back issues of this periodical are available upon request.

Center staff are available to make direct use presentations on topics such as system design, economic considerations, and successful project examples (case histories) to inform both lay and technical audiences. Individual and group tours will be arranged for the Klamath Falls district heating system, campus geothermal heating/cooling system, residential, and local greenhouse applications.

\section{For Additional Information:}

Contact:

\author{
Paul J. Lienau \\ Geo-Heat Center \\ Oregon Institute of Technology \\ Klamath Falls. OR 97601 \\ (503) 882-3583
}

\section{References:}

Geo-Heat Center. Publications Request Form. 1988, available from Geo-Heat Center.

Lienau, Paul; ed. Geo-Heat Center Quarterly Bulletin. Klamath Falls: GeoHeat Center; 1975-1988. $10 \mathrm{~V}$. 


\section{DIRECT USE TECHNICAL SERVICES}

Under a U.S. Department of Energy program, Geo-Heat Center staff can provide assistance to those actively involved in geothermal direct use development. This assistance can range from answering technical questions and simple consultations on methods, equipment and applications to providing technical and engineering economic feasibility studies. Applications areas include space heating, district heating, greenhousing, industrial processing, aquaculture, and water source heat pumps. Assistance can consist of resource evaluation based on published information, well temperature profiling, water testing, application of engineering principles to determine development options and costs, basic equipment selection for type, size and materials, initial and operating cost estimation, life cycle costing and related items.

Over 70 published feasibility studies are available as examples and to stimulate ideas and discussions.

\section{For Additional Information:}

Contact: Gene Culver

Geo-Heat Center

Oregon Institute of Technology

3201 Campus Drive

Klamath Falls, OR 97601

(503) 882-3583

References:

Geo-Heat Center. Publications Request Form, 1988; available from Geo-Heat Center. 


\section{DOWNHOLE HEAT EXCHANGER PERFORMANCE}

In 1978, the Geo-Heat Center and Oregon State University completed the first definitive engineering study on DHE performance. That work serves as the basis for the limited DHE research being carried on throughout the world even today. The Geo-Heat Center has completed a limited amount of work since then, but most current research is in foreign countries and includes the use of heat pipes and very large $(6 \mathrm{MWt})$ applications.

The Geo-Heat Center is currently gathering information on designs, applications and research throughout the world. That information should be available by winter of 1988 .

\section{For Additional Information:}

Contact: Gene Culver, Associate Director

Geo-Heat Center

Oregon Institute of Technology

Klamath Falls, OR 97601

(503) 882-3583

\section{References:}

Culver, G.G. and Reistad, G.M.: Evaluation and Design of Downhole Heat

Exchangers for Direct Application, report to USDOE. 1978; available from Geo-Heat Center.

Allis, R.G.: A Study of the Use of Downhole Heat Exchangers in the Moana Hot Water Area, Reno, report to USDOE. 1981; available from the GeoHeat Center.

Pan, He-Song: Geothermal Downhole Heat Exchangers, Thesis to University of Auckland. 1983, available from Department of Mechanical Engineering, University of Auckland, New Zealand. 
5.2 PROCESSES/PROCEDURES

$162 / 163$ 



\section{MINERAL HEAP - LEACHING PROCESS}

The University of Nevada Las Vegas Division of Earth Sciences has been evaluating the feasibility of using geothermal heat energy to enhance gold and silver heap-leaching operations. The investigation, originally funded by the Department of Energy, indicated that the abundant geothermal energy sources in Nevada could provide important benefits to the mining industry in general and to Nevada gold mines in particular.

The major operations in Nevada are open pit mines that use a process known as heapleaching to extract gold and silver from low-grade ore. The process entails mining, crushing, grading, and stacking the ore, which is then soaked with a dilute solution of sodium cyanide. The cyanide dissolves both gold and silver which is eventually recovered from solution by additional processing. Heap-leaching takes many months to complete, and the operation depends heavily on the weather. Active mines that use cyanide heap-leaching either shut down during the winter or use expensive oil emersion heaters to prevent freezing in the heap and the pipelines.

Lab experiments undertaken during the study indicated that metal recovery was from $17 \%-40 \%$ greater when geothermal heat was added to the cyanide heap leaching process. Increasing cyanide solution reaction rates decreases the time required for batch heapleaching and increases productivity. In addition, maintaining a constant temperature in the piles by heating the cyanide solution will permit the operation to continue at a profitable level on a year-round basis, even through the cold winter months. According to the report, at least six operating mines are located near or adjacent to known geothermal resources with temperatures compatible with the cyanide heap-leaching process.

Two Nevada mines, Pegasus Gold Corporation's Florida Canyon Mine, and Echo Bay's Round Mountain Mine, have independently begun using geothermal heat for the cyanide solution since the report was published.

The next phase of this project is being funded by the U.S. Bureau of Mines (Interior Department). Studies during this phase will include new field work to determine the feasibility of using the geothermal fluids (which are now being injected into the ground) directly in the cyanide circuits. This process would reduce the amount of geothermal brines to be disposed of and eliminate the expense involved with importing water. The Big Unknown is whether the chemistry of the geothermal fluids would be detrimental to ore recovery. As part of the field work, Earth Science staff will work with the Pegasus and Echo Bay companies, initially conducting large-scale column tests on the ore to determine the compatibility of the geothermal fluids with the cyanide solution.

For Additional Information:

Contact: Dennis Trexler

University of Nevada, Las Vegas

255 Bell St.

Reno, NV 89502

(702) 784-6151

References:

"Geothermal Enhances Mineral Processing in Nevada," Earth Science Division - University of Nevada, Los Vegas. Prepared for US Department of Energy/San Francisco Operations Office. Grant No. FG03-85SF15603, November 1986.

"Geothermal Enhances Mineral Processing in Nevada," Geothermal Report, 2/16/87, pp. 4.

"Mineral Processing Project to Enter Second Phase," Geothermal Report, 2/1/88, pp. 2. 


\subsection{HANDBOOKS}


n. 


\section{DISTRICT HEATING SYSTEM PERFORMANCE OF MATERIALS AND EQUIPMENT}

Information is being assembled by Oregon Institute of Technology's Geo-Heat Center on the original design and subsequent performance of a selected group of geothermal district heating systems, which have logged at least three years of operation. Specific areas of investigation are equipment type and materials of construction for production pumps, transmission piping, customer connect time, and disposal. The operational performance of the equipment in each of these areas will be described and will serve as a reference to designers of new systems and operators of existing systems.

This report on 14 geothermal districts heating systems should be available by the winter of 1988 .

For Additional Information:

Contact: $\quad$ Kevin Rafferty, P.E.

Geo-Heat Center

Oregon Institute of Technology

Klamath Falls, OR 97601

(503) 882-3583 

The OIT Geo-Heat Center will publish a geothermal direct use guidebook for the technical community and users of low and moderate temperature resources. Text contributors include personnel from Battelle Pacific Northwest Labs, the Geo-Heat Center, Idaho National Engineering Laboratory, Radian Corporation, Utah University Research Institute, and Washington State Energy Office. The contents of the document will be of a practical and technical nature, providing guidance to the direct use industry in the following areas, which correspond to the 20 chapters of the document.

\section{Chapter \& Title}

1. Intro. \& State of the Art

2. Demonstration Projects, Lessons

\section{Learned}

3. Nature of Geothermal Resources

4. Exploration for Direct Heat Resources

5. Fluid Sampling Techniques

6. Drilling \& Well Construction

7. Well Testing \& Reservoir Evaluation

8. Materials Selection

9. Well Pumps

10. Piping

\section{Chapter \& Title}

11. Heat Exchangers

12. Space Heating Equipment

13. Heat Pumps

14. Absorption Refrigeration

15. Greenhouses

16. Aquaculture

17. Industrial Applications

18. Engineering Cost Analyses

19. An Analysis of the Legal \& Institutional Framework

20. Potential Environmental Effects of Geothermal Development \& Suggestions for Mitigation

Completion of the document is scheduled for the summer of 1988 .

For Additional Information:

Contact:

Paul J. Lienau

Geo-Heat Center

Oregon Institute of Technology

Klamath Falls, OR 97601

(503) 882-3583

Ben Lunis

Idaho National Engineering Laboratory

PO Box 1625 WCB E-3

Idaho Falls, ID 83415 
CHAPTER 6

ECONOMICS

$17 / / 172$ 


\subsection{SOFTWARE}





\section{GCFM COMPUTER MODEL}

GCFM or Geothermal Loan Guaranty Cash Flow Model (GCFM) is a computer simulation that estimates project costs and cash flows for geothermal producers and electric plants throughout construction and operation phases. It was written for the purpose of assisting in the analysis of DOE Geothermal Loan guaranty applications.

The field program module calculates the year by year costs associated with developing and operating the geothermal field. The reservoir is characterized by its depth, wellhead temperatures, pressures, and brine composition. It is modeled as an infinite system with constant parameters over the lifetime. Drilling costs are a function of depth and rock hardness or can be input by the user. There are costs for production and injection wells. A success ratio for drilling is also input. The user defines the flow rate per well, and the program calculates if downhole pumps are necessary. Well life is input to determine the schedule of replacement well drilling. Ten different field designs can be stored in the computer memory while running the program to perform comparisons and sensitivity analyses. Default values are included in the program, based on a detailed industry survey, to allow performance of preliminary calculations with minimal information. The costing equations are based on MITRE's GELCOM Model, updated to 1979.

The power plant program module can be used to study dry steam, single or dual flash, and binary systems. Costing equations are based upon the GEOCOST Model (Battelle-PNL). User-controlled variables include turbine/generator efficiencies, outlet temperature, coolant temperature, pump types, etc. The model calculates brine flow requirements which are then input to the field program module. Plant life is 50 years. As with the field module, up to 10 plant types can be stored as data sets to perform sensitivity analyses. Default values used in preliminary studies can be replaced in the analysis as data become available. Life cycle costs such as operation and maintenance, capital asset replacement, and salvage value are considered.

The financial program module has as input the initial and year by year costs from the other module and outputs a year by year cash flow and a levelized busbar cost. Initial debt is structured to provide as much leverage as possible, loan life and a sinking fund are designated by the user. State, federal and property taxes are included, as well as tax credits, tax benefits, depreciation, depletion allowances, etc. Electricity prices, geothermal fluid prices, and capital costs are subject to escalation and inflation. There is the possibility to store up to 15 financial data sets. The model can consider either producers or utilities in a given run, but not in combination. All values are in 1979 dollars, but cost indexes exist in the equations to update the values.

The program is written in FORTRAN IV under a VM/CMS operating system. It is highly user interactive, and has been installed on the IBM 370 and HewlettPackard 3000 Series 3 systems.

Version 5.0, is available from the National Energy Software Center at Argonne, with Revisions through February 1982. The code is available for IBM 370 or 303x series systems. The DOE Geothermal Loan Guaranty Program, DOE San Francisco Operations Office, has the HP-3000 version. 
For Additional Information:

R\&D Contact:

Daniel J. Entingh

Meridian Corporation

4300 King St., Ste. 400

Alexandria, VA 22302-1508

(703) 998-3600

Sof tware Contact:

National Software Center

Argonne National Laboratory

9700 South Cass Avenue

Argonne, IL 60439

(312) $972-2000$

Reference:

Keimig, M.A., Rosenberg, J.I., and Entingh, D.J.: Geothermal Loan Guaranty Cash Flow Model - Description and User's Manual, MTR-80W160, November 1980. 


\section{GEOCITY COMPUTER MODEL}

GEOCITY is a large-scale simulation model which combines both engineering and economics to systematically calculate the cost of geothermal district heating systems for space heating and cooling.

Exploration, development, and operation of the geothermal field are simulated in the reservoir model. Costs for field exploration are determined in a seven step process, each step of which is characterized by input costs, time, and success ratios. Alternatively, the user can input these costs directly. The reservoir itself is modeled as a constant (over time), infinite system. In the development stage, the user can specify the well design, whereby costs are calculated from default values (function of depth, diameter, bottom-hole temperature, percent of well cased, rock hardness) or the costs per well can be input directly. The ratio of producers to dry wells is considered. Based upon wellhead characteristics (temperature pressure, flow rate, geothermal fluid) and fluid requirements, the transmission system is sized and priced. Downhole pumps are used if needed. All calculated costs can be overridden with input data. Costs for interim capital replacements and operation and maintenance are a function of capital costs and fluid chemistry. Well life is input directly. Fluid characteristics are determined from ASME Steam Tables, incorporated into the computer code.

The GEOCITY computer program considers domestic hot water heating, space heating, and space cooling. The demand is calculated based upon climate (degree days, design temperatures), population, and area. A city is divided into districts, each of which is characterized as one of six standards types (high density, single family; high-rise apartments; etc.) with an associated demand profile. Other types may be specified by the user. The program designs the distribution system and calculates fluid requirements to meet the needs. It also determines pipe sizes and materials, insulation, and physical layout. Pipe sizes and insulation are optimized on a minimum cost basis, with regard to heat losses. Optionally, a binary system with heat exchanger may be chosen, or the capability of wellhead fluid mixing. Operation and maintenance, electrical pumping, and supplemental heating costs are included. The distribution model is derived in part from SOLTES, a solar energy district heating design code written at Sandia National Laboratories.

For both the producer and distributor, the model calculates the levelized cost of energy. The reservoir model cost output is input to the distribution economics model. There are options for debt or equity financing, and the discount rate is calculated from the corresponding interest rates. State, federal, and property taxes are included as well as tax credits and depreciation. Tangible and intangible costs are differentiated for tax purposes. Insurance and royalty payments are included. Either a private enterprise or a public utility is selected by the user for consideration. Escalation of capital replacement and fuel costs is available. Maximum project life is $\mathbf{5 0}$ years. Costs are in $\mathbf{1 9 8 0}$ dollars. Indexes are available to escalate base-year costs to the desired year.

The program is written in Fortran IV and is not interactive. Code for the ASME Steam Tables is included for thermodynamic calculations.

The 1978 version (described here) is available from the National Energy Software Center, Argonne, IL, in source deck or magnetic tape for CDC6600 and CYBER74 computers. The user's manual is available either through NESC or NTIS. An updated version of the code (circa approximately 1982) has been completed at PNL but not released. The updated user's manual is available from NTIS. 
For Additional Information:

Contact: $\quad$ Linda Fassbender

Battelle Pacific Northwest Laboratory

2030 M Street, N.W., Suite 800

Washington, D.C. 20036

(202) $785-8400$

References:

McDonald, C.L., Bloomster, C.H., and Schulte, S.C.: GEOCITY; A Computer Code for Calculating Costs of District Heating Using Geothermal Resources. BNWL2208, February 1977.

McDonald, C.L., and Bloomster, C.H.: The GEOCITY Model: Descriotion and Application. BNWL-SA-6343, June 1977.

Huber, H.D. et al.: User Manual for GEOCITY: A Computer Model For District Heating Cost Analysis. PNL-2742, October 1978.

Huber, H.D., Fassbender, L.L., and Bloomster, C.H.: User Manual For GEOCITY: A Computer Model for Geothermal District Heating Cost Analysis. PNL-4422, September 1982.

Fassbender, L.L., and Bloomster, C.H.: The Economics of Power Plant District and Process Heating in Richland. Washington. PNL-3719, April 1981. 


\section{GEOCOST COMPUTER MODEL}

GEOCOST is a computer model that simulates the over-all design, including major components, of a geothermal-steam electric power plant. Components are sized based upon themodynamic relationships and costs are calculated as a function of size.

The exploration, development, and operation of the geothermal field are simulated in the reservoir model. Costs for field exploration are determined in a seven step process, each step of which is characterized by input costs, time, and success ratios. Alternatively, the user can input these costs directly. In the development stage, the user can specify the well design, whereby costs are calculated from default values (function of depth, diameter, bottom-hole temperature, percent of well cased, rock hardness) or the total cost per well can be input directly. The ratio of producers to dry wells is considered. Based upon wellhead characteristics (temperature, pressure, flow rate, geothermal fluid) and fluid requirements, the transmission system is sized and priced. These can be overridden with input data. Costs for injection wells are included. Costs for interim capital replacements and operation and maintenance are a function of capital costs and fluid chemistry. Well life is input directly by the user. Fluid characterisitcs are determined from ASME Steam Tables, incorporated into the computer code.

This version of GEOCOST considers steam powered electric generation. Based upon the specified power plant design, capacity, and geothermal fluid characteristics, the program calculates plant size, cost, and fluid requirements. There are options for particulate removal and multi-stage flashing. Operation and maintenance costs as well as those for replacement of components are based on initial capital cost and fluid chemistry. Construction time for the geothermal power plant is considered.

For both the geothermal field and the power plant, the program calculates the levelized cost of energy. The reservoir model cost outputs are input to the power plant model. There are options for debt or equity financing and the discount rate is calculated from these interest rates. State, federal, and property taxes are included as well as tax credits and depreciation. Tangible and intangible costs are differentiated. Insurance and royalty payments are also included. Maximum total project life is 50 years. Costs are in 1974 dollars. Indexes are available to escalate base-year costs to the desired year.

The program is written in Fortran IV and is not interactive. Code for the ASME Steam Tables is included for thermodynamic calculations.

The 1975 version (described here) is available from the National Energy Sof tware Center, Argonne, IL, in source deck or on magnetic tape for CDC 6600 and CYBER74 computers. The user's manual is available either through NESC or NTIS. An updated 1984 version of the code for use on a UNIVAC 1100 has been completed at PNL. This 1984 version was converted to operate on an IBM-AT or equivalent microcomputer. Costs in the code for the microcomputer version were updated to 1987 dollars. Documentation to support the use of the microcomputer version is also available. The 1984 UNIVAC and microcomputer versions of the code have not been released. 
For Additional Information:

Laboratory Contact:

Linda Fassbender

Battelle Pacific Northwest Laboratories

2030 M Street, N.W., Suite 800

Washington, D.C. 20036

(202) 785-8400

Sof tware Contact

National Energy Sof tware Center

Argonne National Laboratory

9700 South Cass Avenue

Argonne, IL 60439

(312) $972-2000$

References:

Bloomster, C.H. et al.: GEOCOST: A Computer Program for Geothermal Cost Analysis. BNWL-1888, February 1975.

Bloomster, C.H.: "An Economic Model for Geothermal Cost Analysis." Proceedings.

2nd United Nations Symposium on the Development and Use of Geothermal Resources. (May 1975): 2273-2282.

Huber, H.D., Bloomster, C.H., and Walter, R.A.: User's Manual for GEOCOST: A Computer Model for Geothermal Cost Analysis. Volume 1. Steam Crcle Yersion. BNWL1942-VI, November 1975.

Cohn, P., and Bloomster, C.H.: Capital Cost Models for Geothermal Power Plants. BNWL-1990, July 1976.

Schulte, S.C.: Capital Cost Models for Geothermal Power Plants and Fluid Transmission Systems. PNL-2307, September 1977. 


\section{GEOCOST-BC COMPUTER MODEL}

GEOCOST-BC is a computer program that simulates the overall design, including all major components, of a geothermal binary electric power plant. Components are sized based upon thermodynamic relationships and costs are calculated as a function of size.

The exploration, development, and operation of the geothermal field are simulated in the reservoir model. Costs for field exploration are determined in a seven step process, each step of which is characterized by input costs, time, and success ratios. Alternatively, the user can input these costs directly. In the development stage, the user can specify the well design, whereby costs are calculated from default values (function of depth, diameter, bottom-hole temperature, percent of well cased, rock hardness) or the costs per well can be input directly. The ratio of producers to dry wells is considered. Based upon well-head characterization (temperature, pressure, flow rate, geothermal fluid) and fluid requirements, the transmission system is sized and priced. These inputs can be overridden with userdefined data. Costs for injection wells are included. Costs for interim capital replacements and operation and maintenance are a function of capital costs and fluid chemistry. Well life is input directly. Fluid characteristics are determined from ASME Steam Tables, incorporated into the computer code.

GEOCOST-BC considers geothermal electric power generation using the binary cycle. One of 10 available working fluids is selected, and dependent upon the characteristic, either subcritical or supercritical Rankine Cycles are selected by the program (although the user may override). Power plant life, load factor, capacity, and design are input. The program calculates component sizes (and costs), fluid requirements, and parasitic power loads. Operation and maintenance costs, as well as those for replacement of components, are based upon plant size, capital costs, and fluid chemistry.

For both the geothermal field and the power plant, the program calculates the levelized cost of energy. The reservoir model cost output is input to the power plant model. There are options for debt or equity financing and the discount rate is calculated from these interest rates. State, federal and property taxes are included as well as tax credits and depreciation. Tangible and intangible costs are differentiated. Insurance and royalty payments are also included. Maximum total project life is 50 years. Costs are in 1974 dollars. Indexes are available to escalate base-year costs to the desired year.

The program is written in Fortran IV and is not interactive. Code for the ASME Steam Tables is included for thermodynamic calculations.

The 1976 version (described here) is available from the National Energy Software Center, Argonne, IL, in source deck or magnetic tape for CD660 and CYBER74 computers. The user's manual is available either through NESC or NTIS. An updated 1984 version of the code for use on a UNIVAC 1100 has been completed at PNL. This 1984 version was converted to operate on an IBM-AT or equivalent microcomputer. Costs in the code for the microcomputer version were updated to 1987 dollars. Documentation to support the use of the microcomputer version is also available. The 1984 UNIVAC and microcomputer versions of the code have not been released. 
For Additional Information:

Laboratory Contact: Linda Fassbender

Battelle Pacific Northwest Laboratories

2030 M Street, N.W., Suite 800

Washington, D.C. 20036

(202) $785-8400$

Software Contact: National Energy Software Center

Argonne National Laboratory

9700 South Cass Avenue

Argonne, IL 60439

(312) $972-2000$

References:

Bloomster, C.H. et al.: GEOCOST: A Computer Program for Geothermal Cost Analysis, BNWL-1888, February 1975.

Bloomster, C.H.: "An Economic Model for Geothermal Cost Analysis." Proceedings. 2nd United Nations Symposium on the Development and Use of Geothermal Resources. San Francisco, CA, May 1975, pp. 2273-2282.

Huber, H.D., Walter, R.A., and Bloomster, C.H.: Users Manual for GEOCOST: A Computer Model for Geothermal Cost Analysis. Volume 2, Binary Cycle Version. BNWL1942-V2, March 1976.

Cohn, P., and Bloomster, C.H.: Canital Cost Models for Geothermal Power Plants. BNWL-1990, July 1976.

Walter, R.A.: Modeling and Optimization of Geothermal Power Plants Using the Binary Fluid Cycle, BNWL-2112, September 1976.

Schulte, S.C.: Capital Cost Models for Geothermal Power Plants and Fluid Transmission Systems. PNL-2307, September 1977. 
6.2 HANDBOOKS

183 


\section{HOT DRY ROCK VENTURE RISKS INVESTIGATION}

The largest Hot Dry Rock (HDR), systems created to date, at Fenton Hill, New Mexico and at Rosemanowes, England, are research and development projects that have proved the HDR technology concept by drilling into hot dry rocks, hydraulically fracturing the rock mass, and extracting thermal energy by circulating water through the man-made fractures. Although HDR systems have been created on a research scale, HDR has not yet been applied commercially. The "Hot Dry Rock Venture Risks Investigation" study is the first sitespecific evaluation to test the commercial readiness of HDR technology.

In mid-1986, the DOE issued a request for proposals to investigate a specific site for HDR commercial venture potential. In response to this request, Bechtel National, Inc. proposed to evaluate the Roosevelt Hot Springs, Utah resource as the location for a potential $50 \mathrm{MWe}$ power generating facility, and DOE awarded a contract to Bechtel for this investigation. The accompanying figure shows the location and some of the prominent features of the Roosevelt Hot Springs resource area in south central Utah.

The methodology utilized in this study may be applied to other HDR resource areas. Basically, the methodology involved:

- extensive technical analysis of the geotechnical aspects of the site

- design of the subsurface system and surface facilities

- estimates of project costs

- assessment of environmental and socioeconomic issues

- preparation of a development plan

- assessment of economic feasibility and associated risk

- final recommendations

The "Hot Dry Rock Venture Risks Investigation" report records the results of this particular investigation and makes recommendations for the next step toward implementing a commercial HDR facility. The results indicate that, if the HDR reservoir productivity equals expectations based on preliminary results from research projects to date, a $50 \mathrm{MWe}$ HDR power facility at Roosevelt Hot Springs could generate power at a cost competitive with coal-fired plants. However, it is imperative that the assumed productivity be demonstrated before funds are committed for a commercial facility.

The report concludes that a site-specific industrial HDR experiment at Roosevelt Hot Springs is highly recommended to resolve the major technical issues and to obtain sitespecific information needed for design and evaluation. Federal support for funding the industrial HDR experiment is also recommended. In addition a commercial-size first-of-akind power plant project is recommended if the industrial HDR experiment verifies the technical and economic projections. 
. 
For Additional Information:

R\&D Contact: Janet Owen

Bechtel National, Inc.

P.O. Box 3965

San Francisco, CA 94119

(415) 768-6108

DOE Contact:

John Crawford

U.S. Department of Energy

San Francisco Operations Office

1333 Broadway

Oakland, CA 94612

(415) 273-7944

Reference:

Hot Dry Rock Venture Risks Investigation, Bechtel National, Inc. Prepared for U.S. Department of Energy/San Francisco Operations Office, Contract No. DE-AC03-86SF16385, January, 1988.

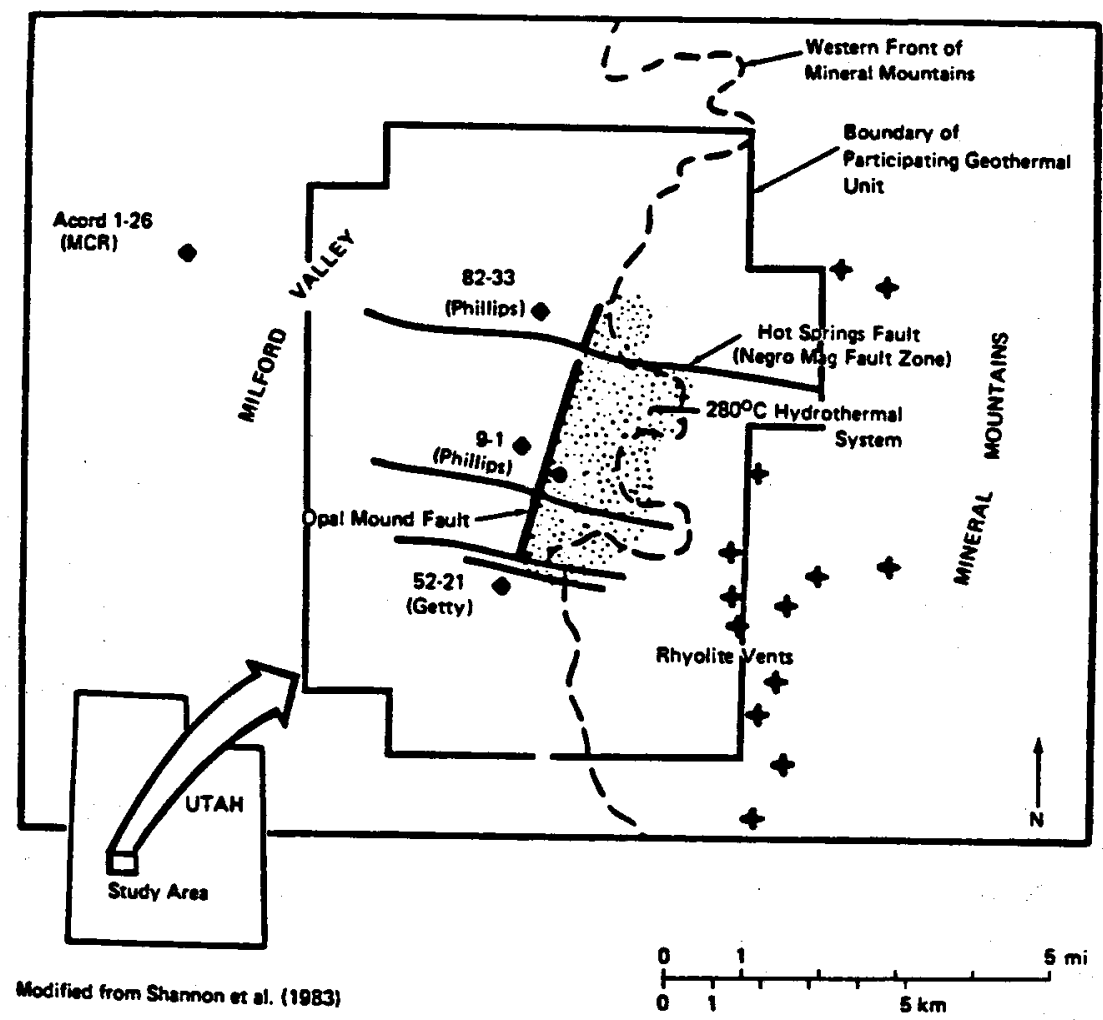




\section{INDEX}

Page

HARDWARE

Exploration

$\begin{array}{llr}\text { 2.1.1 Acoustic Source Detonator } & 8\end{array}$

$\begin{array}{lr}\text { 2.1.2 Crosswell Acoustic Transceiver-Transmitter } & 10\end{array}$

$\begin{array}{ll}\text { 2.1.3 Downhole Geophone } & 12\end{array}$

$\begin{array}{lll}\text { 2.1.4 Slimline Detonator Tool and String Shot } & 14\end{array}$

Drilling, Well Completion, and Reservoir Production

$\begin{array}{lll}\text { 3.1.1 Acoustic Borehole Televiewer } & 60\end{array}$

$\begin{array}{lll}\text { 3.1.2 Borehole Fluid Sampler } & 62\end{array}$

$\begin{array}{lll}3.1 .3 & \text { Caliper Tool } & 64\end{array}$

$\begin{array}{lll}\text { 3.1.4 Cavitating Drill Bit Nozzles } & 66\end{array}$

$\begin{array}{lll}\text { 3.1.5 Downhole Flow Meter } & 68\end{array}$

3.1.6 Downhole Injector and Gamma Ray Detector $\quad 70$

$\begin{array}{lll}\text { 3.1.7 Cement Placement Tool } & 72\end{array}$

$\begin{array}{lll}\text { 3.1.8 Downhole Fluid Injector } & 73\end{array}$

$\begin{array}{lll}\text { 3.1.9 Drill Pipe Severing Device } & 74\end{array}$

$\begin{array}{lll}\text { 3.1.10 } & \text { Explosive Fracture Initiation Tool }\end{array}$

$\begin{array}{lll}\text { 3.1.11 Explosive Side Tracking Tool } & 76\end{array}$

$\begin{array}{lll}3.1 .12 & \text { Hard Rock Geothermal Drill Bit } & 77\end{array}$

$\begin{array}{lll}\text { 3.1.13 Fluid Velocity (Spinner) Probe } & 78\end{array}$

$\begin{array}{lll}\text { 3.1.14 High Temperature Casing Packer } & 80\end{array}$

$\begin{array}{lll}\text { 3.1.15 High Temperature Downhole Fluid Sampler } & 82\end{array}$

$\begin{array}{lll}\text { 3.1.16 High Temperature Drilling Jars } & 83\end{array}$

3.1.17 High Temperature Electronics and Instrumentation $\quad 84$

$\begin{array}{llr}\text { 3.1.18 Passive Thermal Protection System } & 85\end{array}$

3.1.19 High Temperature, High Pressure Cablehead $\quad 86$

3.1.20 High Temperature Open Hole Packers $\quad 88$

3.1.21 High Temperature Turbodrill $\quad 90$

$\begin{array}{lll}\text { 3.1.22 } & \text { PDC Drill Bits } & 92\end{array}$

$\begin{array}{lll}\text { 3.1.23 Spinner/Temperature/Pressure with Collar Locator } & 94\end{array}$

$\begin{array}{lll}\text { 3.1.24 Temperature Probes } & 95\end{array}$

3.1.25 Wellbore Inertial Navigation System 96

Materials and Brine Chemistry

4.1.1 Cements for Geothermal Wells $\quad 140$

$\begin{array}{lll}\text { 4.1.2 High Temperature Elastomers } & 141\end{array}$

$\begin{array}{lll}\text { 4.1.3 High Temperature Drilling Mud } & 142\end{array}$

$\begin{array}{lll}\text { 4.1.4 Improved Well Casing Material } & 144\end{array}$

4.1.5 Polymer Concrete Pipe 145

SOFTWARE

Exploration

2.2.1 Self-Potential Data Interpretation -- Theory and Computer Program

16

2.2.2 Computer Programs for Geophysical Data 
Drilling, Well Completion, and Reservoir Production

3.2.1 CCC Computer Model $\quad 100$

$\begin{array}{ll}\text { 3.2.2 } & \text { ANALYZE Computer Model } \\ \end{array}$

3.2.3 DEGEOWEL Two-Phase Flow Computer Model 103

3.2.4 Geophysical Well Log Data Base Management 104

$\begin{array}{lll}3.2 .5 & \text { GEOTEMP2 Computer Model } & 106\end{array}$

$\begin{array}{lll}3.2 .6 & \text { GRITS Computer Model } & 108\end{array}$

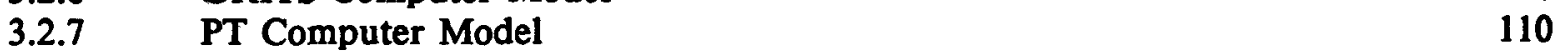

$\begin{array}{lll}\text { 3.2.8 } & \text { PTC Computer Model } & 112\end{array}$

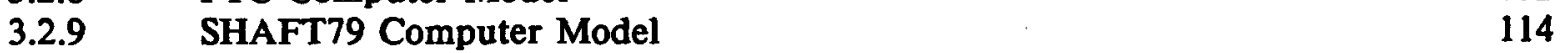

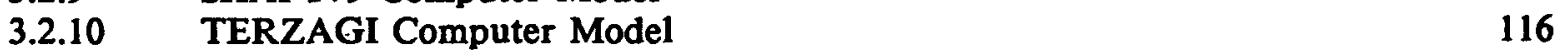

3.2.11 WELBORE Computer Model 118

$\begin{array}{ll}\text { 3.2.12 VARFLW Computer Model } & 120\end{array}$

Economics

$\begin{array}{lll}\text { 6.1.1 } & \text { GCFM Computer Model } & 168\end{array}$

$\begin{array}{ll}\text { 6.1.2 } & 170\end{array}$

$\begin{array}{ll}\text { 6.1.3 GEOCOST Computer Model } & 172\end{array}$

$\begin{array}{lll}\text { 6.1.4 GEOCOST-BC Computer Model } & 174\end{array}$

\section{DATABASES}

\section{Exploration}

$\begin{array}{ll}\text { 2.3.1 DOD Geothermal Projects } & 20\end{array}$

2.3.2 Exploration Technology Data Base $\quad 21$

2.3.3 Industry Coupled Drilling Program Data Base $\quad 22$

2.3.4 LOGDEX Data Base $\quad 24$

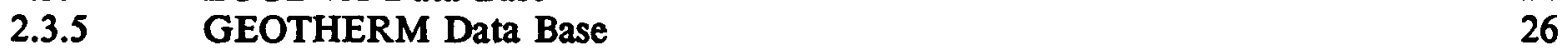

2.3.6 OIT Site Data Base Reports $\quad 27$

2.3.7 State Coupled Resource Assessment Program 28

2.3.8 UUR1/ESL Geothermal Sample Library 29

2.3.9 User Coupled Confirmation Drilling Program 30

Direct Use

5.1.1 Direct Use Information Services 156

$\begin{array}{lll}\text { 5.1.2 Direct Use Technical Services } & 157\end{array}$

$\begin{array}{ll}\text { 5.1.3 Downhole Heat Exchanger Performance } & 158\end{array}$

\section{PROCESSES/PROCEDURES}

Exploration

2.4.1

2.4.2

2.4 .3

2.4.4

2.4.5

2.4.6

2.4.7

2.4.8

2.4 .9

2.4.10

2.4.11

2.4.12
Automated Seismic Processor 32 Borehole Geophysical Research for Fracture Detection 34 Controlled Source Electromagnetic System 36 Cascade Range Exploration Technology 38 Gas Contents of Geothermal Fluids 39 Fluid Movement in Volcanic Terrains $\quad 40$ Fracture Detection Using Low Frequency Cross-Hole Electromagnetic Techniques 
2.4.13 Magnetotelluric Survey $\quad 52$

2.4.14 Mapping Flow Paths in Fracture-Dominated Reservoirs 53

2.4.15 Trace Element Geochemistry of Hydrothermal Systems $\quad 54$

2.4.16 Acoustic Borehole Mapping of Seismicity $\quad 56$

Drilling, Well Completion, and Reservoir Production

$\begin{array}{ll}\text { 3.3.1 Hydraulic Fracturing } & 122\end{array}$

3.3.2 Hot Dry Rock Drilling Technology 124

3.3.3 Scale Control for Geopressured-Geothermal Wells 125

3.3.4 Scale Inhibitor Effectiveness: Injection-Backflow Technique 126

$\begin{array}{lll}\text { 3.3.5 } & \text { Tracer Investigations for Geothermal Injection } & 127\end{array}$

Direct Use

5.2.1 Mineral Heap-Leaching Process

\section{TEST FACILITIES}

Drilling, Well Completion, and Reservoir Production

$\begin{array}{ll}\text { 3.4.1 } & 130\end{array}$

$\begin{array}{ll}\text { 3.4.2 } & 132\end{array}$

Materials and Brine Chemistry

$\begin{array}{lll}\text { 4.2.1 Two-Phase Flow Facility } & 148\end{array}$

HANDBOOKS

Drilling, Well Completion, and Reservoir Production

$\begin{array}{lll}\text { 3.5.1 Geothermal Well Design Handbook } & 134\end{array}$

3.5.2 Corrosion Handbook for Downhole Components 136

Materials and Brine Chemistry

4.3.1 Geothermal Materials Selection Handbook 152

Direct Use

5.3.1 District Heating System Performance of Materials and Equipment 162

5.3.2 Geothermal Direct Use Engineering and Design Guidebook 163

Economics

6.2.1 Hot Dry Rock Venture Risk Investigation

178 
APPENDIX A

$190 / 191$ 
. 


\section{A.1 DIRECTORY OF CONTACTS (INDIVIDUAL)}

Albright, James

Mail Stop J981

Los Alamos National Laboratory

Los Alamos, NM 87545

(505) 667-5061

Ander, $M$.

Los Alamos National Laboratory

Mail Stop C335

Los Alamos, NM 87545

(505) 667-5061

Argonne National Laboratory

National Energy Sof tware Center 9200 South Cass Avenue

Argonne, IL 60439

(312) $972-2000$

Ayden, D.

Sprengnether, Inc.

4150 LaClede

St. Louis, MO 63108

(314) $535-1682$

Baker, W.C.

Smith Tool Company

1207 34th St.

Bakersfield, CA 93301

(805) 323-0656

Bennett, $\mathbf{G}$.

Los Alamos National Laboratory

Los Alamos, NM 87545

(505) 667-5061

Bennett, Rod

Baker Service Tools

9100 Emmott Road

Houston, TX 77040

(713) $466-1322$

Benson, Sally

Earth Sciences Division

Lawrence Berkeley Laboratory

Berkeley, CA 94720

(415) 486-5875

Bliss, J.D.

U.S. Geological Survey

Menlo Park, CA 92008

(415) 853-8300
Bodvarsson, Gudmundur

Earth Sciences Division

Lawrence Berkeley Laboratory

Berkeley, California 94720

(415) 486-4000

Butz, James

ADA Technologies

Honeywell Center, Suite 480

304 Inverness Way South

Englewood; CO 80112

(303) 792-5615

Coury, G.

Coury \& Associates

10088 West 32nd Avenue

Lakewood, CO 80211

(303) 232-3823

Crawford, John

U.S. Department of Energy

San Francisco Operations Office

1333 Broadway

Oakland, CA 94612

(415) 273-7944

Culver, Gene

Oregon Institute of Technology

Geo-Heat Center

3201 Campus Drive

Klamath Falls, OR 97601

(503) 882-3583

Daniel, B.

Unocal Geothermal

Santa Rosa, CA 95401

(707) $545-7600$

Dennis, Bert R.

Mail Stop D448

Los Alamos National Laboratory

Los Alamos, NM 87545

(505) 667-0728

Dreesen, Donald S.

Los Alamos National Laboratory Mailstop J981

Los Alamos, NM 87545

(505) 667-5061 
Duda, Len

Sandia National Laboratories Geothermal Research Division Albuquerque, NM 87185 (505) 844-2377

Dunn, James C. Sandia National Laboratories Geothermal Research Division Albuquerque, NM 87185 (505) 844-4715

Ellis, P.F.

Radian Corporation 8501 Mo-Pack Blvd. Austin, TX 78759 (512) 454-4797

Entingh, Daniel J. Meridian Corporation 4300 King St., Suite 400 Alexandria, VA 22302-1508 (703) $998-3600$

Fassbender, Linda Battelle Pacific Northwest Lab 2030 M Street, NW, Suite 800 Washington, D.C. 20036 (202) 785-8400

Fehler, M.

Los Alamos National Laboratory Mail Stop J979

Los alamos, NM 87545

(505) 667-5061

Frederick, Gary S.

Tracor Hydronautics 7210 Pindell School Road Laurel, MD 20810

(301) 776-7454

Glowka, David Sandia National Laboratories Geothermal Research Division Albuquerque, NM 87185 (505) 844-3933
Goldstein, Norman E.

Lawrence Berkeley Laboratory

Earth Sciences Division

Berkeley, CA 94720

(419) $486-4000$

Guven, N.

Texas Tech University

Lubbock, TX

Haught, Ramsey

Lawrence Berkeley Laboratory

Earth Sciences Division

Berkeley, CA 94720

(415) $486-4000$

Hendron, Robert

Los Alamos National Laboratory

Mail Stop J979

Los Alamos, NM 87545

(505) 667-5061

Hirasuna, A.

L'Garde, Inc.

15181 Woodlawn Avenue

Tustin, CA 92681

(714) 259-0771

Hsien, Cheng Lai

Earth Sciences Division

Lawrence Berkeley Laboratory

Berkeley, CA 94720

(415) $486-4000$

Huertas, D. Fernando

Law Engineering, Iberica, S.A.

Corazon de Maria, 2

28002-Madrid

Hulen, Jeffrey, B.

University of Utah Research Institute

Earth Science Laboratory

391 Chipeta Way, Suite C

Salt Lake City, UT 84108

(801) 524-3422

Jester, M.L.

Bechtel Power Corp.

50 Beale Street

San Francisco, CA 94105

(415) 768-1234 
Kaeding, Albert 0.

Quazite Corporation

5515 Gasmer

Houston, TX 77035

(713) $723-5310$

Kohler, Stewart, $\mathbf{M}$.

Guidance and Control Division

I 2334

Sandia National Laboratories

Albuquerque, NM 87185

(505) 844-5678

Kukacka, L.E.

Brookhaven National Laboratory

Upton, NY 11973

(516) 282-3065

Lienau, Paul J.

Oregon Institute of Technology

Geo-Heat Center

3201 Campus Drive

Klamath Falls, OR 97601

(503) 882-3583

Lippmann, M.

Earth Sciences Division

Lawrence Berkeley Laboratory

Berkeley, CA 94720

(415) 486-5035

Loeppke, Glen

Sandia National Laboratories

Geothermal Research Division

Albuquerque, NM 87185

(505) 846-0301

Lunis, Ben

Idaho National Engineering Lab

P.O. Box 1625 WCB E-3

Idaho Falls, ID 83415

MacRae, C.

Baker Service Tools

9100 Emmott Road

Houston, TX 77040

(713) 466-1322

Maeder, P.F.

Brown University

Providence, RI
Majer, E.

Lawrence Berkeley Laboratory

Berkeley, CA 94720

(415) 486-6709

Maurer, W.C.

Maurer Engineering, Inc.

2916 West P.C. Jester

Houston, TX 77071

(713) 683-8227

Menzies, Anthony

Geothermex, Inc.

5221 Central Avenue, Suite 201

Richmond, Ca 94804

(415) 527-9876

Mitchell, R.

Enertech Engineering \& Research Company 5847 San Felipe Road, Suite 1000

Houston, TX 77057

(713) 789-0055

Moore, Joseph N.

University of Utah Research Institute

Earth Science Laboratory

391 Chipeta Way, Suite A

Salt Lake City, UT 84108

(801) 524-3422

Murphy, Hugh

Los Alamos National Laboratory

Mail Stop J979

Los Alamos, NM 87545

(505) 667-3185

Narasimhan, $T$.

Lawrence Berkeley Laboratory

Earth Sciences Division

Berkeley, CA 94720

(415) 486-4000

National Energy Sof tware Center (NESC)

Argonne National Laboratory

9200 South Cass Avenue

Argonne, IL 60439

(312) $972-2000$

National Technical Information Service (NTIS)

U.S. Department of Commerce

5285 Port Royal Road

Springfield, VA 22161

(703) 487-4650 
Nelson, E.B.

Dowell Schlumberger

Houston, TX

Nielson, Dennis L.

University of Utah Research Institute

Earth Science Laboratory

391 Chipeta Way, Suite C

Salt Lake City, UT 84108

(801) 524-3422

Owen, Janet

Bechtel National, Inc.

P.O.Box 3965

San Francisco, CA 94119

(415) 768-6108

Paddison, F.

John Hopkins University

Applied Physics Laboratory

Laurel, MD 20810

(301) 953-5170

Portanova, Wayne

Mother Earth Industries

Scottsdale, AZ

Pruess, Karsten

Earth Sciences Division

Lawrence Berkeley Laboratory

Berkeley, CA 94720

(415) 486-4000

Rafferty, Kevin

Oregon Institute of Technology

Geo-Heat Center

3201 Campus Drive

Klamath Falls, OR 97601

(503) 882-3583

Rocky Mountain Well Log Service

P.O. Box 3150

Denver, CO 80201

(303) 825-2181

Ross, Howard P.

University of Utah Research Institute

Earth Science Laboratory

391 Chipeta Way, Suite C

Salt Lake City, UT 84108

(801) 524-3422
Rowley, J.

Los Alamos National Laboratory

Mailstop D462

Los Alamos, NM 87545

(505) 667-5061

Schneider, $\mathbf{R}$.

University of Texas at Austin

Center for Energy Studies

Austin, TX 78712

(415) 853-8300

Schroeder, Ron

Berkeley Group Inc.

1330 Broadway, Suite 1450

Oakland, CA 94612

(415) $465-1744$

Shannon, Don

Battelle Pacific Northwest Lab

Battelle Blvd.

P.O. Box 999

Richland, WA 99352

(509) 376-3139

Smith, D.K.

Halliburton Services

Solbau, Ray

Earth Sciences Division

Lawrence Berkeley Laboratory

Berkeley, CA 94720

(415) 486-4000

Stiger, Susan

EG\&G Idaho Inc.

P.O. Box 1625

Idaho Falls, ID 83415

(208) 526-0457

Taylor, D.

OTIS Engineering

P.O. Box 819052

Dallas, TX 75381

(214) 323-3694

Traeger, Richard

Sandia National Laboratories

Geothermal Research Division

Albuquerque, NM 87185

(505)844-5678 
Trexler, Dennis

University of Nevada, Las Vegas

255 Bell St.

Reno, NV 89502

(702) 784-6151

Van Rooyen, D.

Brookhaven National Laboratory

Upton, NY 11973

(516) $282-4050$

Uhl, James

Sandia National Laboratories

Geothermal Research Division

Albuquerque, NM 87185

(505) 844-1700

Wannamaker, Philip E.

University of Utah Research Institute

Earth Science Laboratory

391 Chipeta Way, Suite C

Salt Lake City, UT 84108

(801) 524-3422

Ward, Stanley, $\mathbf{H}$.

University of Utah Research Institute

Earth Science Laboratory

391 Chipeta Way, Suite C

Salt Lake City, UT 84108

(801) 524-3422

Webb, D.

Houston Engineering

Houston, TX

Wright, Phillip M.

University of Utah Research Institute

Earth Science Laboratory

Salt Lake City, UT 84108

(801) 524-3422 


\section{A.2 DIRECTORY OF CONTACTS (ORGANIZATIONAL)}

\author{
ADA Technologies \\ James Butz \\ Honeywell Center, Suite 480 \\ 304 Inverness Way South \\ Englewood, CO 80112 \\ (303) $792-5615$ \\ Argonne National Laboratory \\ National Energy Software Center \\ 9200 South Cass Avenue \\ Argonne, IL 60439 \\ (312) $972-2000$
}

\section{Baker Service Tools}

Rod Bennett

9100 Emmott Road

Houston, TX 77040

(713) $466-1322$

C. MacRae

9100 Emmott Rd.

Houston, TX 77040

(713) 466-1322

Battelle Pacific Northwest Laboratory

Linda Fassbender

2030 M Street NW, Suite 800

Washington, D.C. 20036

(202) $785-8400$

Don Shannon

Battelle Blvd.

P.O. Box 999

Richland, Wa 99352

(509) 376-3139

Bechtel National, Inc.

Janet Owen

P.O. Box 3965

San Francisco, CA 94119

(415) 768-6108
Bechtel Power Corporation

M.L. Jester

50 Beale Street

San Francisco, CA 94105

(415) 768-1234

Berkeley Group Inc.

Ron Schroeder

1330 Broadway, Suite 1450

Oakland, CA 94612

(415) 465-1744

Brookhaven National Laboratory

L.E. Kukacka

Brookhaven National Laboratory

Upton, NY 11973

(516) 282-3065

D. van Rooyen

Brookhaven National Laboratory

Upton, NY 11973

(516) 282-4050

Brown University

P.F. Maeder

Providence, RI

Coury \& Associates

G. Coury

10088 West 32nd Avenue

Lakewood, CO 80211

(303) 232-3823

Dowell Schlumberger

E.B. Nelson

Houston, TX 
EG\&G Idaho Inc.

Susan Stiger

P.O. Box 1625

Idaho Falls, Id 83415

(208) 526-0457

Energy, U.S. Department of San Francisco Operations Office

John Crawford

1333 Broadway

Oakland, CA 94612

(415) 273-7944

Enertech Engineering and Research Co.

R. Mitchell

5847 San Felipe Road, Suite 1000

Houston, TX 77057

(713) 789-0055

Geothermex, Inc.

Anthony Menzies

5221 Central Avenue, Suite 201

Richmond, CA 94804

(415) 527-9876

Johns Hopkins University

F. Paddison

Applied Physics Laboratory

Laurel, MD 20810

(301) 953-5170

Halliburton Services

D.K. Smith

Houston Engineering

D. Webb

Houston, TX
Idaho National Engineering Laboratory

Ben Lunis

P.O. Box 1625 WCB E-3

Idaho Falls, ID 83415

Lawrence Berkeley Laboratory

Earth Sciences Division

Sally Benson

Berkeley, CA 94720

(415) 486-5875

Gudmundur Bodvarsson

Berkeley, CA 94720

(415) $486-4000$

Norman E. Goldstein

Berkeley, CA 94720

(415) 486-4000

Ramsey Haught

Berkeley, CA 94720

(415) 486-4000

Cheng Hsien Lai

Berkeley, CA 94720

(415) 486-4000

M. Lippmann

Berkeley, CA 94720

(415) 486-5035

E. Majer

Berkeley, CA 94720

(415) 486-6709

T. Narasimhan

Berkeley, CA 94720

(415) 486-4000

Karsten Pruess

Berkeley, CA 94720

(415) 486-4000

Ray Solbau

Berkeley, CA 94720

(415) 486-4000 
Law Engineering

D. Fernando Huertas

Iberica, S.A.

Corazon de Maria, 2

28002-Madrid

L'Garde, Inc.

A. Hirasuna

15181 Woodlawn Avenue

Tustin, CA 92681

(714) 259-0771

Los Alamos National Laboratory

James Albright

Mail Stop J981

Los Alamos, NM 87545

(505) 667-5061

M. Ander

Mail Stop C335

Los Alamos, NM 87545

(505) 667-5061

G. Bennett

Los Alamos, NM 87545

(505) 667-5061

Bert R. Dennis

Mail Stop D448

Los Alamos, NM 87545

(505) 667-0728

Donald S. Dreesen

Mail Stop J981

Los Alamos, NM 87545

(505) 667-5061

M. Fehler

Mail Stop $\mathbf{J 9 7 9}$

Los Alamos, NM 87545

(505) 667-5061

Robert Hendron

Mail Stop $\mathbf{J 9 7 9}$

Los Alamos, NM 87545

(505) 667-5061
LANL (cont)

Hugh Murphy

Mail Stop J979

Los Alamos, NM 87545

(505) 667-3185

J. Rowley

Mail Stop D462

Los Alamos, NM 87545

(505) 667-5061

Maurer Engineering, Inc.

W.C. Maurer

2916 West P.C. Jester

Houston, TX 77071

(713) 683-8227

Meridian Corporation

Daniel J. Entingh

4300 King St., Ste. 400

Alexandria, VA 22302-1508

(703) $998-3600$

Mother Earth Industries

Wayne Portanova

Scottsdale, Arizona

National Energy Software Center

Argonne National Laboratory

9200 South Cass Avenue

Argonne, IL 60439

(312) $972-2000$

National Technical Information Service

U.S. Department of Commerce

5285 Port Royal Road

Springfield, VA 22161

(703) $487-4650$ 
University of Nevada, Las Vegas

Dennis Trexler

255 Bell St.

Reno, NV 89502

(702) 784-6151

OTIS Engineering

D. Taylor

P.O. Box 819052

Dallas, TX 75381

(214) 323-3694

Oregon Institute of Technology GEO-Heat Center

Gene Culver

3201 Campus Drive

Klamath Falls, OR 97601

(503) 882-3583

Paul J. Lienau

3201 Campus Drive

Klamath Falls, OR 97601

(503) 882-3583

Kevin Rafferty

3201 Campus Drive

Klamath Falls, OR 97601

(503) 882-3583

Quazite Corporation

Albert O. Kaeding

Quazite Corporation

5515 Gasmer

Houston, TX 77035

(713) 723-5310

Radian Corporation

P.F. Ellis

8501 Mo-Pac Blvd.

Austin, TX 78759

(512) 454-4797
Rocky Mountain Well Log Service

P.O. Box 3150

Denver, CO 80201

(303) $825-2181$

Sandia National Laboratory

Len Duda

Geothermal Research Division

Albuquerque, NM 87185

(505) 844-2377

James C. Dunn

Geothermal Research Division

Albuquerque, NM 87185

(505) 844-4715

David Glowka

Geothermal Research Division

Albuquerque, NM 87185

(505) 844-3933

Stewart M. Kohler

Guidance and Control Division I 2334

Albuquerque, NM 87185

(505) 844-5678

Glen Loeppke

Geothermal Research Division

Albuquerque, NM 87185

(505) 846-0301

Richard Traeger

Geothermal Research Division

Albuquerque, NM 87185

(505) 844-2377

James Uhl

Geothermal Research Division

Albuquerque, NM 87185

(505) 844-1700

Smith Tool Company

W.C. Baker

1207 34th St.

Bakersfield, CA 93301

(805) 323-0656 
Sprengnether, Inc.

D. Ayden 4150 LaClede

St. Louis, MO 63108

(314) 535-1682

Texas Tech University

N. Guven

Lubbock, TX

University of Texas at Austin

R. Schneider

Center for Energy Studies

Austin, TX 78712

(415) $853-8300$

Tracor Hydronautics

Gary S. Frederick

7210 Pindell School Rd.

Laurel, MD 20810

(301) 776-7454

U.S. Geological Survey

J. D. Bliss

Menlo Park, CA 92008

(415) 853-8300

Unocal Geothermal

B. Daniel

Santa Rosa, CA 95401.

(707) 545-7600
University of Utah Research Institute Earth Science Laboratory

Jeffrey B. Hulen

391 Chipeta Way, Suite C

Salt Lake City, UT 84108

(801) 524-3422

Joseph N. Moore

391 Chipeta Way, Suite C

Salt Lake City, UT 84108

(801) 524-3422

Dennis L. Nielson

391 Chipeta Way, Suite C

Salt Lake City, UT 84108 (801) 524-3422

Howard P. Ross

391 Chipeta Way, Suite C

Salt Lake City, UT 84108

(801) 524-3422

Philip E. Wannamaker 391 Chipeta Way, Suite C Salt Lake City, UT 84108 (801) 524-3422

Stanley H. Ward 391 Chipeta Way, Suite C Salt Lake City, UT 84108 (801) 524-3422

Phillip M. Wright

391 Chipeta Way, Suite C Salt Lake City, UT 84108 (801) 524-3422 